Florida International University FIU Digital Commons

\title{
Landscape Genetics of Phaedranassa Herb. (Amaryllidaceae) in Ecuador
}

Nora Oleas

Florida International University, nolea002@fiu.edu

DOI: $10.25148 /$ etd.FI1 1080201

Follow this and additional works at: https://digitalcommons.fiu.edu/etd

\section{Recommended Citation}

Oleas, Nora, "Landscape Genetics of Phaedranassa Herb. (Amaryllidaceae) in Ecuador" (2011). FIU Electronic Theses and Dissertations. 443.

https://digitalcommons.fiu.edu/etd/443 


\section{FLORIDA INTERNATIONAL UNIVERSITY \\ Miami, Florida}

LANDSCAPE GENETICS OF PHAEDRANASSA HERB. (AMARYLLIDACEAE) IN ECUADOR

A dissertation submitted in partial fulfillment of the

requirements for the degree of

DOCTOR OF PHILOSOPHY

in

BIOLOGICAL SCIENCES

by

Nora Helena Oleas Gallo 
To: Dean Kenneth Furton

College of Art and Sciences

This dissertation, written by Nora Helena Oleas Gallo, and entitled Landscape Genetics of Phaedranassa Herb. (Amaryllidaceae) in Ecuador, having been approved in respect to style and intellectual content, is referred to you for judgment.

We have read this dissertation and recommend that it be approved.

Timothy Collins

Kenneth Feeley

Jennifer Gebelein

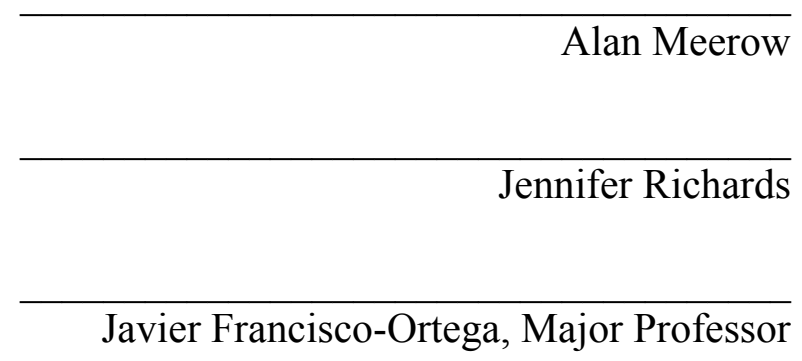

Date of Defense: June 30, 2011

The dissertation of Nora Helena Oleas Gallo is approved.

\begin{tabular}{r}
$\begin{array}{r}\text { Dean Kenneth Furton } \\
\text { College of Arts and Sciences }\end{array}$ \\
\hline Interim Dean Kevin O’ Shea \\
University Graduate School
\end{tabular}

Florida International University, 2011 
(C) Copyright 2011 by Nora Helena Oleas Gallo

All rights reserved. 


\section{DEDICATION}

To my family, Luciana and Cristian 


\section{ACKNOWLEDGMENTS}

This project was conducted thanks to the support of a Florida International University Graduate School Dissertation Evidence Acquisition Fellowship (2009), GSA Research Fund, Judith Parker Fellowship and the South Florida Chapter of The Explorer's Club. This research was also financed by NSF Grant DEB 0129179 of Dr. Meerow.

I would like to thank my Major Professor Dr. Javier Francisco-Ortega for his help, support and constant encouragement, and Dr. Alan Meerow for opening up his lab to me and providing with numerous opportunities to learn and improve my knowledge in population genetics. Thank you Alan for your patience and guidance, I am so glad I had the opportunity to work with you. Also, I thank my committee members Dr. Tim Collins, Dr. Jennifer Richards, Dr. Jennifer Gebelein and Dr. Kenneth Feeley for all their support and suggestions during all of these years.

I appreciate the extraordinary working environment and collaboration of the staff at the USDA-ARS-SHRS research lab in Miami. Thank you for the innumerable times you guys help me and made my day productive. You all were the best!

Also, I would like to thank to all my friends at FIU and Miami who made this journey unforgettable. I am in debt to all the great people I met at FIU, thanks to all my graduate fellows, professors and administrative staff personnel at the Biological Sciences Department. A special thank to Mo, Lidia, Helen, Carola, Erin and Ana Sippin for their help with university related paper work.

I would like to thank the Herbario QCA, especially its director, Dr. Hugo Navarrete, and its secretary, Carmen Torres; the Ministerio del Medio Ambiente in 
Ecuador, in particular to Gabriela Montoya and Ing. Segundo Fuentes; Galo Rosales and to Susana Oleas who helped me with collection and export permits.

To all my colleagues and friends who came with me during the fieldtrips for this study: Lou Jost, Jorge Caranqui director of the Herbarium CHEP of the Escuela Politécnica del Chimborazo, Veronica Quitigüiña, Tania Sánchez, Marcelo Ayabaca; Jorge, Lucho y Angel Oleas, Susana Gallo, Susana Oleas; Marco, Carlos, Cristian Roberto, María and Luciana Melo, Teresa González, Alan Meerow.

Finally, thanks to my family and friends in Ecuador for all their support and help. 


\title{
ABSTRACT OF THE DISSERTATION \\ LANDSCAPE GENETICS OF PHAEDRANASSA HERB. (AMARYLLIDACEAE) IN ECUADOR
}

by

\author{
Nora Helena Oleas Gallo \\ Florida International University, 2011 \\ Miami, Florida \\ Professor Javier Francisco-Ortega, Major Professor
}

Speciation can be understood as a continuum occurring at different levels, from population to species. The recent molecular revolution in population genetics has opened a pathway towards understanding species evolution. At the same time, speciation patterns can be better explained by incorporating a geographic context, through the use of geographic information systems (GIS). Phaedranassa (Amaryllidaceae) is a genus restricted to one of the world's most biodiverse hotspots, the Northern Andes. I studied seven Phaedranassa species from Ecuador. Six of these species are endemic to the country. The topographic complexity of the Andes, which creates local microhabitats ranging from moist slopes to dry valleys, might explain the patterns of Phaedranassa species differentiation. With a Bayesian individual assignment approach, I assessed the genetic structure of the genus throughout Ecuador using twelve microsatellite loci. I also used bioclimatic variables and species geographic coordinates under a Maximum Entropy algorithm to generate distribution models of the species. My results show that Phaedranassa species are genetically well-differentiated. Furthermore, with the exception of two species, all Phaedranassa showed non-overlapping distributions. 
Phaedranassa viridiflora and P. glauciflora were the only species in which the model predicted a broad species distribution, but genetic evidence indicates that these findings are likely an artifact of species delimitation issues. Both genetic differentiation and nonoverlapping geographic distribution suggest that allopatric divergence could be the general model of genetic differentiation. Evidence of sympatric speciation was found in two geographically and genetically distinct groups of $P$. viridiflora. Additionally, I report the first register of natural hybridization for the genus. The findings of this research show that the genetic differentiation of species in an intricate landscape as the Andes does not necessarily show a unique trend. Although allopatric speciation is the most common form of speciation, I found evidence of sympatric speciation and hybridization. These results show that the processes of speciation in the Andes have followed several pathways. The mixture of these processes contributes to the high biodiversity of the region. 


\section{TABLE OF CONTENTS}

CHAPTER

PAGE

I. INTRODUCTION 1

Taxonomic history of Phaedranassa 1

$\begin{array}{ll}\text { Phylogenetic relationships } & 2\end{array}$

Overview of the study organism 3

Biogeography and Ecology $\quad 4$

Understanding plant evolution in the tropical Andes: a landscape genetics 5

approach

$\begin{array}{ll}\text { Population genetic studies in plants } & 6\end{array}$

Modeling species distribution of tropical plants $\quad 7$

General overview and outline of the dissertation 9

REFERENCES 11

II. EIGHT MICROSATELLITE LOCI IN PHAEDRANASSA SCHIZANTHA 15

BAKER (AMARYLLIDACEAE) AND CROSS-AMPLIFICATION IN OTHER PHAEDRANASSA SPECIES

$\begin{array}{ll}\text { Abstract } & 15\end{array}$

$\begin{array}{ll}\text { Acknowledgements } & 18\end{array}$

REFERENCES $\quad 22$

III. MUDDY BOOTS BEGET WISDOM: A CAUTIONARY TALE FOR 23 SPECIES DISTRIBUTION MODELS ON ENDANGERED SPECIES $\begin{array}{ll}\text { Abstract } & 23\end{array}$

Introduction $\quad 24$

Methods $\quad 26$

Study species $\quad 26$

Collection of occurrence data $\quad 27$

Model building $\quad 29$

Evaluation of the models $\quad 30$

Results $\quad 31$

Discussion $\quad 32$

Acknowledgements $\quad 36$

$\begin{array}{ll}\text { REFERENCES } & 47\end{array}$

IV. POPULATION GENETIC STRUCTURE OF PHAEDRANASSA HERB. 50 (AMARYLLIDACEAE)

$\begin{array}{ll}\text { Introduction } & 50\end{array}$ 
Methods $\quad 57$

Sample collection and species delimitation $\quad 57$

DNA extraction, genotyping and DNA quality control 57

$\begin{array}{ll}\text { Statistical analysis } & 58\end{array}$

$\begin{array}{ll}\text { Results } & 61\end{array}$

Descriptive statistics among species $\quad 61$

$\begin{array}{ll}\text { Cluster analysis } & 63\end{array}$

$\begin{array}{ll}\text { Individual assignment to species } & 63\end{array}$

Individual assignments within species $\quad 65$

Landscape genetics $\quad 66$

$\begin{array}{ll}\text { Discussion } & 66\end{array}$

Species identification $\quad 66$

Genetic mosaic in the landscape $\quad 67$

$\begin{array}{ll}\text { Conservation implications } & 75\end{array}$

Limitations of this study $\quad 76$

$\begin{array}{ll}\text { REFERENCES } & 99\end{array}$

V. CONCLUSIONS AND FUTURE RESEARCH DIRECTIONS 110

REFERENCES 112

$\begin{array}{ll}\text { VITA } & 114\end{array}$ 


\section{LIST OF TABLES}

TABLE

PAGE

\section{CHAPTER I}

1 Recognized species of Phaedranassa Herb. (Amaryllidaceae)

\section{CHAPTER II}

1 Primer sequences and basic descriptive statistics of eight microsatellite loci from Phaedranassa schizantha

2 Cross-amplification of eight set of microsatellite primers of Phaedranassa schizantha

\section{CHAPTER III}

1 Kappa statistics evaluating the degree of agreement between species distribution models for species of Phaedranassa. Numbers without parenthesis corresponds to kappa values for models with five bioclimatic variables, while the numbers inside parenthesis is kappa from model built with all 19 bioclimatic variables

2 Comparison among Phaedranassa species distribution models (SDMs). Datasets are represented with superscript numbers in each species: (1) database, (2) taxonomy-based, (3) field-based. Numbers without parenthesis are values for models with five bioclimatic variables, numbers inside parentheses are values of model built with all 19 bioclimatic variables. Altitudinal range (a) geographic coordinates, (b) SDMs

\section{CHAPTER IV}

1 Basic descriptive statistics of the genetic structure of Phaedranassa spp.

2 Test for recent bottleneck events in seven populations of Phaedranassa spp. on the basis of three tests. In bold are evidence of bottleneck cases

3 Analysis of molecular variance (AMOVA) results as average over 13 loci

4 Number of migrants ( $\mathrm{Nm}$ ) using two methods: private alleles (after size correction)

5 Comparison of the number of collecting sites and the population number $(k)$, inferred genetically by Evanno method (2008). The average pairwise similarity (H') among 20 runs of the optimal

6 Percentages of Species Distribution Model overlap

7 New proposed conservation status of Phaedranassa (Amaryllidaceae) in Ecuador 


\section{LIST OF FIGURES}

FIGURE

PAGE

\section{CHAPTER III}

1 Distribution maps for Phaedranassa spp. Dark areas indicate predicted presence. Lower case letter indicates dataset source type: (a) database; (b) taxonomy-based; (c) field-based; numbers are (1) SDMs with 5 bioclimatic variables (www.WorldClim.org) and (2) SDMs with all 19 bioclimatic variables

\section{CHAPTER IV}

1 Ecuador's species of Phaedranassa. a) Phaedranassa brevifolia; b) $P$. cinerea; c) P. dubia; d) P. glauciflora; e) P. schizantha ; f) P. tunguraguae; g) P. viridiflora; h) Up: P. viridiflora; Down: possible P. dubia $x$ P. viridiflora hybrid

2 Distribution map of Phaedranassa spp. in Ecuador. Squares are locations with more than one Phaedranassa species

3 Unrooted neighbor joining tree showing relationship among populations of Phaedranassa spp. in Ecuador. Number in branches are boostrap values > $50 \%$ over 1000 replications

4 Plots of the individual assignment of Phaedranassa under the assumption of $k=7$ (number of species). Individuals are represented as a thin vertical line with colors indicating cluster membership. Population ID is listed under the plot

5 Bayesian individual assignment for Phaedranassa brevifolia and P. dubia.

A) Assignment with number of populations $k=2$ with both species analyzed together, B) Assignment for each species separately ( $k=2$ each). Area in grey is altitude $>3500 \mathrm{~m}$

6 Analysis of population structure of P.glauciflora, and P. cinerea. Plot bar represent the estimated population structure per each one of the species' populations $(k=10)$. Area in pink represents the species distribution model (SDM) for P. glauciflora, in green is SDM for P. cinerea

7 Plots of the individual assignment of each species of Phaedranassa analyzed separately. Individuals are represented as a thin vertical line with colors indicating cluster membership 
8 Population genetic structure of P.viridiflora. A) P. viridiflora and $P$. dubia in Pululahua, B) $P$. viridiflora $(\mathrm{Pv})$ and $P$. schizantha $(\mathrm{Ps})$, C) $P$. viridiflora $(\mathrm{Pv})$ and $P$. cinerea $(\mathrm{Pc})$. Plot bar represent the estimate population structure per each one of the species' populations Area in yellow is $P$. viridiflora's distribution model, in grey is area with altitude $>3500 \mathrm{~m}$

9 Principal Coordinates Analysis (PCA) of Phaedranassa individuals in Pululahua crater. The first, second and third axes explained 44, 23 and $10 \%$ respectively, of the total variability. Symbols are: orange flowers (a), red flowers (b) and yellow flowers (c)

10 Altitudinal range $(\mathrm{m})$ from the Species Distribution Model of seven Phaedranassa species in Ecuador 


\section{CHAPTER I.}

\section{INTRODUCTION}

\section{Taxonomic history of Phaedranassa}

Phaedranassa is a small genus of Amaryllidaceae established by Herbert (1845) from a specimen originally named $P$. chloracra. The name Phaedranassa is derived from the greek "phaidos" (gay) and "anassa" (queen) (Quattrocchi 2000). In its native Ecuadorian highlands it is known as "ashpa cebolla" in Quichua (fake onion), "cebolleta" or "papa de lobo" in Spanish (fox's potato). Twenty two species have been described in this genus (www.tropicos.com). Phaedranassa chloraca was later considered synonomy and changed to P. dubia by Macbride (1931), because of the description of a previous basionym Haemanthus dubius H.B.K. (1815). Lindley (1845) presented a figure and a description of Phaedranassa chloracra, which share the same description as Herbert's (1845) and was published at the same volume. However, Lindley's description is supposed to be from a specimen collected at Saraguro in Loja whereas Herbert's corresponded to a specimen collected in Guayllabamba. Other synonyms of $P$. dubia are Collania dubia Schult. f. (1830), Crinum quitense Spreng. (1825), Phycella obtusa (Herbert) Lindley (1844) and Phaedranassa obtusa Herb (1845). During the late 1800's, Baker described four new species of Phaedranassa: P. carmioli in 1869, from a cultivated specimen from Costa Rica; $P$. viridiflora (1877); $P$. ventricosa (1887) and $P$. schizantha (1880). Through the same period, Regel (1883) described P. lehmanni from material collected in Colombia. Kraenzl (1917) described P. megistophylla, which was later changed to Rauhia multiflora (Ravenna 1969). Ravenna (1969) published a synoptic treatment of Phaedranassa in which he recognized eight species in the genus: $P$. 
carmioli, P. dubia, P. lehmanni, P. schyzantha (with " $y$ " in the original paper), $P$. viridiflora, P. eucrosoides, $P$. tunguraguae, $P$. loxana (the latter two as new species). He also presented the first key for the genus, and he assigned Phaedranassa to the Tribe Stenomesseae, recognizing the genus as related to Rauhia, Stenomesson, Eucrosia and Paramongaia. Ravenna (1984) described P. cinerea and P. viridilutea. Meerow (1987b) described P. brevifolia and proposed three changes: P. eucrosoides as a synonym of Eucrosia stricklandii var. stricklandii (Meerow 1987a), P. loxana as a synonym of Eucrosia stricklandii var. montana Meerow (Meerow 1986) and $P$. viridilutea as $P$. viridiflora. Meerow (1990) treated Ecuadorian Amaryllidaceae, describing a new species: P. glauciflora and a new variety, $P$. schizantha var. ignea. He also provided a new key for the Ecuadorian Phaedranassa species with descriptions of each species and notes about geographic distribution and habitat (Meerow 1990). Currently a total of nine species and one variety are recognized in Phaedranassa (Govaerts 2011) (Table 1). In this research I follow Meerow's (1990) species classification.

\section{Phylogenetic relationships}

A phylogenetic study of the internal transcribed spacers (ITS) of nuclear ribosomal DNA revealed that Phaedranassa is part of a subclade in the tetraploid-derived Andean clade ( $\mathrm{n}=23$ ) of the American Amaryllidaceae (Meerow et al. 2000). The Amaryllidaceae has a total of 59 genera and 850 species worldwide (Meerow and Snijman 1998). In Ecuador there are 11 genera and 32 species (Jørgensen and León 1999). Phaedranassa was resolved as a well-supported monophyletic group within the tribe Eucharideae, a clade representing all of the petiolate-leafed Andean genera (Meerow et al. 2000). Rauhia resolved as a sister taxa of Phaedranassa (Meerow et al. 2000). In a 
previous cladistic analysis of plastid $r b c L$ and $t r n L-F$ genes, Eucrosia resolved as a sister taxon of Phaedranassa (Meerow et al. 1999). The phylogenetic relationships among Phaedranassa species are unknown.

\section{Overview of the study organism}

Phaedranassa species are hysteranthous geophytes. They produce bulbs with a brown tunic and contractile roots. They have one or two petiolate leaves that are usually absent at flowering. The lamina is elliptic to lanceolate with an acute apex and an attenuate base that tapers towards the petiole (Meerow 1990). The leaves have a prominent central vein throughout their length and are sometimes glaucous. Glaucous leaves, as well as the size and the color of the leaves, are features that vary among species and have been used in taxonomic keys (Meerow 1990).

Phaedranassa develops a scape, with a pseudo-umbellate inflorescence consisting of six to 20 tubular flowers. The flowers in Phaedranassa are actinomorphic and perfect. They have six tepals, usually green at the base and apices, with an intervening area of red, pink, yellow or orange. The flowers have six free stamens adnate at the base to the tepals. The staminal filaments are 3-seriate in length and the anthers are yellow or green. The stigma is capitate. The ovary is inferior and 3-locular with multiple ovules. The fruit is a loculicidal capsule with many flat black or dark brown winged seeds. Many of the floral characters (such as color, size and number of the flowers, color of the filaments) are used to identify species (Meerow 1990).

A new alkaloid called fedranamina has been found in P. dubia (Osorio 2008); and some anti-parasitic effect against Plasmodium falsiparum has been reported from other alkaloids of this species (Osorio 2008). 


\section{Biogeography and Ecology}

Phaedranassa is found in Ecuador, Colombia and Costa Rica (Meerow 1990). Three species have been recorded in Colombia: P. lehmani, $P$. ventricosa and P. dubia (Meerow pers com); the latter is also distributed in the Northern part of Ecuador. Phaedranassa carmioli was described from a cultivated specimen that was reportedly collected in Costa Rica and apparently recollected later (according to records in Herbertia 1940, according to Ravenna 1969). Information in the TROPICOS database (www.tropicos.org), cite a collection by Leon, which is reportedly deposited in the National Herbarium in San Jose, Costa Rica (CR). However, I did not find the specimen in the museum during my visit to $\mathrm{CR}$ in 2005. Six species are endemic to Ecuador $(P$. brevifolia, $P$. cinerea, $P$. glauciflora, $P$. schizantha, $P$. tunguraguae and $P$. viridiflora).

In Ecuador, Phaedranassa's populations are isolated and occur in one of the most deforested regions of the country, where little native vegetation is remaining (Valencia et al. 1999). Originally, these species lived in areas that corresponds to Cloud Forest and Dry and Wet Inter-Andean Shrubs (Valencia et al. 1999); these areas are now dedicated to agriculture, mining or, increasingly residential development. The species have never been found in a forest, and their natural habitat might be any open spot, such as between rocky mountain slopes or near rivers deep canyons flanks. In general, each species is restricted to a particular valley (Fig. 1). It seems that certain species have adapted to particular climate conditions (e. g., P. cinerea and P. tunguraguae are found in moist habitats, while P. brevifolia and P. dubia inhabit mesic areas). However, the specific climatic tolerance of each species is unknown and studies are needed to more accurately define their ecological niche. 


\section{Understanding plant evolution in the tropical Andes: a landscape genetics approach}

The tropical Andes have been recognized as a biodiversity hotspot on the basis of their confluence of species endemism and degree of threat (Brummit and Lughadha 2003; Mittermeyer et al. 1999; Mittermeyer et al. 1998). Within the hotspot, Ecuador is acknowledged as a megadiverse country with probably the highest concentration of species per area in the world (Mittermayer et al. 1999). More than 4000 endemic plant species have been reported from the country, of which more than half are restricted to the Andes (Valencia et al. 2000). The current variety of habitats in Ecuador and consequent species richness has been influenced by Andean geological history (Hughes and Eastwood 2006; Jørgensen et al. 1995; Luteyn 2002). However, the biological richness in this area is not matched by a commensurate level of understanding of speciation processes in the region.

In general, it has been understood that mountains constitute either bridges for plant colonization or isolating barriers, both of which play a role in speciation (Hewitt 2004; Ohsawa and Ide 2007). The inter-Andean valleys are naturally isolated from each other because of deep and narrow topographic contours (Young et al. 2002). This topographic complexity creates local microhabitats ranging from moist slopes to dry valleys.

The recent molecular revolution in population genetics has created a pathway towards answering evolutionary questions that were previously difficult to address, such as how species evolve (Barraclough and Vogler 2000). It has been proposed that there is a continuum of evolutionary processes that influence genetic variation at different levels, from populations to species to higher level taxa (Carstens et al. 2004). One of the most 
problematic questions of speciation is the geographical model of speciation (Losos and Glor 2003). There are two different views of speciation: sympatric and allopatric. In general terms, sympatric speciation occurs when competition among populations leads to ecological niche differentiation, while allopatric speciation requires a spatial barrier leading to genetic isolation (Mayr 1963). Parapatric speciation is somehow in between both models because it allows speciation to occur even with migration among adjoining populations (Gavrilets et al. 2000). With the increased availability of molecular tools as well as geographic information systems (GIS), it is now possible to study the genetic variation in a geographic context, an approach called landscape genetics (Manel et al. 2003).

\section{Population genetic studies in plants}

Molecular markers changed the scenery of population genetic studies. In conjunction with the neutral theory, they allowed a new understanding of isolation and migration in populations (Frankham et al. 2002). Microsatellites (SSRs), one of these molecular markers, are two to six nucleotides that are repeated many times in tandem and that display high dissimilarity in repeat number among individuals. For nearly two decades, DNA microsatellites have been used as a preferred method to address population genetic inquiries in plants (Morgante and Olivieri 1993, Chase et al. 1996, Aldrich et al. 1998, Ouborg et al. 2010). They are popular in part because SSRs are highly reproducible among laboratories. Because they are codominant, it is possible for SSRs to distinguish homozygotes and heterozygotes. They are also highly variable and relatively easy to analyze, and they occur regularly throughout the genome (Frankel et al. 
1995; Cruzan 1998; Rossetto et al. 1999; Susol et al. 2000; Zane et al. 2002; Squirrell et al. 2003).

Molecular markers are powerful tools for species conservation because they can be used to estimate levels of genetic variation among and within populations (Frankham et al. 2002). The amount of neutral genetic variation in a population is caused by the equilibrium between drift (loss of variability) and mutation (gain of variability) (Frankham et al. 2002). In general, it is expected that without migration from external sources, populations with a reduced number of individuals will experience an increase of genetic drift and increase of inbreeding (Frankham et al. 2002). Such data are important to better design conservation strategies to preserve genetic diversity, which provides species with the means to evolve and adapt in a changing environment (Geffen et al. 2006).

Despite the advantages of molecular markers, studies using them to address the conservation of undomesticated plants from the tropical Andes are largely lacking. Only two studies with microsatellites of threatened plant species of the tropical Andes have been published. One concerned the microevolution of the wax palm (Ceroxylon echinulatum Galeano, Arecaceae) (Trenel et al. 2008), and another addressed mating patterns and their role in genetic variation of the Andean Oak (Quercus humboldtii Bonpl., Fagaceae) (Fernandez and Sork 2005).

\section{Modeling species distribution of tropical plants}

Understanding landscape genetics requires knowledge of species distributions across the landscape. Species Distribution Models (SDMs) are a general suite of models that estimate the ranges of species on the basis of relationships between the species' 
probability of occurring and environmental factors such as temperature, precipitation, seasonality, soil type, etc. Because of the multiple applications of SDMs, these methods have rapidly gained in popularity and are in widespread use by ecologists, biogeographers, conservation scientists and practitioners.

In recent years there has been an increase in the availability of species occurrence data on the World Wide Web (Canhos et al. 2004, Soberón and Peterson 2004, JiménezValverde et al. 2008, Feeley and Silman 2011). International initiatives' such as the Global Biodiversity Information Facility (GBIF http://www.gbif.org), SpeciesLink (http://splink.cria.org.br/), Mantis (http://insects.oeb.harvard.edu/mantis/) and others, have compiled data from thousands of disparate sources (e.g., herbarium and museum collections and sighting records), allowing users to rapidly acquire vast amounts of occurrence data. As a result of the low cost and ease of acquiring data and generating distributions along with their many potential important applications (e.g., conservation of endangered species, prediction of invasive species, propagation, and predicting species distributions under different past and future climate change scenarios [Peterson 2003, Martinez-Meyer 2005; Powell et al. 2005; Guisan et al. 2006; Peterson 2006; Thuiller et al. 2006; Peterson and Nakazawa 2008; Feeley and Silman 2010]). Species Distribution Models have rapidly gained in popularity and are in widespread use by ecologists, biogeographers, conservation scientists and practitioners.

However, accessibility to data may come at the expense of data quality or reliability. In general, SDMs rely on three primary components: (1) species occurrence data, (2) environmental variables and (3) the underlying statistical model. The accuracy of the SDM's range predictions will be directly influenced by the accuracy of these three 
components. In the case of species occurrence data, there are several issues associated with data obtained from large online databases and natural history collections that may limit their utility in SDMs (Newbold 2010). For example, one problem linked with historical records from herbarium and museums specimens is the lack of geographical coordinates - information that is essential for the implementation of SDMs (Beaman and Conn 2003). Geographic coordinates can often be obtained from location data, that accompany the records, in conjunctions with maps, gazettes or software (Guralnick et al. 2006; Murphey et al. 2004); however, in many instances the geographical information found in the specimen labels/annotations is vague, and/or of uncertain accuracy.

\section{General overview and outline of the dissertation}

The goal of my dissertation is to contribute to a better understanding of speciation in the tropical Andes, one of the most diverse places on Earth. The specific objectives of my dissertation are to (1) unravel intra-specific patterns at the population level in Ecuadorian Phaedranassa and (2) investigate the connection between the genetic differentiation among species and spatial distribution patterns.

The results of my dissertation are presented in three chapters (Chapters II to IV). In Chapter II, I report the development of microsatellite markers from $P$. schizantha. This chapter is published in Conservation Genetics (Oleas et al. 2009). Chapter III corresponds to an empirical assessment of the use of species' occurrences for the development of Species Distribution Models using three different sources: (a) databases only, (b) specialist evaluation and (c) field corroboration. Chapter III. In Chapter IV, I discuss the species genetic patterns in a geographic context. Finally in Chapter V, I summarize the conclusions of my investigation. 
Table 1. Recognized species of Phaedranassa Herb. (Amaryllidaceae)

\begin{tabular}{lll}
\hline Species name & Author & Year of publication \\
\hline P. brevifolia & Meerow & 1987 \\
P. carmioli & Baker & 1869 \\
P. cinerea & Ravenna & 1984 \\
P. dubia & (HBK) J.F. Macbride & 1931 \\
P. glauciflora & Meerow & 1990 \\
P. lehmanni & Regel & 1883 \\
P. schizantha var. schizantha & Baker & 1880 \\
P. schizantha var. ignea & Meerow & 1990 \\
P. tunguraguae & Ravenna & 1969 \\
P. ventricosa & Baker & 1887 \\
P. viridiflora & Baker & 1877 \\
& & \\
\hline
\end{tabular}




\section{REFERENCES}

Aldrich P, Hamrick JL, Chavarriaga P, Kochert G (1998) Microsatellite analysis of demographic genetic structure in fragmented populations of the tropical tree Symphonia globulifera. Molecular Ecology 7:933-944

Baker JG (1869) Phaedranassa carmiolii. Refugium Botanicum 1:t. 46

Baker JG (1877) Phaedranassa viridiflora. The Gardeners' Chronicle \& Agricultural Gazette 8:134

Baker JG (1880) Phaedranassa schizantha. The Gardeners' Chronicle \& Agricultural Gazette 14:556

Baker JG (1887) Phaedranassa ventricosa. Botanische Jahrbücher für Systematik, Pflanzengeschichte und Pflanzengeographie 8:210-211

Barraclough TG, Vogler AP (2000) Detecting the geographic pattern of speciation from species-level phylogenies. The American Naturalist 155:419-434

Beaman RS, Conn BJ (2003) Automated geoparsing and georeferencing of Malesian collection locality data. Telopea, 10, 43-52

Carstens BC, Stevenson AL, Degenhardt JD, Sullivan J (2004) Testing nested phylogenetic and phylogeographic hypothesis in the Plethodon vandykei species group. Systematic Biology 53:781-792

Chase M, Kesseli R, Bawa K (1996) Microsatellite Markers for populations and conservation genetics of tropical trees. American Journal of Botany 83:51-57

Cruzan MB (1998) Genetic markers in plant evolutionary ecology. Ecology 79:400-412

Feeley KJ, Silman MR (2010) Land-use and climate change effects on population size and extinction risk of Andean plants. Global Change Biology 16:3215-3222

Feeley KJ, Silman MR (2011) The data void in modeling current and future distributions of tropical species. Global Change Biology 17:626-630

Frankel OH, Brown AHD, Burdon J (1995) The conservation of plant biodiversity. Cambridge University Press, NY

Frankham R, Ballou JD, Briscoe DA (2002) Introduction to conservation genetics. Cambridge University Press, Cambridge, UK

Geffen E, Luikart G, Waples RS (2006) Impacts of modern molecular genetic techniques on conservation biology. Pages 46-63 in D. Macdonald and K. Service, editors. Key Topics in Conservation Biology. Blackwell Publishing, Oxford 
Gavrilets S, Li H, Vose MD (2000) Patterns of parapatric speciation. Evolution 54:11261134

Govaerts R (2011). World Checklist of Phaedranassa. The Board of Trustees of the Royal Botanic Gardens, Kew. Published on the Internet; http://www.kew.org/wcsp/ accessed 19 July 2011

Guralnick RP, Wieczorek J, Beaman R, Hijmans, RJ (2006) BioGeomancer: automated georeferencing to map the world's biodiversity data. PLoS Biology 4:1908-1909

Herbert W (1844). Phycella obtusa. Edwards' Bot. Reg. 30:misc.93

Herbert W (1845) Phaedranassa chloracra. Edwards' Bot. Reg. 31:p. 16 misc.23

Jørgensen PM, León S (1999) Catalogue of the Vascular Plants of Ecuador. Missouri Botanical Garden Press, St Louis, Missouri

Kraenzl, F (1917) Amaryllidaceae andinae. Botanische Jahrbücher für Systematik, Pflanzengeschichte und Pflanzengeographie 54:2

Losos JB, Glor RE (2003) Phylogenetic comparative methods and the geography of speciation. Trends in Ecology and Evolution 18:220-227

Luikart G, Cornuet J (1998) Empirical evaluation of a test for identifying recently bottlenecked populations from allele frequency data. Conservation Biology $12: 228-237$

Macbride JF (1931) Phaedranassa dubia. Field Museum Natural History, Bot. Ser., $11: 12$

Manel S, Schwartz MK, Luikart G, Taberlet P (2003) Landscape genetics: combining landscape ecology and population genetics. Trends in Ecology and Evolution 18:189-197

Mayr E (1963) Animal species and evolution Belknap Press, Cambridge, MA.

Meerow AW (1986) Eucrosia stricklandii var. montana and the identity of Phaedranassa loxana (Amaryllidaceae). Phytologia 60:101-104

Meerow AW (1987a) A monograph of Eucrosia (Amaryllidaceae). Systematic Botany 12:460-492

Meerow AW (1987b) New species of Phaedranassa and Eucharis (Amaryllidaceae). Sida 1:20-49

Meerow AW (1990) Amaryllidaceae.in G. Harling and L. Andersson, editors. Flora of Ecuador, Vol. 41. University of Gotenborg; Riksmuseum, Pontificia Universidad Católica del Ecuador, Goteborg, Stockholm, Quito 
Meerow AW, Fay MF, Guy CL, Li Q.-B, Zaman FQ, Chase M (1999) Systematics of Amaryllidaceae based on cladistic analysis of plastid rbcL and trnL-F sequences data. American Journal of Botany 86:1325-1345

Meerow AW, Guy CL, Li Q (2000) Phylogeny of the American Amaryllidaceae based on nrDNA ITS sequences. Systematic Botany 25:708-726

Meerow AW, Snijman DA (1998) Amaryllidaceae.in K. Kubitzki, editor. The Families and Genera of Vascular Plants, Volumme III, Flowering Plants Monocotyledons, Lilianae (except Orchidaceae). Springer-Verlag, Berlin

Morgante M, Olivieri AM (1993) PCR-amplified microsatellites as markers in plant genetics. The Plant Journal 3:175-182

Murphey PC, Guralnick RP, Glaubitz R, Neufeld D, Ryan JA (2004) Georeferencing of Museum Collections: A review of the problems and automated tools, and the methodology developed by the Mountain and Plains Spatial-Temporal Databaseinformatics initiative (MaPSTeDI). PhyloInformatics 3:1-29

Newbold, T (2010) Applications and limitations of museum data for conservation and ecology, with particular attention to species distribution models. Progress in Physical Geography 34:3-22

Oleas NH, Meerow AW, Francisco-Ortega J (2009) Eight microsatellite loci in Phaedranassa schizantha Baker (Amaryllidaceae) and cross-amplification in other Phaedranassa species. Conservation Genetics 10:1887-1889

Osorio EJD (2008) Busqueda de sustancias bioactivas a partir de dos especies de la flora colombiana: alcaloides de Phaedranassa dubia (Amaryllidaceae) y biflavonoides de Garcinia madruno (Clusiaceae). Universidad de Barcelona, Barcelona

Ouborg NJ, Pertoldi C, Loeschcke V, Bijlsma R K, Hedrick PW (2010) Conservation genetics in transition to conservation genomics. Trends in Genetics 26:177-187

Quattrocchi U (2000) CRC World Dictionary of Plant Names: Common Names, Scientific Names, Eponyms, Synonyms, and Etymology. first edition. CRC Press, Boca Raton

Ravenna PF (1969) Contributions to South American Amaryllidaceae-III. Plant Life 26:55-62

Ravenna PF (1984) New species in Phaedranassa and Eucrosia (Amaryllidaceae). Phytologia 56:196-198

Regel EA (1883) Phaedranassa lehmanni. Gartenflora 32: 354

Rossetto M, McLauchlan A, Harris FCL, Henry RJ, Baverstock PR, Lee LS, Maguire TL, Edwards KJ (1999) Abundance and polymorphism of microsatellite markers in 
the tea tree (Mellaleuca alternifolia, Myrtaceae). Theoretical and Applied Genetics 98:1091-1098

Schult F (1830) Collania dubia. Systema Vegetabilium 7:53, 893

Sprengel KPJ (1825) Crinum quitense. Systema Vegetabilium, editio decima sexta 2:55

Squirrell J, Hollingsworth PM, Woodhead M, Russell J, Lowe AJ, Gibby M, Powell W (2003) How much effort is required to isolate nuclear microsatellites from plants? Molecular Ecology 12:1339-1348

Susol E, Eyre S, John S (2000) Hight-Thorughput genotyping of microsatellite markers.in A. Hajeer, J. Worthington, and S. John, editors. SNP and Microsatellites Genotyping: Markers for genetic analysis. A Biotechniques Books Publication. Eaton Publishing, Natick, MA

Trenel P, Hansen MM, Normand S, Borchsenius F (2008) Landscape genetics, historical isolation and cross-Andean gene flow in the wax palm, Ceroxylon echinulatum (Arecaceae). Molecular Ecology 17:3528-3540

Valencia R, Cerón C, Palacios W, Sierra R (1999) Las formaciones Naturales de la Sierra del Ecuador.in R. Sierra, editor. Propuesta Preliminar de un Sistema de Clasificación de Vegetación para el Ecuador Continental. Proyecto INEFAN/GEF-BIRF y EcoCiencia, Quito

Zane L, Bargelloni L, Patarnello T (2002) Strategies for microsatellite isolation: a review. Molecular Ecology 11:1-16 


\title{
CHAPTER II.
}

EIGHT MICROSATELLITE LOCI IN PHAEDRANASSA SCHIZANTHA BAKER (AMARYLLIDACEAE) AND CROSS-AMPLIFICATION IN OTHER PHAEDRANASSA SPECIES

\begin{abstract}
Phaedranassa schizantha is a species endemic to Ecuador from which eight polymorphic microsatellite loci were isolated from an enriched genomic library. A total of 31 alleles with an average of four alleles per locus were detected across 29 individuals from a single natural population of $P$. schizantha. Observed heterozygosity ranged from 0.05 to 0.68. Most of the eight loci were successfully amplified in six Phaedranassa species. Five of those species are either "Vulnerable" or "Endangered" under IUCN criteria. These loci will be used to investigate patterns of inter- and intraspecific variation of Phaedranassa species, which will contribute data relevant to their conservation status. Keywords: Microsatellite primers, Phaedranassa schizantha, Ecuador, Amaryllidaceae, Andes, Endangered species, Conservation, Population genetics

Phaedranassa Herb. is a small monophyletic genus restricted to the dry valleys and wet slopes of the northeast Andes (Meerow 1990; Oleas 2000a). Ten species are known of which six are endemic to Ecuador. Because of their small population numbers as well as habitat alteration, these six species are considered either endangered or vulnerable to extinction according to the IUCN Red List (Oleas 2000b). In order to design adequate strategies for their conservation, it is necessary to understand their population genetic structure. In this paper, I report new primers generated from genomic DNA of
\end{abstract}


Phaedranassa schizantha, developed in an order to increase the number of microsatellite loci available to study the population genetic structure across the genus in Ecuador.

A microsatellite-enriched library was built with methods described previously (Oleas et al. 2005) using DNA of $P$. schizantha. All cloning of isolated fragments used the pGEM-T and pGEM-T Easy Vector Systems (Promega, Madison, WI, USA) following manufacturer's protocols. The PCR primer sequences were designed with Primer 3 software (Rozen and Skaletsky 1998) using the default options with the exception of the primer GC content range of 40-80, self-complementarity and 3'selfcomplementary of 5 and CG clamp of 1 . Amplification and polymorphism were screened by PCR cold primers using dUTPs. Polymerase chain reactions were carried out with polymorphic loci in a $10 \mu 1$ reaction mix containing $1 \mu 1$ template DNA ( 20ng/ $\mu 1), 6.25$ $\mu 1 \mathrm{dH}_{2} \mathrm{O}, 1 \mu \mathrm{l}$ of standard Buffer (New England BioLabs, Inc. Ipswich, MA, USA), 0.25 $\mu 1$ 10mM dNTP, $0.05 \mu 1$ Taq (5U/ $\mu 1)$ (New England BioLabs, Inc. Ipswich, MA, USA), $0.25 \mu \mathrm{l}$ fluorescent 5 'end-labelled forward primer $(10 \mu \mathrm{M}), 0.25 \mu 1$ reverse primer $(10$ $\mu \mathrm{M})$. The PCR temperature profile consisted of $5 \mathrm{~min}$ at $94{ }^{\circ} \mathrm{C} ; 45 \mathrm{~s}$ at $94{ }^{\circ} \mathrm{C} ; 45 \mathrm{~s}$ at 60 ${ }^{\circ} \mathrm{C} ; 60 \mathrm{~s}$ at $72{ }^{\circ} \mathrm{C}$; steps 2 repeated 14 times $\left(<1\right.$ degree/cycle); $45 \mathrm{~s}$ at $46{ }^{\circ} \mathrm{C} ; 60 \mathrm{~s}$ at 72 ${ }^{\circ} \mathrm{C}$; steps 6 though 8 repeated 25 times and $4{ }^{\circ} \mathrm{C}$ storage. The products were genotyped in an ABI 3730 Genetic Analyzer (Applied Biosystems Inc. Carlsbad, CA, USA) and allele size identified by capillary gel electrophoresis. Allele calls were made in GeneMapper 4.0 (Applied Biosystems Inc. Carlsbad, CA, USA). Descriptive statistics, exact tests for Hardy-Weinberg equilibrium and linkage disequilibrium were calculated with Arlequin 3.1 (Excoffier et al. 2005). 
Overall, 74 unique microsatellite-containing sequences were identified through sequencing the inserts of 288 positive clones. Almost half of the sequences were not suitable for primer design mainly because of short flanking region on either side of the repeats, inadequate GC content, lack of CG clamp or too high or too low melting temperature $(\mathrm{Tm})$. A total of 34 sequences were suitable for primer design, from which sets of primers were screened by PCR using dUTPs. Fluorescently labeled forward primers were obtained from 18 sets of primers out of the 34 that amplified and showed polymorphism in eight individuals.

Ultimately, eight primer pairs were selected that amplified highly polymorphic repeats (Table 1). An average of 3.9 alleles per locus was detected, and observed heterozygosity ranged from 0.048 to 0.679 . With the exception of ps9, ps 16 , and ps33 all the loci departed significantly from Hardy-Weinberg Equilibrium in my test population. A total of 23 out of the 28 comparisons between loci showed linkage disequilibrium ( $P<$ 0.001). An explanation for this high level of linkage disequilibrium could be that Phaedranassa species are inbred, self-compatible and reproduce clonally by bulbs (Oleas unpublished data). Furthermore, Phaedranassa's populations are small, living in a mosaic of agricultural and rural landscapes. Recent bottlenecks in the history of the populations could also contribute to non-random association of alleles among loci (Frankham et al. 2002). With the exception of ps4, ps9 and ps33 with P. glauciflora, loci were amplified in other Phaedranassa species (Table 2). Furthermore, most of them showed high levels of polymorphism, which make them useful for the investigation of genetic variation and conservation of $P$. schizantha and other species of Phaedranassa. 


\section{Acknowledgements}

The authors gratefully acknowledge financial support from NSF Grant DEB 0129179 to AWM. I also want to acknowledge Dr. David Kuhn, Kyoko Nakamura and plant science technicians at USDA-ARS Miami for methodological assistance. I thank the Herbario QCA and Ministerio del Medio Ambiente of Ecuador for collection and export permits.

This is contribution 161 to the Tropical Biology Program of Florida International University. 
Table 1. Primer sequences and basic descriptive statistics of eight microsatellite loci from Phaedranassa schizantha.

\begin{tabular}{llll}
\hline Locus & $\begin{array}{l}\text { GenBank } \\
\text { accession no. }\end{array}$ & Forward primer $\left(5^{\prime}-3^{\prime}\right)$ & Reverse primer(5'-3') \\
\hline & & & \\
Ps2 & FJ427510 & TCTTGATGTACGCCCTCGG & TTTCGGCTCACACCCTCC \\
Ps4 & FJ427511 & ATGAAGGGGAGGCCAAAGG & ACCACACACTACACCCACC \\
Ps9 & FJ427512 & CCGCCCGATTACCCAACTC & CACGCGTTGCCATATTAAGC \\
Ps13 & FJ429258 & AGCTTGGAAGAGGTCAGGC & AGCTTTCTCACATCTTGGCTTC \\
Ps16 & FJ429259 & TGGACATTGAAGTCGAACTCTTATC & TCGTGTCAACAAATATCAAGTGTG \\
Ps27 & FJ571145 & TCCTGGTGTTTCTTCCCCTC & TGAATTGTCTGAAGTCTACTACTGC \\
Ps28 & FJ429260 & TGGCAATCAACCAAAGGCTC & GCTTGGCATCTCCTCTTTGC \\
Ps33 & FJ429261 & TGACGACGACCCTATCTTCC & TTGATTCCGCGATTACAGGC \\
\hline
\end{tabular}


Table 1. (continued)

\begin{tabular}{lllllll}
\hline Locus & Repeat & $n$ & A & Allele size range (bp) & $H_{O}$ & $H_{E}$ \\
\hline & & & & & \\
Ps2 & $(\mathrm{GA})^{16}$ & 29 & 5 & $193-207$ & 0.655 & $0.731^{* * *}$ \\
Ps4 & $(\mathrm{AG})^{9}$ & 29 & 3 & $148-162$ & 0.483 & $0.580^{* * *}$ \\
Ps9 & $(\mathrm{CT})^{10}$ & 29 & 5 & $189-213$ & 0.571 & $0.518^{\mathrm{ns}}$ \\
Ps13 & $(\mathrm{AG})^{7}$ & 19 & 3 & $217-225$ & 0.158 & $0.243^{* *}$ \\
Ps16 & $(\mathrm{AAG})^{7}$ & 29 & 3 & $176-185$ & 0.517 & $0.490^{\mathrm{ns}}$ \\
Ps27 & $(\mathrm{CT})^{12}$ & 21 & 5 & $151-203$ & 0.048 & $0.505^{* * *}$ \\
Ps28 & $(\mathrm{AAG})^{7}$ & 28 & 2 & $203-206$ & 0.679 & $0.456^{*}$ \\
Ps33 & $(\mathrm{GA})^{8}$ & 29 & 5 & $166-182$ & 0.643 & $0.529^{\mathrm{ns}}$ \\
Mean & & 26.4 & 3.9 & & 0.469 & 0.498 \\
\hline
\end{tabular}

$n$, number of samples, $H_{E}$, expected heterozygosity; $H_{O}$, observed heterozygosity; A, Number of Alleles. Departure from HWE: $\mathrm{ns}=$ not significant, $* \mathrm{P}<0.05, * * \mathrm{P}<0.01, * * * \mathrm{P}<0.001$ 
Table 2. Cross-amplification of eight sets of microsatellite primers of Phaedranassa schizantha.

\begin{tabular}{|c|c|c|c|c|c|c|c|}
\hline Locus & & P. brevifolia & P. cinerea & P. dubia & P. glauciflora & P.tunguraguae & P. viridiflora \\
\hline \multirow[t]{3}{*}{ Ps2 } & $\mathrm{n}$ & 8 & 7 & 7 & 6 & 7 & 8 \\
\hline & A & 6 & 3 & 6 & 4 & 4 & 1 \\
\hline & Range & $167-187$ & $189-215$ & $191-211$ & $191-197$ & 189-199 & $191-215$ \\
\hline \multirow[t]{3}{*}{ Ps4 } & $\mathrm{n}$ & 6 & 4 & 8 & 0 & 6 & 28 \\
\hline & A & 8 & 2 & 7 & - & 5 & 5 \\
\hline & Range & $130-168$ & $148-150$ & $122-162$ & - & $142-154$ & $130-152$ \\
\hline \multirow[t]{3}{*}{ Ps 9} & $\mathrm{n}$ & 5 & 3 & 6 & 0 & 8 & 8 \\
\hline & A & 5 & 2 & 3 & - & 8 & 1 \\
\hline & Range & $205-237$ & $183-201$ & $201-206$ & - & $177-213$ & 209 \\
\hline \multirow[t]{3}{*}{ Ps 13} & $\mathrm{n}$ & 8 & 7 & 7 & 7 & 8 & 12 \\
\hline & A & 5 & 2 & 6 & 5 & 5 & 7 \\
\hline & Range & $211-227$ & $219-221$ & $221-241$ & $213-225$ & $213-235$ & $183-227$ \\
\hline \multirow[t]{3}{*}{ Ps 16} & $\mathrm{n}$ & 8 & 8 & 6 & 8 & 8 & 19 \\
\hline & A & 3 & 2 & 3 & 3 & 1 & 3 \\
\hline & Range & $179-185$ & $176-182$ & $179-185$ & $179-185$ & 179 & $176-185$ \\
\hline \multirow[t]{3}{*}{ Ps27 } & $\mathrm{n}$ & 7 & 6 & 8 & 6 & 8 & 8 \\
\hline & A & 3 & 6 & 7 & 2 & 1 & 3 \\
\hline & Range & $187-193$ & $121-189$ & $157-203$ & $187-201$ & 189 & $149-187$ \\
\hline \multirow[t]{3}{*}{ Ps28 } & $\mathrm{n}$ & 8 & 5 & 8 & 7 & 8 & 8 \\
\hline & A & 4 & 3 & 4 & 3 & 1 & 1 \\
\hline & Range & $164-206$ & $122-206$ & $155-206$ & $194-206$ & 203 & 200 \\
\hline \multirow[t]{3}{*}{ Ps33 } & $\mathrm{n}$ & 3 & 7 & 7 & 0 & 8 & 8 \\
\hline & A & 5 & 3 & 3 & - & 4 & 1 \\
\hline & Range & $170-198$ & $172-188$ & $178-186$ & - & $120-182$ & 186 \\
\hline
\end{tabular}

$n$, number of amplified samples (maximum 8); A, Number of Alleles. 


\section{REFERENCES}

Excoffier L, Laval G, Schneider S (2005) Arlequin ver. 3.0: An integrated software package for population genetics data analysis. Evolutionary Bioinformatics Online 1:47-50

Frankham R, Ballou JD, Briscoe DA (2002) Introduction to conservation genetics. Cambridge University Press, Cambridge

Meerow AW (1990) Amaryllidaceae.In: Harling G, Andersson L (eds) Flora of Ecuador, Vol. 41. University of Gotenborg; Riksmuseum, Pontificia Universidad Católica del Ecuador, Goteborg, Stockholm, Quito

Oleas N (2000a) Abundancia, distribución y estado de conservación de cuatro especies del género Phaedranassa (Amaryllidaceae) endémicas de la Sierra Ecuatoriana. Undergraduate thesis. Pontificia Universidad Católica del Ecuador, Quito

Oleas N (2000b) Amaryllidaceae. In: Valencia R, Pitman N, Leon-Yanez S, Jørgensen PM (eds) Libro Rojo de las Plantas Endémicas del Ecuador 2000. Publicaciones del Herbario QCA, Pontificia Universidad Católica del Ecuador, Quito, pp 66-67

Oleas N, Meerow AW, Francisco-Ortega J (2005) Isolation and characterization of eight microsatellite loci from Phaedranassa tunguraguae (Amaryllidaceae). Molecular Ecology Notes 5:791-793

Rozen S, Skaletsky HJ (1998) Primer3. http://wwwgenome.wi.mit.edu/genome_software/other/primer3.html 
CHAPTER III.

MUDDY BOOTS BEGET WISDOM: A CAUTIONARY TALE FOR SPECIES

DISTRIBUTION MODELS ON ENDANGERED SPECIES

\begin{abstract}
Aim: I aim to investigate the impact of species occurrence data quality on estimates of species ranges. I highlight the data quality impact in poorly collected plant species using tropical endangered plants.

Location: Northern Andes, Ecuador

Methods: I used species distribution models (SDMs) to predict potential species distributions for seven species of Phaedranassa (Amaryllidaceae) with three progressively edited species occurrence sources: (1) database, which are occurrence records available online; (2) taxonomy-based, specimens which species identification was revised by experts and (3) field-based records taken with GPS in situ.

Results: The SDMs generated out of different occurrence record sources did not generally agree. The SDMs with species occurrence data from records obtained from online databases performed worse than the taxonomically-revised and the field-based models. Main conclusions: In order to generate accurate models, species occurrence records to be used for SDMs need to be carefully evaluated with: (1) appropriate filters (e.g., altitude range, ecosystem); (2) taxonomy monographs and/or specialist corroboration; and (3) confirmation in the field. This study is a cautionary tale that speaks against extrapolating the results of SDMs produced with unverified online records to species' extinction risks associated with climate change.
\end{abstract}


Key words: Andes, Species Distribution Models, endangered plants, geo-referencing error, species occurrence data, taxonomy, Phaedranassa

\section{Introduction}

In recent years there has been an increase in the availability of species occurrence data on the World Wide Web (Canhos et al. 2004; Soberón and Peterson 2004; JiménezValverde et al. 2008; Feeley and Silman 2011). International initiatives' such as the Global Biodiversity Information Facility (GBIF http://www.gbif.org), SpeciesLink (http://splink.cria.org.br/), Mantis (http://insects.oeb.harvard.edu/mantis/) and others, have compiled data from thousands of disparate sources (e.g., herbarium and museum collections and sighting records), allowing users to rapidly acquire vast amounts of data. These data can then be used in Species Distribution Models (SDMs). The SDMs are a general suite of models which estimate the ranges of species on the basis of relationships between the species' probability of occurring and environmental factors such as temperature, precipitation, seasonality, soil type, etc. (Franklin 2009). As a result of the low cost and ease of acquiring data and generating distributions along with their many potential important applications (e.g., conservation of endangered species, prediction of invasive species propagation, and predicting species distributions under different past and future climate change scenarios [Peterson 2003; Martinez-Meyer 2005; Powell et al. 2005; Guisan et al. 2006; Peterson2006; Thuiller et al. 2006; Peterson and Nakazawa 2008; Feeley and Silman 2010]). SDMs have rapidly gained in popularity and are in widespread use by ecologists, biogeographers and conservation scientists.

Accessibility to data, however, may come at the expense of data quality or reliability. In general, SDMs rely on three primary components: (1) species occurrence 
data, (2) environmental variables and (3) the underlying statistical model. The accuracy of the SDMs' range predictions will be directly influenced by the accuracy of these three components. In the case of species occurrence data, there are issues associated with data obtained from large online databases and natural history collections that may limit their utility in SDMs (Newbold 2010). For example, historical records from herbarium and museums specimens typically lack geographical coordinates - information that is essential for the implementation of SDMs (Beaman and Conn 2003). Geographic coordinates can often be obtained from location data that accompany the records and using maps, gazettes or software (Murphey et al. 2004; Guralnick et al. 2006); however, in many instances the geographical information found in the specimen labels/annotations is vague, and/or it is uncertain to what extent errors were made when the information was originally recorded. For example, in one instance I found a herbarium label indicating that a specimen of $P$. cinerea had been collected from the Ecuadorian Paramo (vegetation $>4000 \mathrm{~m}$ ) at higher altitudes than had been previously reported for this species. After further research (which involved contacting a crewmember of the botanic group that originally collected the plant), I found that there was an error in the label: the species was actually collected in a different location on the way to the Paramo site but the information in the specimen label was that of the Paramo plot where the group was focusing their collecting efforts.

It has been suggested that GIS analysis (Hijmans et al. 1999) and the use of environmental filters can help to screen for errors in species occurrence data (Feeley and Silman 2010). In the anecdotal note above, using an automatic "altitude" or "ecosystem" filter would have eliminated the erroneous record. 
Another, potentially important, but underappreciated source of error in collection records is the need for taxonomic validation by experts, since misidentifications will clearly have implications for the ability of SDMs to accurately portray species ranges (Guralnick et al. 2007; Lozier et al. 2009).

In order to understand the impact of data accessibility vs. data quality, we need to quantify the degree that different types of data have on SDMs. The objective of this study is to investigate the impact of differing data quality as associated with different data sources on estimates of species ranges produced using SDMs. I am specifically interested in addressing the problems in generating SDMs using species records from large online databases, since this is a common practice. Towards this goal, I compared species range estimates in Ecuador for seven species in the genus Phaedranassa generated from three data sources: (1) standard species occurrence data available online through GBIF and other sources; (2) a combination of records available online and specimens from physical herbaria in Ecuador for which taxonomic identity was corroborated by a specialist; and (3) locations of plants in the field as recorded during field work for this research from 1999 to 2009. By comparing the range estimates resulting from these three datasets I hope to highlight the importance of data quality and taxonomic verification. I anticipate that my study will serve as a cautionary tale exemplifying how conclusions on the basis of SDMs may be misleading if the source and quality of data is not carefully considered.

\section{Methods}

\section{Study species}

Phaedranassa (Herb.) is a small genus of bulbous plants in the family Amaryllidaceae. This genus is represented by ten species that, except for one species 
described from Costa Rica, are restricted to open moist slopes and xeric valleys in the Andes mountains of Colombia and Ecuador (Meerow 1990). Out of the ten Phaedranassa species, seven are native to Ecuador with six of them endemic to the country. Within Ecuador, each of the species is known by no more than 10 populations, each with a distribution smaller than $100 \mathrm{~km}^{2}$ (Oleas 2000). Because of their restricted geographic distribution, as well as the limited number of populations, all the Ecuadorean endemic Phaedranassa species are listed as either "endangered" or "vulnerable to extinction" under the International Union for the Conservation of Nature (IUCN) criteria (Oleas 2000).

\section{Collection of occurrence data}

I used three sources of species occurrence data to generate SDMs. First, I compiled records from sources available through the Global Biodiversity Information Facility (GBIF http://www.gbif.org/) online data clearing house, as is common practice in many SDM studies. These data (hereafter referred to as "database" records) came primarily from individual herbarium collections at the (1) the Missouri Botanical Garden (MO, http://www.TROPICOS.org), (2) the University of Aarhus, Denmark (AAU, http://herb42.bio.au.dk/aau_herb/default.php), (3) the New York Botanical Garden (NYBG, http://www.nybg.org/), (4) the Royal Botanical Garden Kew (K, http://www.kew.org/), and (5) the University of Florida Herbarium (FLAS, http://www.flmnh.ufl.edu/herbarium/). When geographical coordinates were available with the database records, they were included with no modification. Besides downloading records available online, I took some additional steps to ensure that my database set had the best possible quality for this source. I excluded any record that was obviously 
incorrect (e.g., located in a large body of water) or located in a country other than Ecuador. All the records collected before the year 1900 were also excluded because of uncertainties in associated locations. In an effort to increase the number of records, localities without coordinates were geo-referenced from the online data using regional maps. With the exception of P. dubia, all Phaedranassa species in Ecuador are listed at some level of threat under IUCN criteria. Geo-referenced records of endangered species are not provided in some online databases to avoid over-collection. Thus, coordinates of endangered Phaedranassa records in TROPICOS were not available through GBIF and were obtained directly from MO. I did not calculate the distribution for $P$. brevifolia and P. glauciflora with the database set because there was only one specimen for each species available online.

My second dataset (hereafter referred to "taxonomy-based" records) includes all the records accessible online as well as records that are available only as physical specimens in Ecuador in the two main herbaria in Ecuador: Herbario de la Pontificia Universidad Catolica del Quito (QCA), and the Herbario Nacional del Ecuador (QCNE). Many of these specimens were used in the latest the taxonomic treatment of the family (Meerow, 1990), which greatly reduces taxonomic uncertainty. Herbarium specimens not included in the taxonomic treatment were inspected by myself at the QCA, QCNE and MOBOT herbaria and identified to the species level using the keys in Meerow's (1990) treatment.

My third dataset (hereafter referred to as "field-based" records) includes only the geographic coordinates (GPS-based) of plants encountered during my fieldwork in Ecuador from 1999 to 2009. It was during the fieldwork that I noticed errors in the 
specimen's labels. These data were originally collected for use in an extensive study of the population genetics of the genus. In collecting field data, all of the locations listed in the previous two datasets (database and taxonomy-based) were visited, at least once, to collect samples for the population genetic portion of this dissertation (Chapter IV) and to verify occurrence.

\section{Model building}

Distribution models for Phaedranassa spp. were generated through a maximum entropy approach as implemented in the program MAXENT ver. 3.3.3a (Phillips et al. 2006). The maximum entropy method is appropriate for presence only data (Newbold et al. 2010) and is one of the most widely programs used to generate species distribution models. Maximum entropy has shown superior prediction accuracy compared to other methods (Elith et al. 2006) and is less sensitive to sample size than other SDMs (Hernandez et al. 2006; Pearson et al. 2007; Hernandez et al. 2008; Wisz et al. 2008), an important consideration because small sample sizes are expected for collections of endangered species from the tropics. When implementing MAXENT, I used the default options but removed duplicate records.

I obtained the environmental variables to use in MAXENT from WorldClim (www.worldclim.org, spatial resolution of 30 arc second or $\sim 1 \mathrm{~km}^{2}$ ). I conducted the SDMs using two different sets of climatic variables. First, I used all 19 bioclimatic variables (Hijmans et al. 2005) available through WorldClim - a common approach for SDMs. I also used a subset of five bioclimatic variables known be to be important for species distribution and uncorrelated for the region: temperature annual range, annual mean precipitation, annual mean temperature, precipitation seasonality (Loiselle et al. 
2007; Hernandez et al. 2008; Seo et al. 2009) and minimum temperature of the coldest month.

The output of MAXENT is a continuous probability field. I transformed this into a predicted presence vs. absence map by thresholding at the point of maximum training sensitivity plus specificity (Jiménez-Valverde et al. 2008). In all, I generated six sets of range predictions for each of the seven species occurring in Ecuador, using the "database", "taxonomy-based" and "field-based" data sets and the two sets of climatic variables (Fig. 1).

\section{Evaluation of the models}

I assessed model performance with the receiver operating characteristic analysis (ROC) as implemented in MAXENT (Phillips et al. 2006). The ROC value shows the relationship between the false positive error versus the true positive rate (Franklin 2009), and is usually reported as the area under the curve (AUC). The area under the curve is a threshold-independent measure that shows the probability that a random selection of species presence will show higher probability than an absence site chosen at random (Franklin 2009). Values of AUC higher than 0.9 are considered to indicate high model performance, values of 0.7- 0.9 indicate moderate model performance, and values lower than 0.7 are considered to show poor model performance (Manel et al. 2001; Franklin 2009).

I evaluated the degree of agreement between the range predictions produced from the different occurrence datasets using the Kappa test statistic. Kappa is a thresholddependent categorical measure of the difference between observed versus random agreement (Franklin, 2009). Kappa values closer to one represents a good agreement 
between range predictions. For this study I used Kappa to compare the probability threshold range predictions of each species generated with the three data sources (database, taxonomy-based and field-based).

I also compared the total area and elevation range of the probability threshold distribution for each species obtained with each one of the three datasets. For the total area I counted the number of pixels of the distribution model multiplied by 0.86 to obtain the approximate area in $\mathrm{km}^{2}$. Elevation value was obtained from the altitude layer available in WorldClim (www.worldclim.org), for each distribution prediction as well as the altitudinal range of the data points themselves using the extracting option of ArcToolBox in ESRI ArcMap 9.2. For field-work records, altitude was also measured using an Etrex Garmin GPS unit on site.

\section{Results}

I found 65 unique records available through GBIF for Phaedranassa in Ecuador. The number of records per species in my "database" set ranged from one to 40 (mean = 9). The total number of records in my "taxonomy-based" set was 73 with a range of zero to 25 records per species (mean $=10)$. My "field-based" dataset had 184 records with a range of 16 to 41 records per species $($ mean $=26)$.

The model performance as judged by AUC was generally high (Table 2). In terms of Kappa, overall there was poor agreement between the range predictions generated with each of the three datasets (Table 1). The exception was $P$. dubia, with high Kappa values between all datasets, and P. schizantha in the "database" vs. "taxonomy-based" assessment with five bioclimatic variables but not when all bioclimatic variables were included (Table 1). 
The area of the range predictions generated using field-based data were smaller than the areas of range predictions created with either "database" or "taxonomy-based" data (Table 2, Fig 1). The areas of the range predictions obtained using all the bioclimatic variables were smaller than the area obtained with the models using just five bioclimatic variables (Table 2, Fig 1).

The average difference between the altitudes of each collection point estimated by GPS and the altitude extracted from the altitude layer was 86 meters and ranged from $247 \mathrm{~m}$ to $+617 \mathrm{~m}$. In general, both "database" and "taxonomy-based" records resulted in wider altitudinal range predictions for each species compared to the altitudinal range predictions with "field-based" data (Table 2). The difference was highest in "database" vs. "fieldwork-base" comparisons. I found the same pattern for both models obtained with either five or all bioclimatic variables (Table 2).

\section{Discussion}

The increased accessibility of free data from disparate sources through online clearing houses such as the GBIF has the potential to greatly advance our understanding of large-scale geographic and ecological patterns in species distributions. However, the indiscriminate use of these data also has the potential to produce inaccurate or misleading results, clouding our understanding of the species distributions and the extrapolations made with them. To highlight this risk, I compared range predictions generated by SDMs with data garnered directly from GBIF (with standard levels of data filtering) to those generated with data that has undergone increased levels of scrutiny (i.e., taxonomic verification) and data on the basis of expert observations in the field. 
In this study my principal interest was to highlight the implications of different species occurrence datasets on SDMs. In most cases, the degree of agreement among models was low. The agreement was weaker when I compared "database" vs. "fieldbased" predictions (Table 1) as was expected because of the large differences in data quality in terms of both geo-referencing and taxonomic certainty.

I found two opposite patterns for total amount of area classified as suitable under the SDMs made with different data sources. For species known from only a very small number of collections (e.g., P. brevifolia, P. viridiflora, Table 2), the estimated area for the field-based distribution was larger than the areas of either database or taxonomybased range predictions. This result is likely because of the greater number of records in the field-based dataset compared to the limited number of records available online. In contrast, for species with larger sample sizes, the area of field-based range predictions was smaller than those produced with the other two datasets. The reduction in area is believed to occur as the result of errors found in the database and taxonomy-based dataset which tend to inflate species ranges (Feeley and Silman 2010).

Altitudinal range is an important feature that, because of its association with temperature $\left(\sim 5.5^{\circ} \mathrm{C}\right.$ colder per km elevation gain), it is often used for ecological inference, especially within the context of climate change (Korner 2007). If I translate the differences I found in altitude ranges predicted by "field-based" vs. either "database" or "taxonomy-based" data, into differences in thermal niche breadths, I find an average difference of $-5.6^{\circ} \mathrm{C}\left(+30^{\circ} \mathrm{C}\right.$ to $-21^{\circ} \mathrm{C}$ range $)$ in my five climatic variable models, or an average difference of $-4.6^{\circ} \mathrm{C}\left(+18^{\circ} \mathrm{C}\right.$ to $-24^{\circ} \mathrm{C}$ range $)$ when all 19 bioclimatic variables are included. In other words, the differences in thermal niche breadths predicted for 
species on the basis of online records vs. data collected and verified in the field is higher than some of the worst warming scenarios predicted for the Andes over the next century (Urrutia and Vuille 2009). This unrealistic result should raise a cautionary "red flag" against extrapolating the results of SDMs produced with unverified online records to species' extinction risks related to climate change.

In this study I dealt with two types of errors common in species occurrence data records: geo-referencing errors and taxonomic misidentification. There are ways to minimize error records in species occurrence data. Automatic filters using known features of the species range, such as altitude or ecosystem, might help to eliminate erroneous species records before generating species distribution models (Feeley and Silman 2011). Another simple way to avoid errors is reading the actual specimen herbarium label, instead of relying solely on the geographic coordinates that can be downloaded in a spreadsheet. One mistake that can be identified by reading the label is ex-situ collections. For example, in one case I found one living specimen for which the geo-referenced collection information available online corresponded to the address of a botanical garden where it is cultivated rather than indicating the location of natural origin of the specimen. By chance this false record fell between the natural altitudinal range of the species and thus the error may not have been caught by an automatic altitude based filter.

The effects of taxonomic misidentifications are potentially as important as georeferencing errors but have received considerably less attention. Checking for taxonomic errors requires access to the physical herbarium specimen and a specialist willing to review the data. As such, checking for taxonomic errors cannot be easily automated and thus may be infeasible for large scale, multi-taxa studies. I suggest that taxonomic errors 
can be minimized by using the records reported in recent taxonomic monographs because in these cases the taxonomy of the specimens has been previously verified by experts. I anticipate that for species without recent taxonomic revisions, the level of error of SDMs with data originating from databases alone will be even higher than in my study because, even at my dataset level, many of the specimens were relatively recently curated by the specialist before I conducted this study.

One of the main problems for SDMs of tropical plant species in general, but endangered species in particular, is the lack of species occurrence data. In order to obtain accurate models of species distribution range, a minimum of 20 records per species is needed (Hernandez et al. 2006; Wisz et al. 2008). In this study, only the three sets of data for $P$. dubia met this minimum. A need for more collections in the tropics has been recognized previously (Feeley and Silman 2011). I also found that there were specimen records in local herbaria in the country of origin that were not included in the World Wide Web databases like GIBF. In this case, most of the collection was made by a local botanist who had not collected extra vouchers to share with international herbaria. A program that circumvents this problem through quick data and specimen sharing is the partnership between the Missouri Botanical Garden (MOBOT, USA) and the Herbario Nacional (QCNE, Ecuador). More exchange programs between international institutions and local herbarium and museums are greatly needed and provide a relatively inexpensive way to increase species representation in international databases.

Finally, SDMs, even those generated with fewer than the optimal number of species occurrence records, can be helpful for other purposes. The information obtained from SDMs can be applied to find new populations of endangered species. For example, I 
used a preliminary SDM to predict habit for P. brevifolia, which I then searched for specimens; this approach enabled me to find three new records for this species. Another successful example of this use was reported for Byrsonima subterranean (Malpighiaceae), an endemic plant from Brazil (de Siqueira et al. 2009). Ideally, new populations can be incorporated to the SDM; these additions in turn upgrade the model; and then the use of the improved SDM increases the chances of finding new populations (Guisan et al. 2006).

Species Distribution Models are clearly useful for conservation purposes. The results presented here, however, show that it is indispensable to address the limitations of the species occurrence data first, in order to avoid erroneous outcomes of posterior extrapolations. Data quality certainly matters, and databases do not have the certainty associated with taxonomic revisions and field work.

\section{Acknowledgements}

The authors thank all the botanists who deposit vouchers of collections from the Andes in herbaria and museums. This study was made possible by their work. I also thank the GBIF and other similar efforts for compiling valuable species data and making it accessible on the web. I thank also the Missouri Botanical Garden, especially Carmen Ulloa, for providing access to records in TROPICOS database. This study was financed in part by the Dissertation Evidence Acquisition Fellowship at Florida International University and a grant from The South Florida Chapter of The Explorers Club. 


\section{Phaedranassa brevifolia}
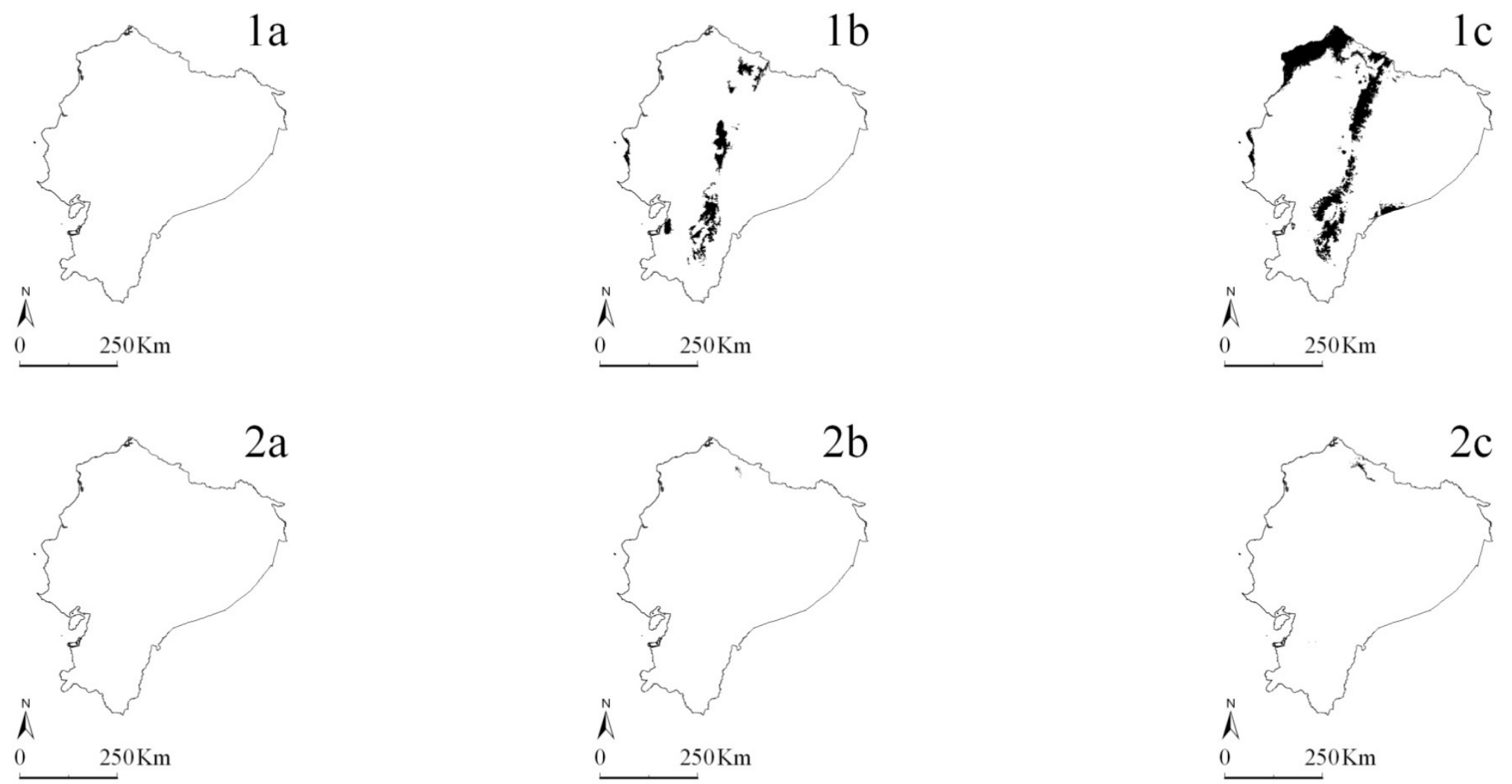

Figure 1. Distribution maps for seven Phaedranassa spp. Dark areas indicate predicted presence. Lower case letter indicates dataset source type: (a) database; (b) taxonomy-based; (c) field-based; numbers are (1) SDMs with 5 bioclimatic variables (www.WorldClim.org) and (2) SDMs with all 19 bioclimatic variables 


\section{Phaedranassa cinerea}
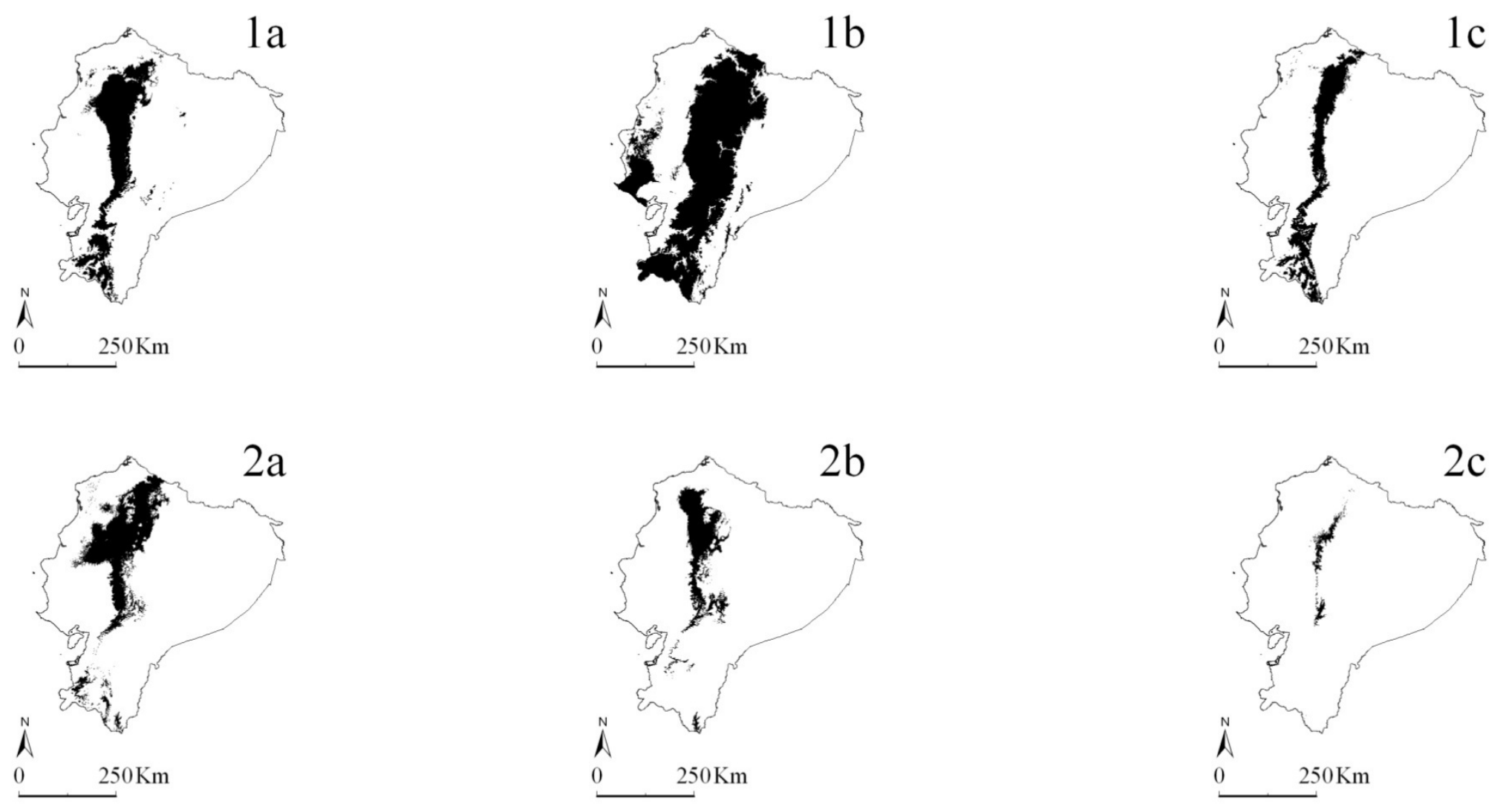

Figure 1 (continued) 


\section{Phaedranassa dubia}
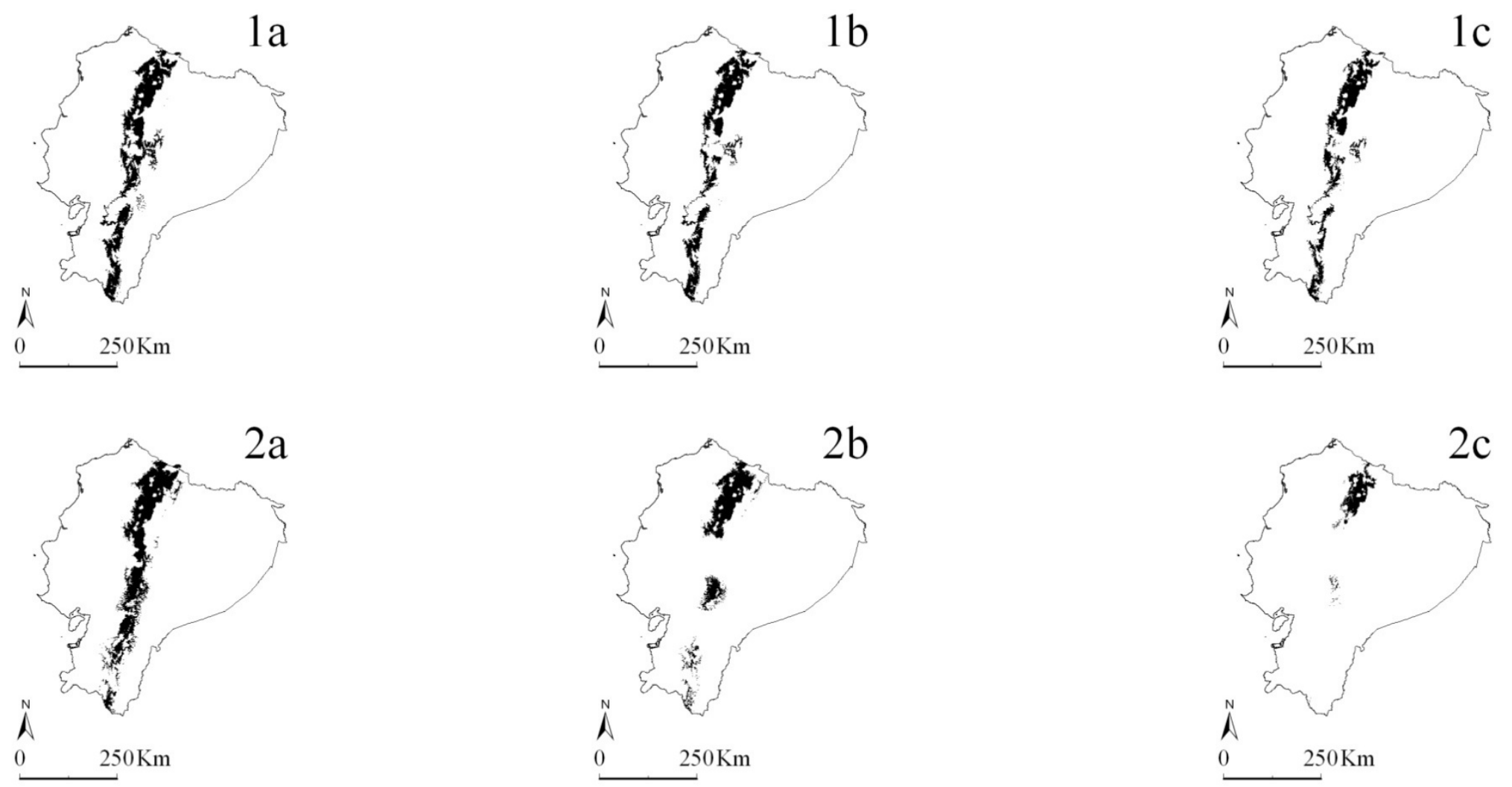

Figure 1 (continued) 


\section{Phaedranassa glauciflora}
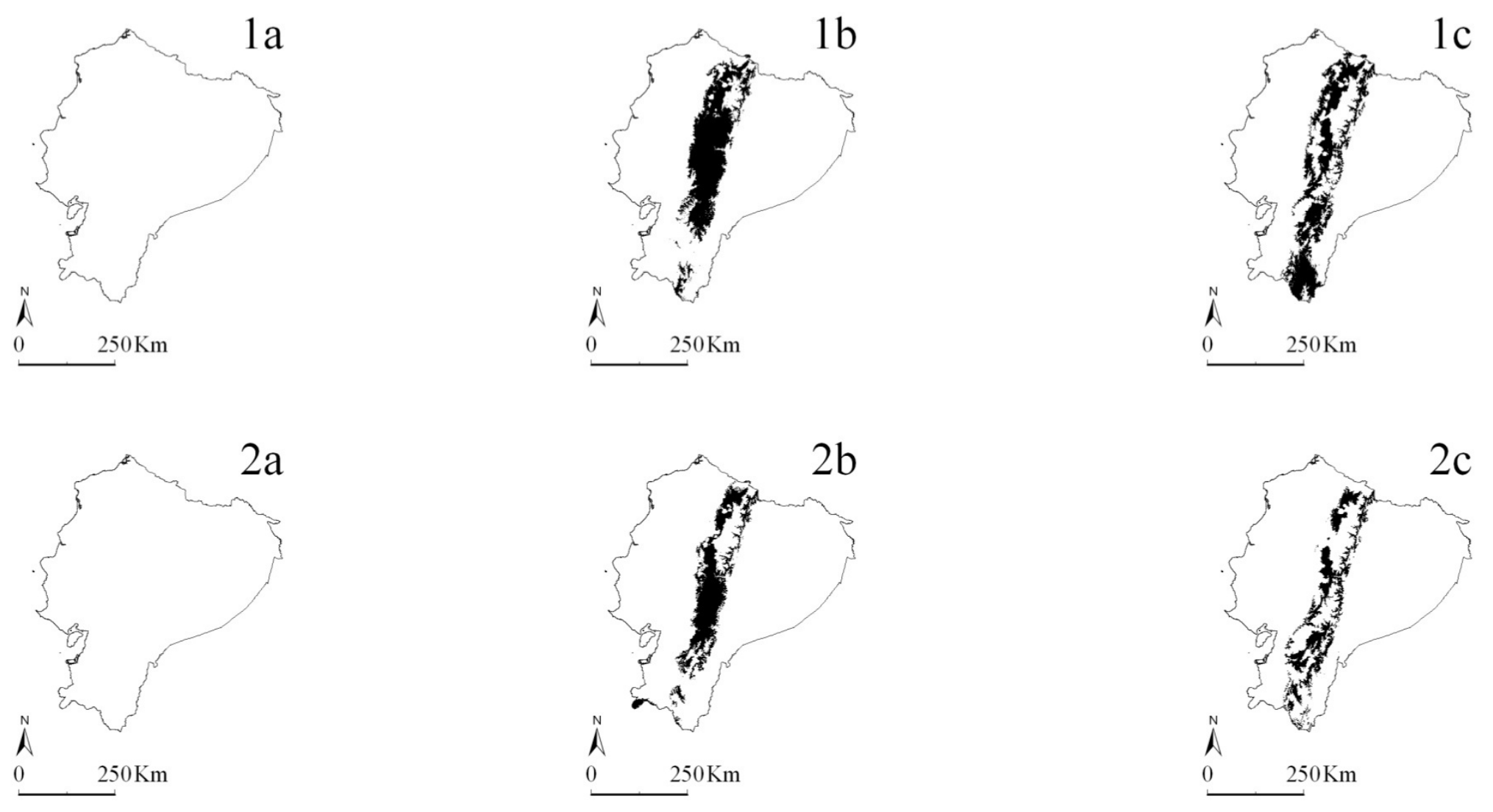

Figure 1 (continued) 


\section{Phaedranassa schizantha}
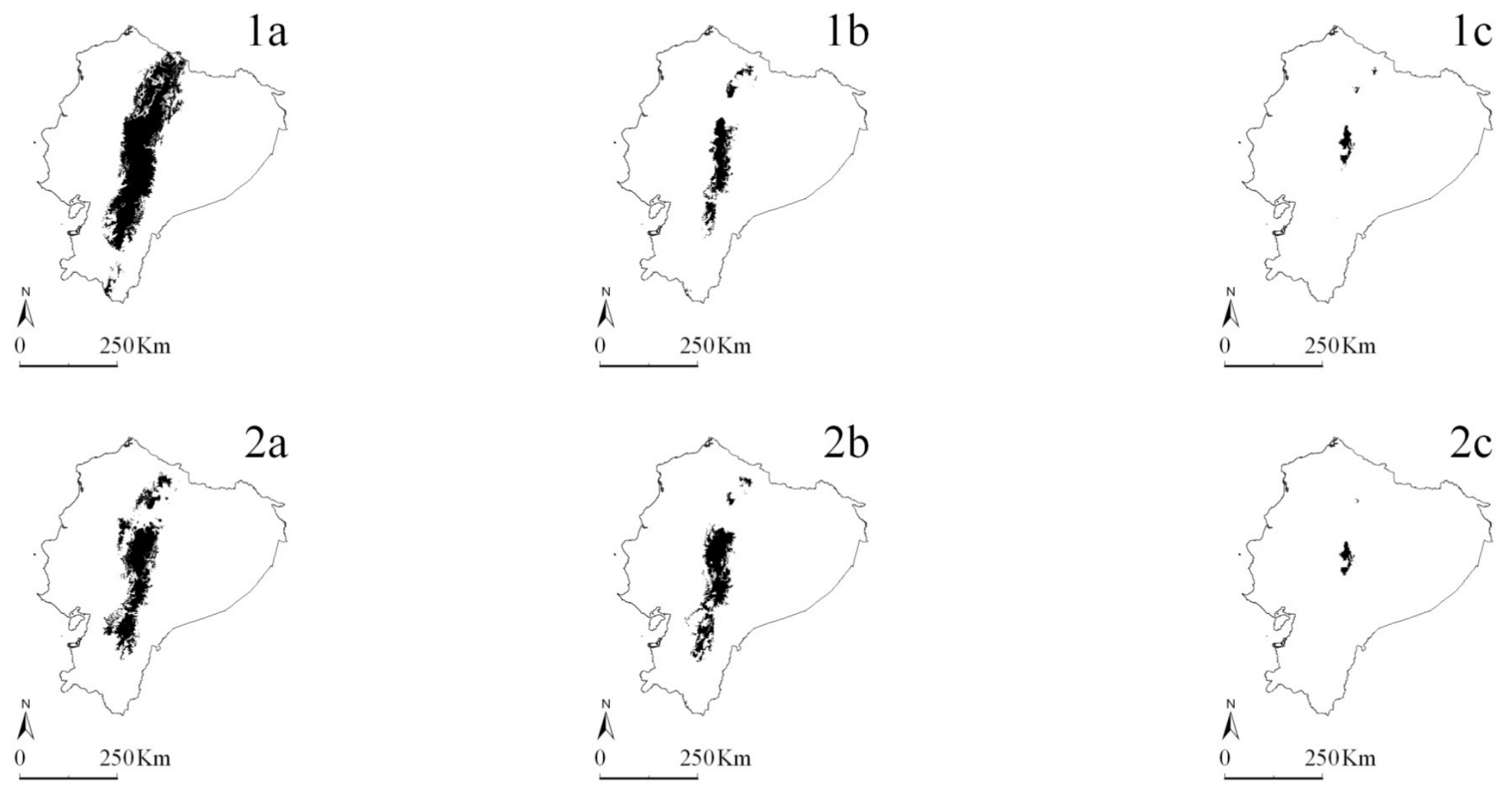

Figure 1 (continued) 


\section{Phaedranassa tunguraguae}
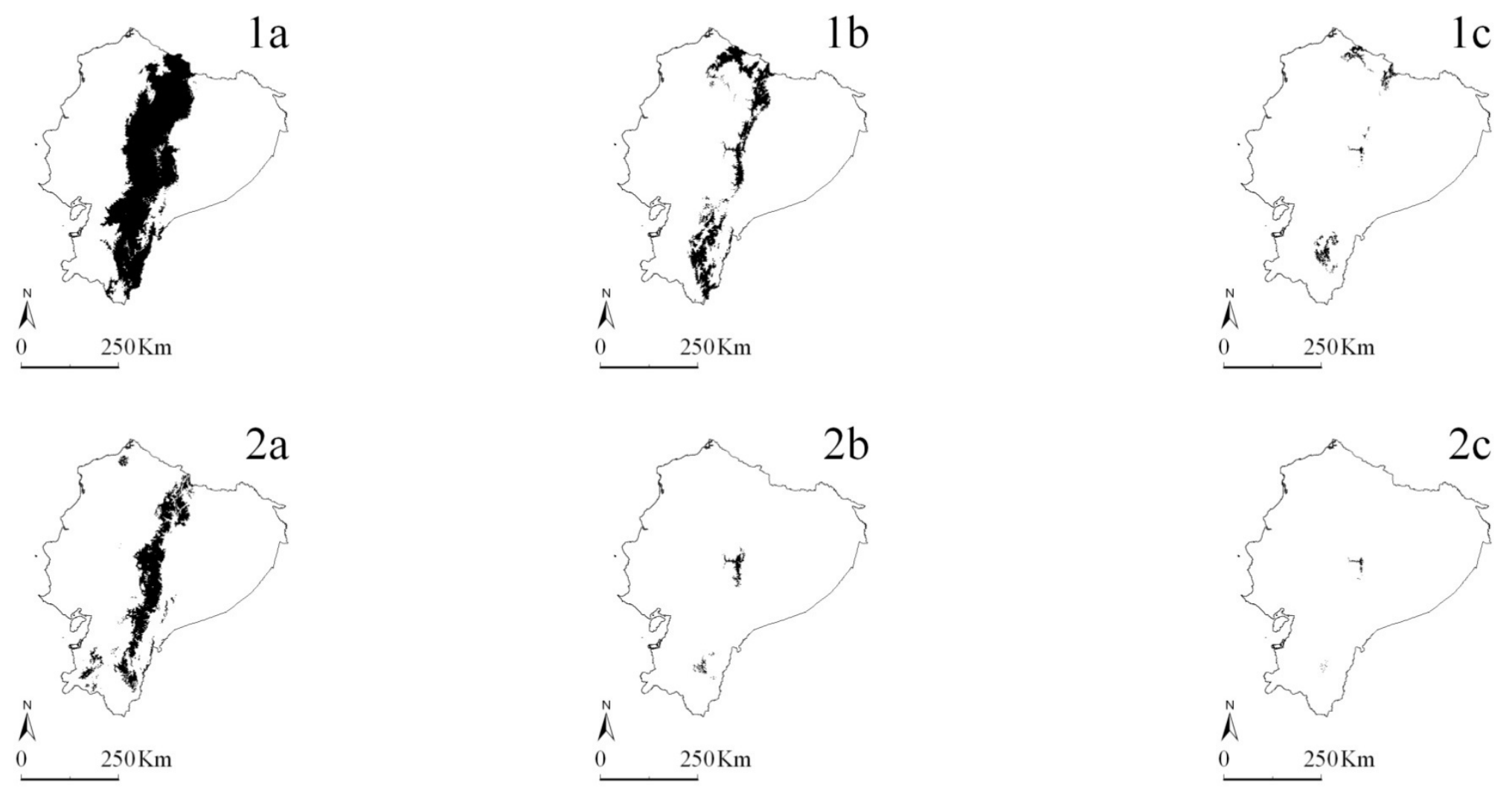

Figure 1 (continued) 


\section{Phaedranassa viridiflora}
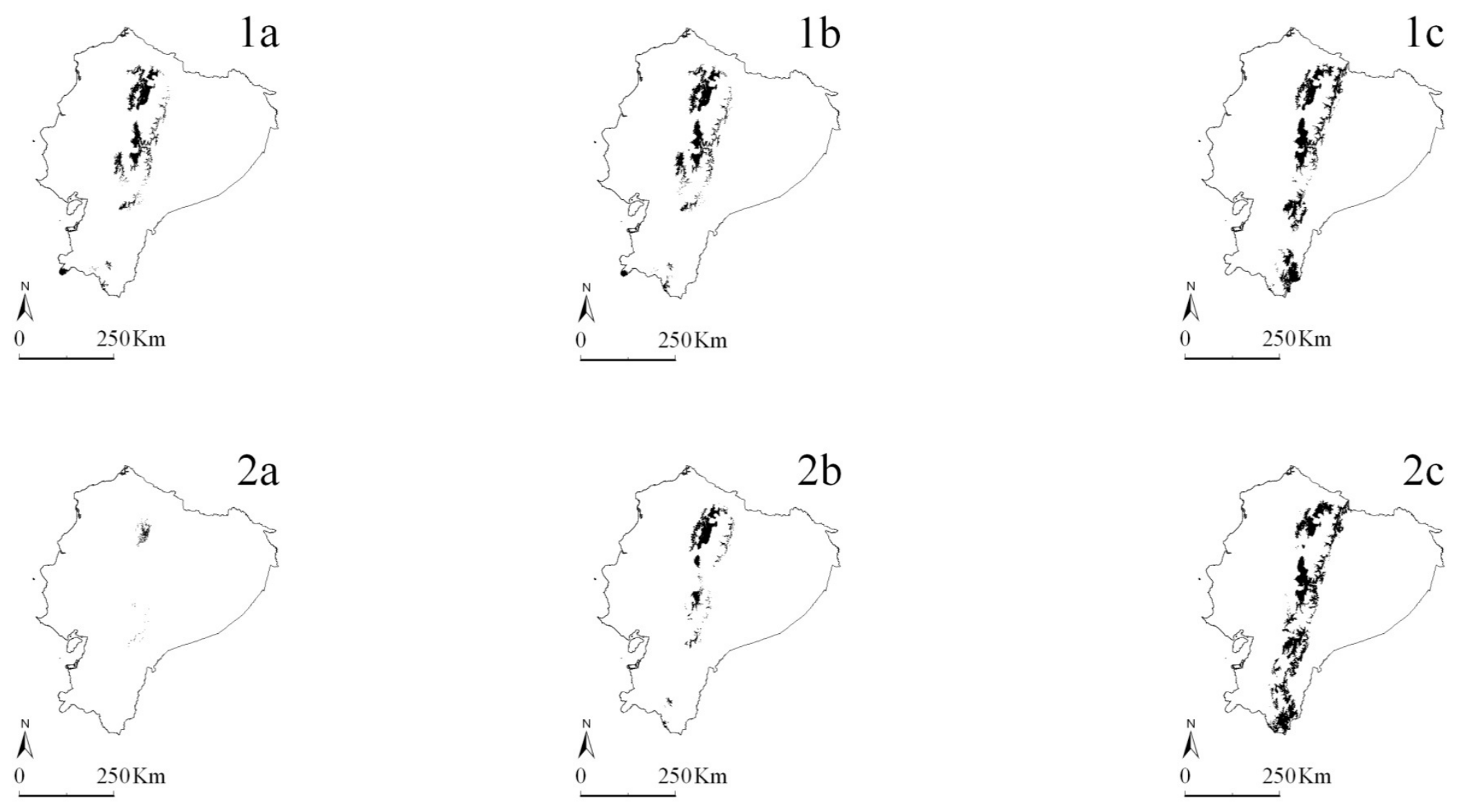

Figure 1 (continued) 
Table 1. Kappa statisticsevaluating the degree of agreement between species distribution models for species of Phaedranassa. Numbers without parenthesis corresponds to kappa values for models with five bioclimatic variables, while the number inside parenthesis is kappa from model built with all 19 bioclimatic variables

\begin{tabular}{lrrr}
\hline Species & $\begin{array}{l}\text { (Database vs. } \\
\text { Field-based) }\end{array}$ & $\begin{array}{l}\text { (Taxonomy-based } \\
\text { vs. Field-base) }\end{array}$ & \multicolumn{2}{l}{$\begin{array}{l}\text { Taxonomy-based) } \\
\text { Tax. }\end{array}$} \\
\hline P. brevifolia & 0 & $0.169(0.147)$ & 0 \\
P. cinerea & $0.531(0.150)$ & $0.322(0.260)$ & $0.396(0.486)$ \\
P. dubia & $\mathbf{0 . 7 7 5}(0.333)$ & $\mathbf{0 . 8 2 6}(0.514)$ & $\mathbf{0 . 9 3 5}(0.725)$ \\
P. glauciflora & 0 & $0.567(0.655)$ & 0 \\
P. schizantha & $0.275(0.116)$ & $0.276(0.157)$ & $\mathbf{0 . 7 9 7}(0.673)$ \\
P. tunguraguae & $0.054(0.022)$ & $0.322(0.306)$ & $0.239(0.108)$ \\
P. viridiflora & $0.456(0.043)$ & $0.474(0.350)$ & $0.521(0.181)$ \\
\hline
\end{tabular}


Table 2. Comparison among Phaedranassa species distribution models (SDMs). Datasets are represented with superscript numbers in each species: (1) database, (2) taxonomybased, (3) field-based. Numbers without parenthesis are values for models with five bioclimatic variables, numbers inside parentheses are values of model built with all 19 bioclimatic variables. Altitudinal range (a) geographic coordinates, (b) SDMs

\begin{tabular}{|c|c|c|c|c|c|}
\hline Species & $\begin{array}{l}\text { Number } \\
\text { of record s }\end{array}$ & $\begin{array}{l}\text { SDMs } \\
\text { Area } \\
\left(\mathrm{Km}^{2}\right)\end{array}$ & $\begin{array}{l}\text { Altitudinal } \\
\text { range }(\mathrm{m})^{\mathrm{a}}\end{array}$ & $\begin{array}{l}\text { Altitudinal } \\
\text { range }(\mathrm{m})^{\mathrm{b}}\end{array}$ & $\begin{array}{l}\text { Area under } \\
\text { curve } \\
\text { (AUC) }\end{array}$ \\
\hline \multirow[t]{2}{*}{ P. brevifolial } & 1 & & & & 0.500 \\
\hline & & $\mathrm{N} / \mathrm{A}$ & 1533 & $\mathrm{~N} / \mathrm{A}$ & $(0.500)$ \\
\hline \multirow[t]{3}{*}{ P. brevifolia ${ }^{2}$} & 3 & & & $0-3549$ & 0.938 \\
\hline & & & & (1211- & (1.000) \\
\hline & 22 & $\begin{array}{r}9811(66) \\
13138\end{array}$ & $1533-1674$ & $\begin{array}{r}1674) \\
0-5068\end{array}$ & 0923 \\
\hline P. brevifolia ${ }^{3}$ & & $(412)$ & $924-1533$ & $(798-1818)$ & (0.999) \\
\hline \multirow[t]{2}{*}{ P. cinerea $^{l}$} & 11 & 43421 & & $79-4810$ & 0.955 \\
\hline & & $(34285)$ & $585-3394$ & $(30-4267)$ & $(0.969)$ \\
\hline \multirow[t]{2}{*}{ P. cinerea $^{2}$} & 11 & 72980 & & $0-6169$ & 0.791 \\
\hline & & (18890) & $585-3439$ & $(48-3175)$ & $(0.932)$ \\
\hline \multirow[t]{2}{*}{ P. cinerea $^{3}$} & 26 & 23704 & & $430-3920$ & 0.980 \\
\hline & & (3235) & $583-2276$ & $(531-3175)$ & $(0.996)$ \\
\hline \multirow[t]{2}{*}{ P. dubia ${ }^{l}$} & 26 & & & $1500-3996$ & 0.966 \\
\hline & & $\begin{array}{r}20289 \\
(\mathbf{2 2 9 2 9})\end{array}$ & $1803-3541$ & $\begin{array}{r}(1164- \\
4114)\end{array}$ & $(0.977)$ \\
\hline \multirow[t]{2}{*}{ P. dubia ${ }^{2}$} & 25 & 18367 & & $1522-3846$ & 0.969 \\
\hline & & $(13752)$ & $1803-3541$ & $(1164-4130)$ & (0.978) \\
\hline \multirow[t]{3}{*}{ P. dubia ${ }^{3}$} & 41 & & & $1640-3892$ & 0.989 \\
\hline & & 13777 & & (1851- & $(0.995)$ \\
\hline & & (4947) & $2255-3394$ & 3897) & \\
\hline \multirow[t]{2}{*}{ P. glauciflora ${ }^{l}$} & 1 & & & & 0.500 \\
\hline & & $\mathrm{N} / \mathrm{A}$ & 2152 & $\mathrm{~N} / \mathrm{A}$ & $(0.500)$ \\
\hline \multirow[t]{2}{*}{ P. glauciflora ${ }^{2}$} & 6 & 59316 & & $1404-6169$ & 0.937 \\
\hline & & $(25518)$ & $2609-3296$ & $(126-5217)$ & $(0.955)$ \\
\hline \multirow[t]{2}{*}{ P. glauciflora ${ }^{3}$} & 39 & 28972 & & $1265-3809$ & 0.944 \\
\hline & & $(20715)$ & $1690-2916$ & $(266-3430)$ & $(0.967)$ \\
\hline \multirow[t]{2}{*}{ P. schizantha ${ }^{l}$} & 15 & 13339 & & $1536-6169$ & 0.938 \\
\hline & & (19703) & $1177-4860$ & $(1092-6169)$ & $(0.967)$ \\
\hline \multirow[t]{2}{*}{ P. schizantha ${ }^{2}$} & 13 & 13103 & & $1813-5415$ & 0.934 \\
\hline & & (13948) & $1177-4860$ & $(1573-4997)$ & (0.977) \\
\hline \multirow[t]{2}{*}{ P. schizantha ${ }^{3}$} & 23 & 2227 & & $1851-3374$ & 0.996 \\
\hline & & (1305) & $2431-3376$ & $(2189-3345)$ & (0.997) \\
\hline
\end{tabular}


Table 2 (continued)

\begin{tabular}{|c|c|c|c|c|c|}
\hline Species & $\begin{array}{l}\text { Number } \\
\text { of record } s\end{array}$ & $\begin{array}{l}\text { SDMs } \\
\text { Area } \\
\left(\mathrm{Km}^{2}\right) \\
\end{array}$ & $\begin{array}{l}\text { Altitudinal } \\
\text { range }(\mathrm{m})^{\mathrm{a}}\end{array}$ & $\begin{array}{l}\text { Altitudinal } \\
\text { range }(\mathrm{m})^{\mathrm{b}}\end{array}$ & $\begin{array}{l}\text { Area under } \\
\text { curve } \\
(\mathrm{AUC})\end{array}$ \\
\hline$P$. & 9 & 58191 & & $639-6169$ & 0.751 \\
\hline tunguraguae $e^{l}$ & & $(22473)$ & $939-2477$ & $(4-4338)$ & $(0.990)$ \\
\hline$P$ & 12 & 16342 & & $789-3167$ & 0.989 \\
\hline tunguraguae $e^{2}$ & & (1532) & $939-2477$ & $(1219-2633)$ & $(0.998)$ \\
\hline$P$. & 17 & 3322 & & $886-2814$ & 0.997 \\
\hline tunguraguae $e^{3}$ & & $(280)$ & $1337-2018$ & $(1260-1590)$ & (0.999) \\
\hline \multirow[t]{2}{*}{ P. viridiflora ${ }^{l}$} & 2 & 5198 & & $126-6169$ & 0.980 \\
\hline & & $(623)$ & $2502-2692$ & $(1590-3027)$ & $(0.998)$ \\
\hline \multirow[t]{2}{*}{ P. viridiflora ${ }^{2}$} & 3 & 12915 & & $126-6169$ & 0.979 \\
\hline & & (5937) & $2502-2911$ & $(1458-3809)$ & $(0.985)$ \\
\hline \multirow[t]{2}{*}{ P. viridiflora ${ }^{3}$} & 16 & 13753 & & $839-3546$ & 0.986 \\
\hline & & $(18002)$ & $2194-2966$ & $(794-3512)$ & $(0.991)$ \\
\hline
\end{tabular}




\section{REFERENCES}

Beaman RS, Conn BJ (2003) Automated geoparsing and georeferencing of Malesian collection locality data. Telopea 10:43-52

Canhos VP, Souza S, Giovanni R, Canhos DAL (2004) Global biodivrsity informatics: setting the scene for a "New World" of ecological modeling Biodiversity Informatics 1:1-13

de Siqueira MF, Durigan G, de Marco PJ, Townsend Peteron A (2009) Something from nothing: Using landscape similarity and ecological niche modeling to find rare plant species. Journal for Nature Conservation 17:25-32

Elith J, Graham CH, Anderson RP, Dudı M, Ferrier S, Guisan A, Hijmans RJ, Huettmann F, Leathwick JR, Lehmann A, Li J, Lohmann LG, Loiselle BA, Manion G, Moritz C, Nakamura M, Nakazawa Y, Overton JM, Peterson AT, Phillips SJ, Richardson K, Scachetti-Pereira R, Schapire RE, Soberon J, Williams S, Wisz MS, Zimmermann NE (2006) Novel methods improve prediction of species' distributions from occurrence data. Ecography 2:129-151

Feeley KJ, Silman MR (2010) Modelling the responses of Andean and Amazonian plant species to climate change: the effects of georeferencing errors and the importance of data filtering. Journal of Biogeography 37:733-740

Feeley KJ, Silman MR (2011) The data void in modeling current and future distributions of tropical species. Global Change Biology 17:626-630

Franklin J (2009) Mapping species distributions: spatial inference and prediction. Cambridge University Press, Cambridge, New York

Guisan A, Broennimann O, Engler R, Vust M, Yoccoz NG, Lehmann A, Zimmermann NE (2006) Using niche-based models to improve the sampling of rare species. Conservation Biology 20: 501-511

Guralnick RP, Hill AW, Lane M (2007) Towards a collaborative, global infrastructure for biodiversity assessment. Ecology letters 10: 663-672

Guralnick RP, Wieczorek J, Beaman R, Hijmans RJ (2006) BioGeomancer: automated georeferencing to map the world's biodiversity data. PLoS Biology 4: 1908-1909

Hernandez PA, Graham CH, Master LL, Albert DL (2006) The effect of sample size and species characteristics on performance of different species distribution modeling methods. Ecography 29: 773-785

Hernandez PA, Franke I, Herzog SK, Pacheco V, Paniagua L, Quintana HL, Soto A, Swenson JJ, Tovar C, Valqui TH, Vargas J, Young BE (2008) Predicting species distributions in poorly-studied landscapes. Biodiversity and Conservation 17: 1353-1366 
Hijmans RJ, Schreuder M, Cruz JD, Guarino L (1999) Using GIS to check co-ordinates of genebank accessions. Genetic Resources and Crop Evolution 46:291-296

Hijmans RJ, Cameron JD, Parra JL, Jones PG, Jarvis A (2005) Very high resolution interpolated climate surface for global land areas. International Journal of Climatology 25:1965-1978

Jiménez-Valverde A, Lobo JM, Hortal J (2008) Not as good as they seem: the importance of concepts in species distribution modelling. Diversity and Distributions 14:885890

Korner C (2007) The use of 'altitude' in ecological research. Trends in Ecology and Evolution 22:569-574

Loiselle BA, Jørgensen PM, Consiglio T, Jiménez I, Blake JG, Lohmann LG, Montiel OM (2007) Predicting species distributions from herbarium collections: does climate bias in collection sampling influence model outcomes? Journal of Biogeography 35:105-116

Lozier JD, Aniello P, Hickerson MJ (2009) Predicting the distribution of Sasquatch in western North America: anything goes with ecological niche modelling. Journal of Biogeography 36:1623-1627

Manel S, Williams HC, Ormerod SJ (2001) Evaluating presence-absence models in ecology: the need to account for prevalence. Journal of Applied Ecology 38:921931

Martinez-Meyer E (2005) Climate change and biodiversity: some considerations in forecasting shifts in species' potential distributions. Biodiversity Informatics 2:42-55

Meerow AW (1990) Amaryllidaceae. Flora of Ecuador, Vol. 41. University of Gotenborg; Riksmuseum, Pontificia Universidad Católica del Ecuador, Goteborg, Stockholm, Quito

Murphey PC, Guralnick RP, Glaubitz R, Neufeld D, Ryan JA (2004) Georeferencing of Museum Collections: A review of the problems and automated tools, and the methodology developed by the Mountain and Plains Spatial-Temporal Databaseinformatics initiative (MaPSTeDI). PhyloInformatics 3:1-29

Newbold T (2010) Applications and limitations of museum data for conservation and ecology, with particular attention to species distribution models. Progress in Physical Geography 34:3-22

Newbold T, Reader T, El-Gabbas A, Berg W, Shohdi WM, Zalat S, Baha El Din S, Gilbert F. (2010) Testing the accuracy of species distribution models using species records from a new field survey. Oikos 119:1326-1334 
Oleas N. (2000) Amaryllidaceae. In: Libro Rojo de las Plantas Endémicas del Ecuador 2000. Publicaciones del Herbario QCA, Pontificia Universidad Católica del Ecuador, Quito, pp. 66-67

Pearson RG, Raxworthy CJ, Nakamura M, Townsend Peterson A (2007) Predicting species distributions from small numbers of occurrence records: a test case using cryptic geckos in Madagascar. Journal of Biogeography 34:102-117

Peterson AT (2003) Predicting the geography of species' invasions via ecological niche modeling. The Quaternarly Review of Biology 78:419-433

Peterson AT (2006) Uses and requirements of ecological niche models and related distributional models. Biodiversity Informatics 3:59-72

Peterson AT, Nakazawa Y (2008) Environmental data sets matter in ecological niche modelling: an example with Solenopsis invicta and Solenopsis richteri. Global Ecology and Biogeography 17:135-144

Phillips SJ, Anderson RP, Schapire RE (2006) Maximum entropy modeling of species geographic distributions. Ecological Modelling 190:231-259

Powell M, Accad A, Shapcott A (2005) Geographic information system (GIS) predictions of past , present habitat distribution and areas for re-introduction of the endangered subtropical rainforest shrub Triunia robusta (Proteaceae) from southeast Queensland Australia. Systems Research 123:165-175

Seo C, Thorne JH, Hannah L, Thuiller W (2009) Scale effects in species distribution models: implications for conservation planning under climate change. Biology Letters 5:39-43

Soberón J, Peterson AT (2004) Biodiversity informatics: managing and applying primary biodiversity data. Philosophical transactions of the Royal Society of London. Series B, Biological Sciences 359:689-698

Thuiller W, Lavorel S, Sykes MT, Araújo MB (2006) Using niche-based modelling to assess the impact of climate change on tree functional diversity in Europe.

Diversity and Distributions 12:49-60

Urrutia R, Vuille M (2009) Climate change projections for the tropical Andes using a regional climate model: Temperature and precipitation simulations for the end of the 21st century. Journal of Geophysical Research 114:D02, doi:10.1029/2008jd011021

Wisz MS, Hijmans RJ, Li J, Peterson AT, Graham CH, Guisan A, Group, N.P.S.D.W. (2008) Effects of sample size on the performance of species distribution models. Diversity and Distributions 14:763-773 


\section{CHAPTER IV.}

\section{POPULATION GENETIC STRUCTURE OF PHAEDRANASSA HERB.}

\section{(AMARYLLIDACEAE)}

\section{Introduction}

Ecuador is recognized as a megadiverse country, with one of the highest concentrations of species per area in the world (Mittermeier et al. 1999; Myers et al. 2000). This massive number of species is not distributed evenly in the country. In fact, more than half of Ecuador's endemic plant diversity (more than 2000 plant species), is restricted to the Andean mountains (Valencia et al. 2000). The Andes in Ecuador are shaped by 86 major volcanoes, whose modern altitudinal range evolved during the lower Holocene-Pleistocene in a process that might have taken place for over $4 \mathrm{Ma}$ (Coltorti and Ollier 2000). The influence of Andean geological history on the current variety of habitats in Ecuador and consequent species richness has been recognized previously (Jørgensen et al. 1995; Luteyn 2002; Hughes and Eastwood 2006). The inter-Andean valleys are naturally isolated from each other as a consequence of deep and narrow topographic contours (Young et al. 2002). The topographic complexity creates local microhabitats ranging from moist slopes to dry valleys (Bush 2002). In this intricate topography, species have extended north and south and also up and down in altitudinal range during climate change events (Struwe et al. 2009). In general, it has been recognized that mountains constitute either bridges to plant colonization or isolating barriers, which indeed play a role in speciation (Hewitt 2004; Ohsawa and Ide 2007). Understanding the speciation process in such a diverse area as the tropical Andes is a fundamental question in Neotropical biology. 
A recent metapopulation analysis of speciation time in the Andes showed that the process in this part of the world occurred gradually since the Tertiary, with less than half of the plant species evolving during the Quaternary (Rull 2008). Recent explosive plant speciation during the late Pliocene or Pleistocene has been reported in these mountains ranges (Hughes and Eastwood 2006). The majority of data has been gathered for taxa located in the highlands, e.g., Valerianaceae in the Paramos (Bell and Donoghue 2005), Halenia (Gentianaceae) (von Hagen and Kadereit 2003) and Lupinus (Fabaceae) (Hughes and Eastwood 2006). An example of rapid speciation in low to mid altitudes is Costus (Kay et al. 2005). Furthermore, a recent investigation on Cyathostegia mathewsii (Benth.) Schery (Fabaceae) from the seasonally dry forest in the inter-Anden valleys of Ecuador and Peru, demonstrated an older diversification as a result of isolation in the valleys for at least 5 millon years (Pennington et al. 2010). All of these examples of diversification have been explained by the environmental conditions created during the recent uplift of the Andes and climate change through the Quaternary (Richardson et al. 2001; Rieseberg and Willis 2007). At the same time, these cases show that high diversification rates in the Andes have occurred across various types of habitats. However, these phylogenetic studies account only for a small percentage of tropical Andean plant biodiversity, and the speciation phenomenon remains largely understudied. One of the most controversial aspects of the speciation process is how this process occurs geographically (Losos and Glor 2003). There are two different views of speciation: sympatric and allopatric. In general terms, sympatric speciation occurs when competition among populations leads to ecological niche differentiation, while allopatric speciation requires a spatial barrier leading to genetic isolation (Mayr, 1963). A middle 
point between both allopatric and sympatric speciation is parapatric speciation because it allows speciation to occur even with migration among adjoining populations (Gavrilets et al. 2000). It has been proposed that there is a continuum of evolutionary processes that influence genetic variation at different levels: from populations to species to higher level taxa (Carstens et al. 2004). The early stages of speciation will be population genetic divergence. In this respect, divergence can be higher among peripheral populations (peripatric speciation), because these populations might be smaller, more isolated and affected by different selection pressures (Mayr 1963). The opposite view proposed that divergence will be more likely in the central and potentially more diverse populations (centrifugal speciation) (Brown 1957). A comprehensive review of speciation models was provided by Gavrilets (2003). Key factors promoting speciation are small populations, mutation, genetic drift and selection to local environment adaptation (Gavrilets 2003).

With the increased availability of molecular tools as well as geographic information systems (GIS), it is now possible to study genetic variation in a geographic context, an approach called landscape genetics (Manel et al. 2003). Interest in landscape genetics among researchers has increased steadily, with a broad array of taxa being studied (Holderegger et al. 2010; Storfer et al. 2010). The geographic aspects of speciation in the tropical Andes have been poorly investigated with empirical approaches, and there are only scattered examples of landscape genetic research available in the literature (Storfer et al. 2010). One recent study describes the complex evolutionary patterns linked to demographic history, dispersal patterns, interspecific divergence and hybridization of two wild tomato species (Solanum lycopersicum and S. pimpinellifolium 
Solanaceae) (Nakazato and Housworth 2011). There are only two other studies of threatened plant species of the Tropical Andes using microsatellites. One concerned the microevolution of the wax palm Ceroxylon echinulatum Galeano, (Arecaceae) (Trenel et al. 2008), and the other addressed mating patterns and their role in genetic variation of the Andean Oak (Quercus humboldtii Bonpl.) (Fernandez and Sork 2005).

The prospect of unraveling genetic relationships in a spatial context is made possible through the use of molecular markers. Among the different molecular markers available (Schlotterer 2004), microsatellites are one of the most popular. Microsatellites, known also as simple sequence repeats (SSRs), are two to six nucleotide motifs repeated many times in tandem. Microsatellites are a preferred molecular tool to study genetic relationships because they capture a high level of polymorphism; they are highly reproducible and codominant; they occur regularly all over the genome; they are easy to automate; they usually are inherited in a Mendelian pattern; and they are generally neutral markers (Frankel et al. 1995; Jarne and Lagoda 1996; Cruzan 1998; Rossetto et al. 1999; Susol et al. 2000; Li et al. 2002; Zane et al. 2002; Squirrell et al. 2003).

Furthermore, the high mutation rate of microsatellites offers excellent resolution of recent or current microevolutionary events (Wang 2010).

One of the disadvantages of this technique is that microsatellite primers need to be developed specifically for the species to be studied. In some cases, but not always, microsatellite primers can be used for other closely related species. Despite the fact that the design of microsatellite primers can be outsourced from specialized laboratories, the method is still relatively expensive, costing approximately $\$ 10,000$ to design 10 to 15 loci (Selkoe and Toonen 2006). Another disadvantage of this molecular technique is the 
possibility of undetected null alleles and allele size homoplasy (Selkoe and Toonen 2006). Currently, next generation sequencing technology has even further reduced the cost and time for microsatellite development in non-model species (e.g., development of 17 polymorphic microsatellite markers at $\$ 5,000$ in six weeks, Csencsics et al. 2010).

The main mechanism of microsatellite mutation is the gain or loss of repeat units as a consequence of DNA-replication slippage (Weber and Wong 1993; Chambers and MacAvoy 2000; Lai et al. 2003; Schlotterer 2004). Several theoretical mutation models for microsatellites have been proposed (reviewed by Chambers and MacAvoy 2000). The most common are: infinite allele model (IAM, Kimura and Crow 1964) and stepwise mutation model (SMM, Kimura and Ohta 1978). In the IAM, mutations could result in a gain or loss of any number of repeat units, but always produce a new allele (Symonds and Lloyd 2003). As a result, this model does not allow homoplasy, i.e., identical alleles that are identical by descent (Balloux and Lugon-Moulin 2002). In the SMM only one repeat unit is gained or lost per mutation and therefore alleles could mutate to allele states already present in the population (Estoup and Cornuet 1999; Symonds and Lloyd 2003). Therefore, this mutation model has a memory of allele size and alleles of very different sizes will be less closely related (Balloux and Lugon-Moulin 2002).

Population genetic structure can be better explained through models. The simplest is the Wright-Fisher model (Fisher 1930; Wright 1931), which corresponds to an ideal population without change because of a constant number of diploid individuals, random mating, non-overlapping generations, and a random number of offspring per individual. In reality, natural populations are more dynamic and complex: diverse in biogeographical history, changing in size, density and dimension over time, and exchanging gene material 
with other populations (Hey and Machado 2003). As a result, genetic structure can be distinguished among populations (Hedrick 2000). In subdivided populations, the amount of genetic connection between subpopulations depends on the effective gene flow, genetic drift and selection (Hedrick 2000). Different models of population genetic structure have been proposed, including mainly additions like direction and rates of genetic flow. The simplest, describing unidirectional gene flow, is the island model of migration (Wright 1940). More complex variants of this model have been proposed, such as the stepping-stone model (Kimura and Crow 1964). The stepping-stone model describes genetic exchange between close populations. Another variant is the isolationby-distance model, where individuals are genetically more similar to their neighbors than to distant individuals (Wright 1943). The matrix model incorporates migration among populations as a matrix with or without symmetric gene flow (Bodmer and Cavalli-Sforza 1968). Models can also incorporate more complexities like extinction and colonization among populations, e.g., in the metapopulation models (Hanski and Gilpin 1991). Both mutational models and populations models represent a baseline for statistical inference to address questions about the genetics of populations. In recent years, population genetics have benefited by the development of coalescence theory (Hudson 1990). The coalescence approach describes the genealogical process of neutral genes backward in time (Kingman 1982). Statistical tools such as Bayesian analysis and the Markov Chain Monte Carlo method contributed to inferring demographic genealogies (Beaumont and Rannala 2004). These two approaches make it possible to estimate population genetic aspects such as recent population bottlenecks (Cornuet and Luikart 1996) and migration rates (Beerli 2008). 
Endemic plants are an excellent subject to study the dynamic processes of speciation and evolution (Matolweni et al. 2000). At the same time, many of these species are in serious risk of extinction, which makes their study a priority (Matolweni et al. 2000; Pitman and Jørgensen 2002). In this paper I used Phaedranassa spp. (Amaryllidaceae) to investigate the speciation process in the tropical Andes. Phaedranassa can be used as a model group to study speciation in the Northern Andes. This genus is a monophyletic group (Meerow et al. 2000). It is represented by ten species that, with the exception of one species described from Costa Rica, are restricted to the Northern Andes. Six species are endemic to Ecuador, having one of the highest proportions of endemic species per genus in Ecuador (Borchsenius 1997). Phaedranassa dubia has been reported from both Ecuador and Colombia, and there are two endemic species in Colombia (Meerow 1990). The geographic distribution of each species in Ecuador has been investigated in depth since the last decade (Oleas 2000). The species of the genus appears limited to a particular inter-Andean valley or open moist slope along river canyons (Fig 2). In terms of conservation, all the Ecuadorian endemic species of Phaedranassa occur in one of the most deforested regions of the country, where little of the native vegetation remains (Valencia et al. 1999). In fact, all six Phaedranassa species endemic to Ecuador are classified as either "Endangered" or "Vulnerable" to extinction under the International Union for Conservation of Nature criteria (IUCN) for red-listing of endangered plants (Oleas 2000).

The objectives of this study were to (1) analyze the population genetic structure of the seven Phaedranassa species in Ecuador; and (2) explore the connection between genetic differentiation among these species and their spatial distribution patterns. 


\section{Methods}

\section{Sample collection and species delimitation}

Fresh leaves from 1367 individuals were collected across the geographical distribution of the seven Phaedranassa species in 52 collecting sites (Fig. 2). These sites were visited in May and June of 2003, December 2005, July to August 2006, December 2007 and from July to December 2009. On average, I collected 25 specimens per collection site (Table 1). Overall, I located $71 \%$ of all the known populations for this genus in Ecuador. Six new localities for the genus were also discovered: three for $P$. brevifolia, two for P. schizantha, and one for P. glauciflora. Samples were collected from plants whose petiole bases were at least one meter distant in an effort to minimize collecting multiple ramets of a single genet. The leaves were fast-dried in silica gel.

Samples were classified into species following the last taxonomic review of Phaedranassa (Meerow 1990). If the individuals were sterile at the moment of collection, living vouchers were collected and kept ex-situ until flowers were obtained, or the locations were revisited until flowers were found in the wild. The name of the species assigned to each population is given in Table 1. Changes to species identifications based on subsequent fieldwork or identification made from living voucher specimens are marked in bold (Table 1).

\section{DNA extraction, genotyping and DNA quality control}

Total DNA extraction protocols followed the methods described in Oleas et al. (2005). For DNA quantification, I followed Livingstone et al. (2009). Individuals were genotyped with 13 microsatellite primers: eight developed from $P$. tunguraguae -locus pt14, pt21, pt32, pt39 (Oleas et al. 2005) and pt43, pt48, pt49 and pt61 (Oleas et al. in 
prep)-; and five developed from $P$. schizantha - ps2, ps13, ps16, ps27 and ps28 (Oleas et al. 2009)-. Polymerase Chain Reaction conditions and genotyping procedures followed the protocols described by Oleas et al. $(2005,2009)$.

Polymerase Chain Reaction procedures were repeated up to three times if the sample did not amplified initially. Samples with alleles showing one base pair (bp) difference rather than a repeat unit variation as expected for microsatellite mutation were also repeated. If the sample still showed a difference of a single base pair, the sample was dropped from the analysis. I also used MICRO-CHECKER version 2.2.3 (Van Oosterhout et al. 2004) to identify genotyping errors, as well as null alleles, stuttering and large allele dropouts.

\section{Statistical analysis}

Descriptive population genetic statistics were estimated with GENALEX 6.4 (Peakall and Smouse 2006): number of alleles per locus, effective number of alleles per locus, number of private alleles, total heterozygosity, observed heterozygosity and fixation index. Significance of Fis and Ris was evaluated after 20,000 repetitions in SPAGEDI 1.3a (Hardy and Vekemans 2002). I used the program FREENA to evaluate difference in $F_{S T}$ values when putative null alleles were detected (Chaupis and Estoup, 2007).

Linkage disequilibrium (LD) was estimated with GENEPOP 4.0.10 (Raymond and Rousset 1995; Rousset 2008) with the following parameters for the Markov chain: 10,000 batches of 10,000 iterations per batch and 10,000 dememorisation. Sequential Bonferroni correction (Rice 1989) was applied to avoid Type I statistical error. Multilocus estimate of the effective number of migrants (Nm) was done in GENEPOP 
4.0.10 (Raymond and Rousset 1995; Rousset 2008). Analysis of molecular variance (AMOVA) was calculated in ARLEQUIN 3.5 (Excoffier et al. 2005); significance was calculated with 10,000 permutations.

I used the allele size permutation test (Hardy and Charbonnel 2003), as implemented in SPAGEDI 1.3a (Hardy and Vekemans 2002), to test the contribution of stepwise-like mutations to population differentiation, when a significantly greater value of observed $\mathrm{R}_{\mathrm{ST}}$ against permuted $\mathrm{R}_{\mathrm{ST}}$ corroborated that $\mathrm{SMM}$ was a factor in population differentiation (Hardy and Charbonnel 2003).

Tests for recent bottleneck events were conducted with BOTTLENECK 1.2.02 (Cornuet and Luikart 1996; Piry et al. 1998). All populations with less than 20 individuals were not included in this analysis because a low number of individuals can be misleading. The estimation was calculated with 100,000 replications, using the sign test and Wilcoxon sign-rank test to establish if populations were in mutation-drift equilibrium (Cornuet and Luikart 1996). Both tests were performed under two models of microsatellite mutation (IAM and SMM). I reported results of both types of mutation models as suggested by Cornuet and Luikart (1996). It is unlikely that microsatellite loci follow a strict IAM or SMM, and these two models represent the extremes. An additional test for recent bottlenecks known as the mode-shift, which is an indicator of shift of the allelic frequency distribution (Luikart et al. 1998), was also reported.

Genetic relationships among populations were estimated in POPULATIONS 1.2.30 (Langella 1999). A phenogram was generated with chord distance Dc (CavalliSforza and Edwards 1967), and Neighbor Joining (NJ) as the clustering method. Chord distance was used because it is less influenced by the presence of null alleles (Chaupis 
and Estoup, 2007), and it has been reported that Chord distance successfully recovers the correct topology in a tree from microsatellite data (Takesaki and Nei 1996). Bootstrap values across loci were calculated with 10,000 permutations by locus. The tree was visualized with TREE EXPLORER in MEGA 4 (Kumar et al. 2004).

Individual assignment was performed with the program STRUCTURE 2.2. (Pritchard et al. 2000), in BIOPORTAL (Kumar et al. 2009). First, individuals were assigned to a pre-defined genetic group $(k)$ of seven, which represents the number of species. The analysis was made under the admixture model, with 1,000,000 repetitions after a burn-in of 500,000 and replicated 20 times. The results were loaded into STRUCTURE HARVESTER (Earl 2011), which calculates $k$ value following Evanno et al. (2005) method. Another set of analyses following the same methods were conducted for each species separately and in groups formed by the populations that came together in the NJ cluster. In this case, to identify the most likely number of genetic groups $(k)$ in each species, a series of analyses was performed using different values of $k$. Additionally, I analyzed three different cases of putative sympatric groups using the same method. A consensus of the results of the independent runs for the optimal $k$ was done in CLUMPP 1.1.2 (Jakobsson and Rosenberg 2007), with the Greedy option, random input order and 100,000 repeats. The results were visualized in DISTRUCT 1.1 (Rosenberg 2004).

Principal Coordinates Analysis (PCA) of the Phaedranassa individuals from Pululahua Crater was performed in GENALEX 6.4 (Peakall and Smouse 2006). Pairwise genetic distance was calculated in POPULATIONS using Cavalli-Sforza chord distance.

In order to investigate the relationship between genetic structure and landscape, I analyzed the data in two ways. First I tested for isolation by distance with a correlation 
between log genetic similarity (chord distance Dc) and log geographic distance. The significance of the correlation was tested with a Mantel test calculated with 9999 randomizations in GENEALEX 6.4. Furthermore, I contrasted the population genetic structure with each Species Distribution Model (SDM). The methods for estimating the species distribution models are explained in Chapter III. In addition, I calculated the percentage of overlap among SDMs between species with the Kappa coefficient. Kappa is a categorical measure of the difference between observed versus random agreement (Franklin 2009). The closest the Kappa value to one of two distribution comparisons will means that both are similar (Franklin 2009). My assumption was that overlapping models among species, showing genetic differentiation, will be indicative of random pattern in the landscape.

\section{Results}

\section{Descriptive statistics among species}

The mean effective number of alleles ranged from 1.28 to 5.39 per population (Table 1). Among species, $P$. viridiflora showed the lowest number of alleles (average of 1.39 effective allele number) and $P$. brevifolia had the maximum effective allele number (4.21) (Table 1). A total of 77 private alleles were found across 36 populations (Table 1). Phaedranassa viridiflora had the lowest number of private alleles, followed by $P$. tunguraguae. Phaedranassa cinerea had the highest number of private alleles per population (Table 1). With the exception of most populations of $P$. viridiflora, all of the species showed evidence of inbreeding (positive F values, Table 1). Overall, the inbreeding coefficient was highly significant $(0.29$ Fis, 0.33 Ris, $p=0.001)$ across all populations. Evidence of null alleles was found in the majority of populations, in an 
average of seven out of 13 loci per population (range 0-12 loci per population). One way to overcome the presence of null alleles is to calculate allele frequencies acknowledging the possibility of null alleles. I did not find significant changes in $F_{S T}$ when genotypes were corrected for null alleles using FreeNA (Chaupis and Estoup, 2007). Both corrected and non-corrected overall $F_{S T}$ were $0.29(\mathrm{p}<0.0001)$.

Linkage disequilibrium (LD) was found in roughly $5 \%$ of the combinations (190 out of 4057) after Bonferroni correction. Indication of LD was found in a total of 10 populations (Table 1). None of the populations of $P$. tunguraguae and $P$. brevifolia show evidence of linked loci. The majority of species had only one population presenting evidence of LD, whereas $P$. schizantha and $P$. viridiflora showed three or more populations with LD (Table 1).

None of the populations showed evidence of recent bottlenecks with all three tests: Wilcoxon, sign statistic test and the mode-shift test (Cornuet and Luikart 1996) (Table 2). The majority of populations (32 out 43 of populations, excluding populations with less than 20 individuals) showed evidence of bottlenecks under the sign test with the SMM, whereas only three populations did under IAM using the same test. With the Wilcoxon test, seven populations tested positively for a bottleneck with the IAM, and only one under the SMM (Table 2). Only one population showed evidence of bottleneck with the mode-shift test (Table 2).

Analysis of Molecular Variance showed that $69 \%$ of genetic variation resided within populations, followed by $21 \%$ of the variance at the within-populations-betweengroups level. Only $9 \%$ of the variation was found among groups, which in my study represented species $(\mathrm{p}<0.00001)$ (Table 3$)$. A permutation test of allele size between 
observed $\mathrm{R}_{\mathrm{ST}}$ against permuted $\mathrm{R}_{\mathrm{ST}}$ was significantly greater, which corroborated SMM was a factor in population differentiation (Hardy and Charbonnel 2003). The multilocus estimate of the effective number of migrants $(\mathrm{Nm})$ were two individuals in average with a range of four to one individual (Table 4).

\section{Cluster analysis}

The neighbor-joining tree showed populations generally clustered with other populations of the same species (Fig. 3), although none of the species clusters were supported by a high bootstrap proportion (Fig. 3). One of the exceptions to species clusters was $P$. viridiflora, populations which comprised two distinct groups, each formed by geographically adjacent populations (Fig. 3). Furthermore, one population of $P$. viridiflora (Population 44) was clustered with P. dubia populations. It is noteworthy that this population was found in sympatry with P. dubia (Pop 41) in the Pululahua crater (Fig. 2). The population Pop52 of $P$. schizantha was also included in the $P$. dubia cluster (Fig. 3). Along with those cases, populations of $P$. glauciflora were included in the $P$. cinerea clade (Fig. 3).

\section{Individual assignment to species}

Individuals' assignment to a given species was first investigated with $k=7$, which is the number of recognized Phaedranassa species in Ecuador (Meerow, 1990). In most cases individuals were assigned to the corresponding species group (Fig 4). There were three exceptions: P. viridiflora, Population 52 (P. schizantha) and Population 35 ( $P$. cinerea 2) (Fig. 4). The majority of the populations of $P$. viridiflora were assigned to the same two groups detected in the neighbor-joining tree (Fig 3, 4). These two groups were formed by geographically close populations, one located in the central part of the country 
and the other in southern Ecuador (Fig. 2). As in the NJ tree, Population 44, which is located inside Pululahua crater, resolved as part of the cluster formed by the P. dubia group (Fig. 3 and 8). Also, the majority of the populations of $P$. schizantha formed a distinctive cluster (Fig. 4). The exception in P. schizantha was Population 52 that showed some individuals genetically similar to P. dubia (Fig. 4). Population 35 assigned originally to $P$. cinerea is more similar to P. glauciflora (Fig 6).

Among all Phaedranassa species, P. brevifolia and P. dubia, at the level of $k=7$ analysis, were not distinguished as two different groups (Fig. 4). Also the neighborjoining tree showed $P$. brevifolia forming a subcluster in the P. dubia group (Fig. 3). However, when analysis was done with $P . d u b i a$ and $P$. brevifolia alone, the resulting $k$ was 2 (Table 5, Fig. 5). Finally P. cinerea showed two groups: (1) the populations at the western portion of the geographical distribution of $P$. cinerea, (2) populations located at the eastern portion of the species range. Some populations of this later group appear to be similar to $P$. glauciflora as the $k=7$ analysis indicates (Fig 4). A separate analysis of $P$. cinerea and P. glauciflora found an optimal $k$ of 10 . The same pattern described above was still present (Table 5, Fig. 6).

There were three possible cases of sympatry in Phaedranassa, all of them involving $P$. viridiflora and several other Phaedranassa species. First, I analyzed the individual assignment for three collection groups of $P$. viridiflora (1) and three populations of $P$. cinerea (2) that are located in southern Ecuador (Fig. 2). These two species are separated to a distance of three to $12 \mathrm{~km}$. The result shows that these groups belong to three genetically defined populations $(k)$ (Table 5). There was no evidence of 
admixture among the individuals assigned to the $P$. viridiflora (1) and individuals of $P$. cinerea (2) (Fig 8).

The second case is geographically located in central Ecuador (Fig. 2) and it includes $P$. viridiflora and $P$. schizantha (Fig. 1). In this case, most of the individuals

were not in flower, thus the identity of the samples were unknown. The analysis showed an optimal population number of $k=2$ : Population 10 and 24 corresponded to one group (P. viridiflora), whereas Population 27 was assigned to a different group ( $P$. schizantha) (Fig. 8). There was no evidence of extensive admixture among collecting sites of $P$. viridiflora and P. schizantha (Fig 8).

In the third case, $P$. viridiflora (yellow flower type), P. dubia (red flower type) and a putative hybrid between the two (orange flower type) are located in the Pululahua crater (Fig. 2 and 8). The individual assignment retrieved three genetically differentiated groups $(k=3)$. The individual assignment analysis also showed admixture between the putative hybrid and P. dubia (Fig. 8). Also, three groups could be distinguished in the PCA: one formed by orange flowers only, other formed by yellow flowers only and one formed by all red flowers and some yellow and orange flowers (Fig. 9).

\section{Individual assignment within species}

Within species, in general the optimal $k$ was either two or three populations, with the exception of $P$. cinerea, for which the optimal $k$ was 4 (Table 5). The number of optimal $k$ represents in some cases a quarter of the number of collecting sites (Table 5, Fig. 7). Most of the patterns observed at the analysis of $k=7$ were still found in the individual species analysis. The main difference is the substructure found within species (Fig.7). Substructure was found in P. schizantha, separating some populations around the 
cities of Ambato and Riobamba from the other populations. On the other hand, I did not find evidence of distinct clusters for the varieties of $P$. schizantha proposed by Meerow (1990): P. schizantha var. schizantha and P. schizantha var. ignea either in the entire genus analysis nor the individual species analysis (Fig. 3 and 7). Phaedranassa tunguraguae was divided in two groups, one at the west and other to the east of the species distribution (Fig 7).

\section{Landscape genetics}

I did not find evidence of overall isolation by distance among populations, when all samples were included in the analysis $\left(\mathrm{R}^{2}=0.11, \mathrm{p}=0.0001\right)$ (figure not shown). Moreover there was no significant isolation by distance when data was separated by species. On the other hand, with the exception of some comparisons including $P$. glauciflora and $P$. viridiflora, there was minimal overlap among species distributions, on the basis of Kappa, especially in the cases of adjacent species like P. brevifolia-P. dubia, P. cinerea- P. glauciflora and P. tunguraguae and P. schizantha (Table 6).

\section{Discussion}

\section{Species identification}

My initial assumption was that Phaedranassa species will show genetic structure among populations and that this structure will be influenced by geography. It turns out to that to address this apparently straight forward query, another issue must first be confronted. The species identity was not known for all the populations, and, in some cases the presumed identity (herbarium records), was likely not accurate. Species identification is relatively easy in the field when flowers are present. Not all populations were in flower at the time of collection. To solve this problem, I assigned an a priori 
identity to species for each population. In cases where I was able to revisit the location during the flowering season, I made changes if needed (marked in bold font in Table 1). In general, the genetic signature at the species level was consistent with the a priori species definition. However, for Population 59, identified as $P$. schizantha in the field, some individuals were assigned to P. dubia in the Bayesian analysis of individual assignment of $\mathrm{k}=7$ (Fig. 4). Furthermore, this species was part of the P. dubia group of the NJ cluster (Fig. 3). One possible explanation of this incongruence is the possibility of some of yellow form individuals ( $P$. viridiflora) present in this collection. This is possible because of the geographic proximity of this site to other populations of both $P$. schizantha and $P$. viridiflora. This supposition needs to be corroborated at the field.

\section{Genetic mosaic in the landscape}

Under isolation, relatedness of individuals will decrease with distance (Hardy and Vekemans 1999). Because of the landscape heterogeneity of the Northern Andes, I was expecting a strong genetic association with geography. I did not find evidence corroborating a correlation between genetic differentiation and geography as a linear distance. What I found was evidence of a more complex pattern of genetic structure associated with restricted species distributions in spatial heterogeneity of the Andes. The following is a case by case description of the genetic mosaic of Phaedranassa in the Ecuadorian Andes is described below.

The species that showed the least amount of genetic diversity was $P$. viridiflora, found in central and south Ecuador (Table 1, Fig. 2). Phaedranassa viridiflora had the lowest number of private alleles, the fewest alleles per population and the lowest heterozygosity values (Table 1). The majority of the populations of this species showed 
an impressive number of putative clones (individuals with the same multi-locus genotype, MLG) (Table 1). This is characteristic of peripheral populations in marginal environments (Stoeckel et al. 2006; Millar et al. 2010). The high level of clonarity in $P$. viridiflora is not found in any other Phaedranassa species, including the populations of P. viridiflora found in the Pululahua crater. Additionally, both cluster and individual assignment method separate the populations of $P$. viridiflora of the central and south area into two different groups, which also includes geographically adjacent species. No evidence of admixture was found between the species in central and southern Ecuador, which is a compatible to sympatric speciation, The origin of the yellow form of Phaedranassa is unknown, but my results suggests that it has evolved three times in different parts of Ecuador and from different species (Fig 8).

On the other hand, the data show a possible case of natural hybridization and introgression among $P$. dubia and $P$. viridiflora in the Pululahua crater. The Pululahua crater constitutes the remains of the collapse of the volcano flanks after intensive volcanism during the Quaternary (Hall and Mothes 2008). This is the only locality where the presence of two different Phaedranassa species was known prior to this study. In this particular collecting site flowers were gathered in an effort to analyze the three color types separately (red for $P$. dubia, yellow for $P$. viridiflora and orange for a presumed hybrid). As opposed to the central and south $P$. viridiflora groups describe above, Pululahua's populations of $P$. viridiflora have almost double the effective number of alleles. In a Bayesian analysis to assign individuals to either three groups, only red individuals ( $P$. dubia) showed in all cases a consistent assignment to a particular group (Fig. 8). This pattern was not always evident for the yellow and orange forms, because 
some individuals showed admixture (Fig. 8). The group formed by yellow flowers showed seven times more identical MLGs than the group formed by the orange flowers.

This fact and the individual assignment results suggest a scenario of introgression between the hybrids and $P$. dubia individuals. Hybridization and probably introgression is occurring in the Pululahua crater. Hybridization has been proposed as a major role in plant speciation in general (Soltis and Soltis 2009). Introgressive hybridization has been found in plants, for example a well studied system is the Iris fulva asymmetric introgression into both I. brevicaulis and I. hexagona, which apparently have adaptative implications (Arnold et al. 2010). Even though the amount of hybridization and introgression in Andean plant species is unknown, evidence have been found across different taxa: wild tomato species Solanum lycopersicum and S. pimpinellifolium (Solanaceae) (Nakazato and Housworth 2011), Vasconcellea (Caricaceae) (van Droogenbroeck et al. 2006) and Puya (Bromeliaceae) (Schulte et al. 2010).

In the latest taxonomic revision of revision of the Amaryllidaceae in Ecuador, the yellow flower form of Phaedranassa was recognized as P. viridiflora (Meerow 1990). Phaedranassa viridiflora was described by Baker in 1877 from cultivated material supposedly from Peru (Baker 1877). Another yellow variety, P. viridilutea, was described from a specimen located at the south of the generic range in Ecuador (Ravenna 1984). In this study, I found two groups that appear to be genetically different from each other (Figs 3, 4, 6 and 8). My results seem to identify at least two different geographic areas where yellow flowers occur. The species distribution model for $P$. viridiflora is not showing the specificity as in other Phaedranassa species, and this might be a result of considering all the individuals as only one species. Unfortunately, I cannot test the 
specificity of the distribution for these two groups because of the limited number of records for each one of the groups, which is not appropriate for building a reliable SDM. A revision of the species including at least morphological evidence to support the separation of $P$. viridiflora into two species is needed.

On the opposite side of the spectrum, P. brevifolia showed the highest number of alleles and one of the highest averages of private alleles (Table 1). Phaedranassa brevifolia occurs at the north-western portion of the generic distribution in Ecuador (Fig 2). Vegetatively, the most evident difference between this species and $P$. dubia is the length of the leaves. Phaedranassa brevifolia is the species with the smallest leaves (ca. $12 \mathrm{~cm}$ long) while $P$. dubia leaves length are ca. $20 \mathrm{~cm}$ long. Phaedranassa dubia has larger flowers with a slightly inflated perianth base and darker red color (Fig 1). Moreover, the Species Distribution Models (SDM) for these two species do not overlap, indicative of niche differentiation (Table 5, Fig. 5). In the NJ cluster analysis, both species formed a group in which P. brevifolia was a subcluster (Fig. 3). The assignment of individuals of these two species together shows a higher degree of admixture between the geographically closer populations of the two (Fig 5). The results suggest that these two species seems to be an example of peripatric speciation and may be a result of a recent divergence.

A more extreme example of geographic divergence is $P$. tunguraguae and $P$. schizantha. Despite the relatively proximity of both species, they showed no overlapping geographic distribution. The former prefers more humid habitats than the later. Both are identified as separate groups by NJ clustering and individual assignment (Fig 3, 4 and 9). Differences between these two species may be influenced by the Tungurahua volcano. 
Tungurahua is one of the most active volcanoes in Ecuador. During the last 1300 years, there is evidence of eruptions at least once every hundred years (Hall, 1999; Le Pennec et al. 2008). Throughout these events, pyroclastic flows and large lahars occurred along the volcano flanks. A large avalanche with a projected deposit volume of $8 \mathrm{~km}^{3}$ took place 3000 years BP (Le Pennec et al. 2008). The avalanche flowed through the Rio Patate and Rio Chambo valleys, which limit the western geographical distribution of $P$. tunguraguae. Moreover, I witnessed the last eruptive period since 1999, with episodes of activity in 2004 (Ruiz et al. 2006), 2006 (Sheridan et al. 2007) and late 2007- early 2008 (Le Pennec et al. 2008), and most recently in December 2010. Tungurahua was especially active in 2006 with more than 20 pyroclastic flows on ravine cuts in the north and western part of the volcano (Sheridan et al. 2007). The direction of the flow of both pyroclastic and lahars might have separated these two species either by a physical barrier or indirectly by creating different habitats during the development of the Tungurahua volcano.

Finally, the southernmost species, $P$. cinerea and $P$. glauciflora also present a pattern that appears to be linked to geography (Fig. 7). Both species distributions do not overlap (Table 6). Some level of admixture is evident among the western populations of P. cinerea and P. glauciflora populations Andes (Fig. 7). What I considered a priori $P$. cinerea, seems to be actually two different species (Fig. 7). One putative species is located at the western side of the Andes, which corresponds to the elevation of the original description of $P$. cinerea. The other group ("P. cinerea 2" in all Tables and Figures) is located at the central area of the Andes in a higher altitude than the original $P$. cinerea. The populations of "P. cinerea 2" might correspond to a new Phaedranassa 
species. The hypothesis of two different species for $P$. cinerea requires further morphological and molecular analysis. Another issue that needs additional investigation is the monophyly of $P$. glauciflora.

Molecular markers are an indirect measure of demographic patterns. Indication of inbreeding was found for all Phaedranassa species except $P$. viridiflora. These results are expected because individuals of these species can reproduce clonally by bulbs and are self-compatible, producing viable seeds. However the values of inbreeding coefficients need to be taken with caution because of the high number of putative null alleles reported in this study. Null alleles can inflate the inbreeding coefficients. Also, evidence of recent bottleneck was found in three, eleven, or 36 populations, depending on the statistical test and mutation model. None of the species seems to be more prone to bottlenecks (Table 2). Conservatively, I can considered three populations that might have experienced a recent bottleneck (Table 2, populations in bold). Some cautionary considerations about the bottleneck test is that the method can fail to detect a bottleneck if the event was not recent enough, thus allowing re-establishment of mutation-drift equilibrium, or when sample size and number of loci are small (Mock et al. 2004). Additional sources of error are Hardy-Weinberg disequilibrium and null alleles (Cornuet and Luikart 1996). Features of Phaedranassa such as self-compatibility and reproduction by bulbs suggest inbreeding and genetic drift as a more likely explanation for the high frequency of homozygotes over the presence of null alleles. Because of the contrasting results among statistic methods and the possibility of violations of the requirements for the bottleneck test, these results needs to be taken as a first evidence that requires further research. 
Taking into consideration all the described scenarios (hybridization, allopatric, peripatric speciation and niche differentiation), this study supports the idea that in a complex, dynamic and hyper-diverse area as the Northern Andes, the speciation process is not uni-dimensional but the result of multiple intricacies. The uplift of the Andes plays an important role in the speciation process of Phaedranassa. In Ecuador the mountains would have achieved 1,500-2,500 $\mathrm{m}$ of altitude during the last part of the Tertiary, and it was only in the Pleistocene that elevations reached altitudes $>4,000 \mathrm{~m}$ (Sauer 1957). Furthermore, climatic fluctuations during the Plio-Pleistocene influenced the species distribution as well as speciation process in the Andes (Luteyn 2002, Young et al. 2002). The entire genus evolved in the Northern Andes, which is a younger area of this mountain range, located north to the Amotape-Huancabamba zone. The AmotapeHuancabamba zone is considered either a phytogeographical barrier between the Northern and Central Andean species or a blend zone for both neo- and paleoendemics (Weigend 2002). The related genera Rauhia Traub (a Peruvian endemic) and Eucrosia Ker Gawler (found in both southern Ecuador and northern Peru); both related to Phaedranassa, are more diverse to the south of the Amotape Huancabamba zone (Meerow et al. 2000).

The data presented in the study suggest mostly allopatric speciation in Phaedranassa. It appears that the mosaic of environments in the Northern Andes contributed to divergence in the genus. This biogeographical scenario is also reported for the genus Macrocarpaea (Gentianaceae- Helieae) from the Andes, in which local allopatric speciation was more common than sympatric speciation (Struwe et al. 2009). Also allopatric speciation was proposed as an explanation for high number of endemic 
species of plants in seasonally dry patches in the Andes (Pennington et al. 2010) and in the highlands (i.e. Lupinus, Hughes and Eastwood 2006). Speciation among birds in the tropical Andes has also been linked to local conditions and topography (Fjeldsa and Irestedt 2009). Adaptation to different climatic conditions in allopatric or parapatric populations may influence the speciation process, causing phenotypic variance that leads to the evolution of reproductive isolation (Gavrilets 2003).

Phaedranassa species appear to be segregated into different distribution ranges. In general there was low or no agreement among species distributions. It appears that 3,500 meters is the natural limit for this genus in Ecuador (Fig 2 and Fig 9). According to the Species Distribution Model (Chapter III in this dissertation), there are differences in the altitudinal range where each Phaedranassa species is located (Fig. 9). Phaedranassa schizantha and P. tunguraguae are different both in morphology and genetically. However, these two species are located in adjacent areas; but at different altitudinal ranges. The former occurs between 2,200 and 3,300 m, whereas the latter reaches 2,300 $\mathrm{m}$ as its upper limit and continues down to 1,300 $\mathrm{m}$. Despite their geographic proximity in terms of distance, they are separated attitudinally. A similar difference in altitudinal range is found between P. brevifolia and P. dubia (Fig. 9). Even in the case of species that share almost the same altitudinal range, as the case of $P$. glauciflora and $P$. cinerea, it is evident that the mean altitudinal distribution is different between both (Fig. 9). The apparently non-specificity of altitudinal range between these two species might be caused by unresolved taxonomic issues. Both genetic differentiation and elevation range are evidence that the populations of $P$. cinerea located to the central-east portion are in fact a 
different species. An exhaustive search for populations in that area, along with a morphological revision, is needed.

Theoretically, allopatric and sympatric speciation are the two opposite ends of a continuum of gene flow among diverging populations (Fitzpatrick et al. 2008, Nosil 2008). The majority of Phaedranassa species appear to have evolved by allopatric speciation; both lack of admixture among species and non-overlapping distribution models corroborate this statement. The divergence among Phaedranassa species does not completely fit allopatric speciation. I found a case of admixture between species $(P$. dubia- P.viridiflora in Pululahua) and species sharing the same localities (P. viriflora-P. cinerea 2 and $P$. viridiflora-P. schizantha). There is no general agreement about the probability of divergence either in the middle or in the periphery of the species distribution. My data suggests that the speciation process is occurring at the periphery of the species distribution, probably by migration and colonization along the Andes topography.

\section{Conservation implications}

All endemic Phaedranassa species (except $P$. dubia, which is also found in Colombia), were classified either as Endangered or Vulnerable to extinction under the IUCN criteria (Oleas 2000). I propose changing the status of $P$. schizantha and $P$. cinerea from Vulnerable to Endangered, because of the reduction of species occurrences (Table 7). The occurrence of these species was overestimated in past assessments as a result of incorrect identification of specimens collected from the southern portion of the genus geographic range in Ecuador. On the other hand, this study shows that molecular markers can contribute to conservation efforts providing information about the genetic structure of 
the species' populations. Using low genetic variation as an indicator, my study can be used to discriminate populations at risk which are the ones with a reduced genetic variation.

\section{Limitations of this study and further research}

Molecular studies of adult individuals in long-lived perennial plants such as Phaedranassa might still show an historical condition in which the genetic erosion as a result of habitat fragmentation is less severe (Tomimatsu and Ohara 2003, Van Geert et al. 2008). Further studies should include analysis of field-collected seedlings, which will be affected by present processes (Van Geert et al. 2008).

The results of this study need to be taken as a first step towards understanding the genetic structure of Phaedranassa species. Pursuing these kinds of studies on non-model species in the tropics is still challenging. Even for species with a relatively recent taxonomic review, species identification is not always clear-cut. In the process of this investigation I changed the species name of seven out of the 52 populations (13\%). My results point out the need for a taxonomic review of the genus, especially for $P$. cinerea, P. glauciflora and P. viridiflora. Additional collections are needed especially of the southern taxa, because the species delimitation in this group requires a taxonomic revision. New occurrence records can then be incorporated in the SDMs for a better model of species ranges. Furthermore, this study is based on one type of molecular marker and microsatellites studies can potentially have issues as interspecific differences in mutation rates, constraints on microsatellite evolution and homoplasy (Estoup and Cornuet 1999; Amos 1999). I hope that in the future the cost of study other molecular 
markers (i.e. single nucleotide polymorphism) will be accessible for further investigation of Phaedranassa speciation. 

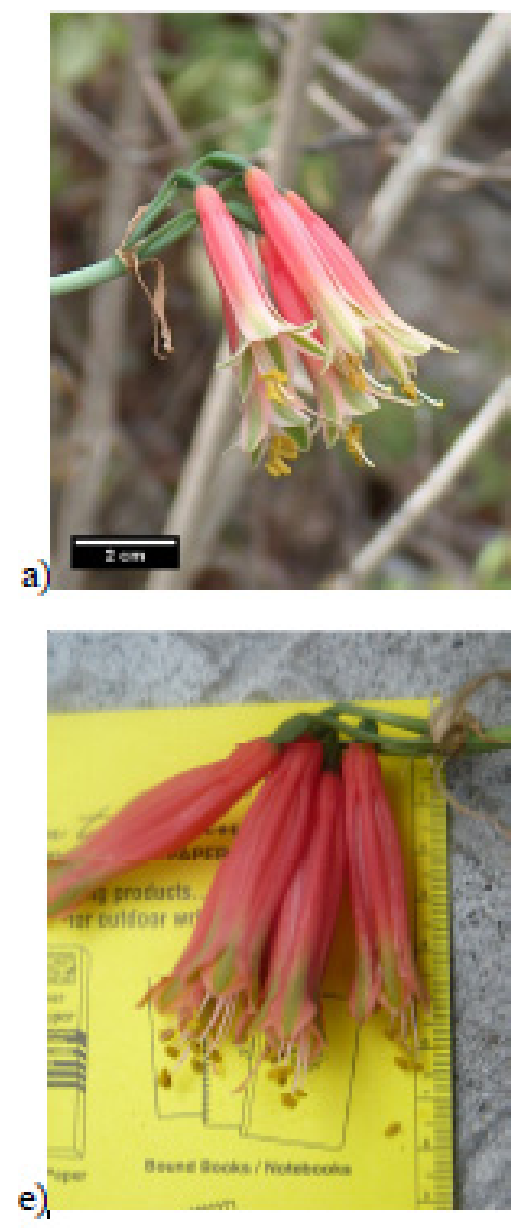
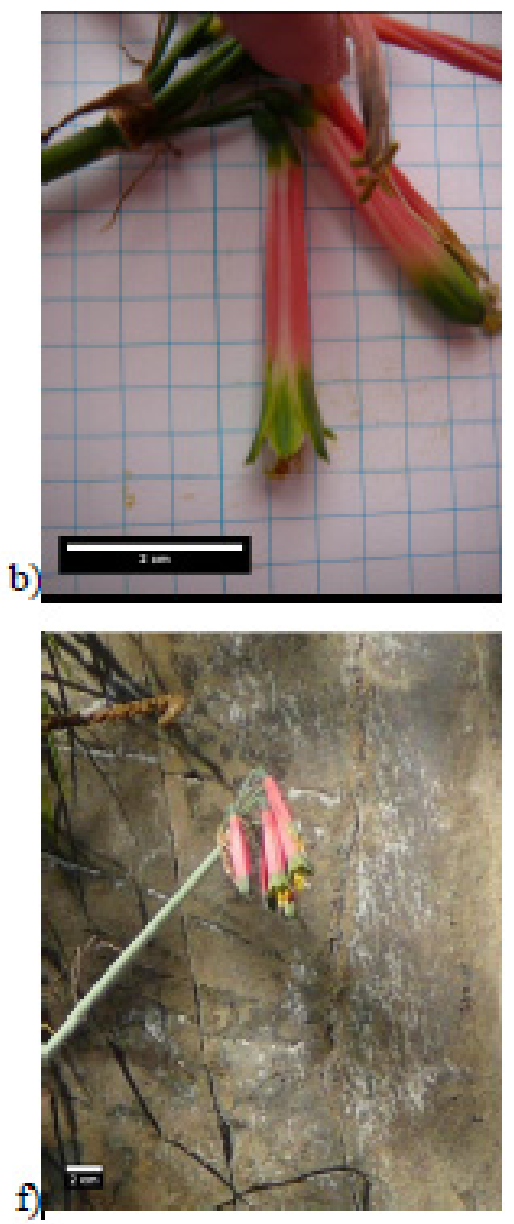
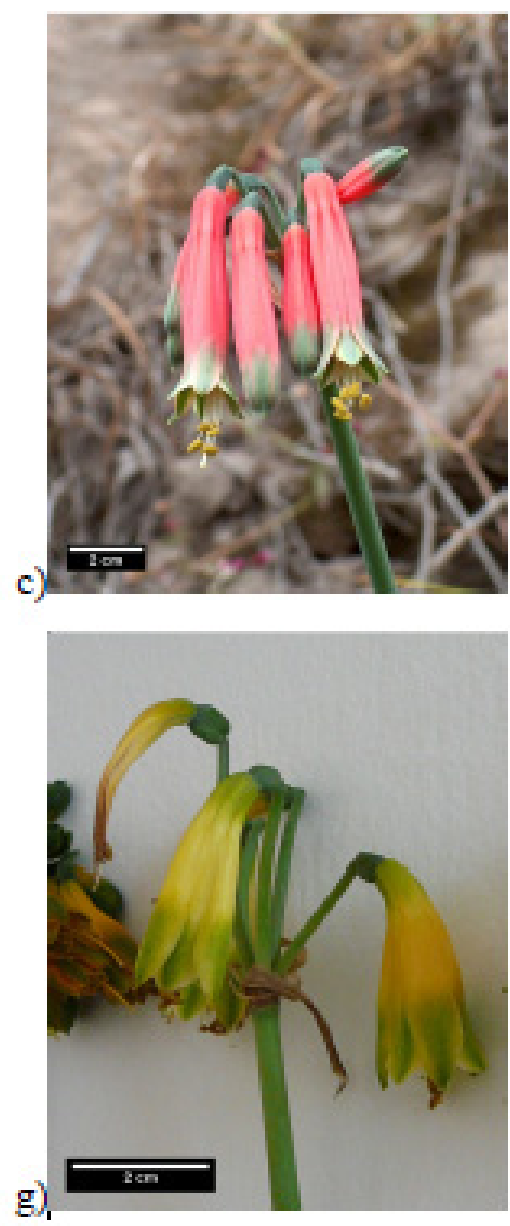
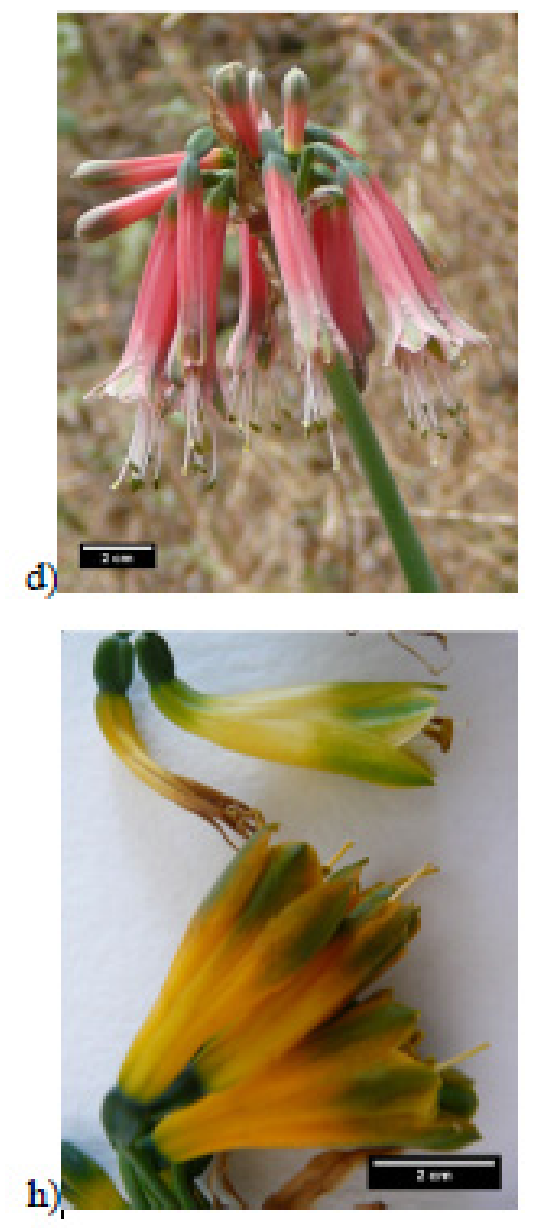

Figure 1. Ecuador's species of Phaedranassa. a) Phaedranassa brevifolia; b) P. cinerea; c) P. dubia; d) P. glauciflora; e) P. schizantha ; f) P. tunguraguae; g) P. viridiflora; h) Up: P. viridiflora; Down: possible P. dubia $x$ P. viridiflora hybrid 


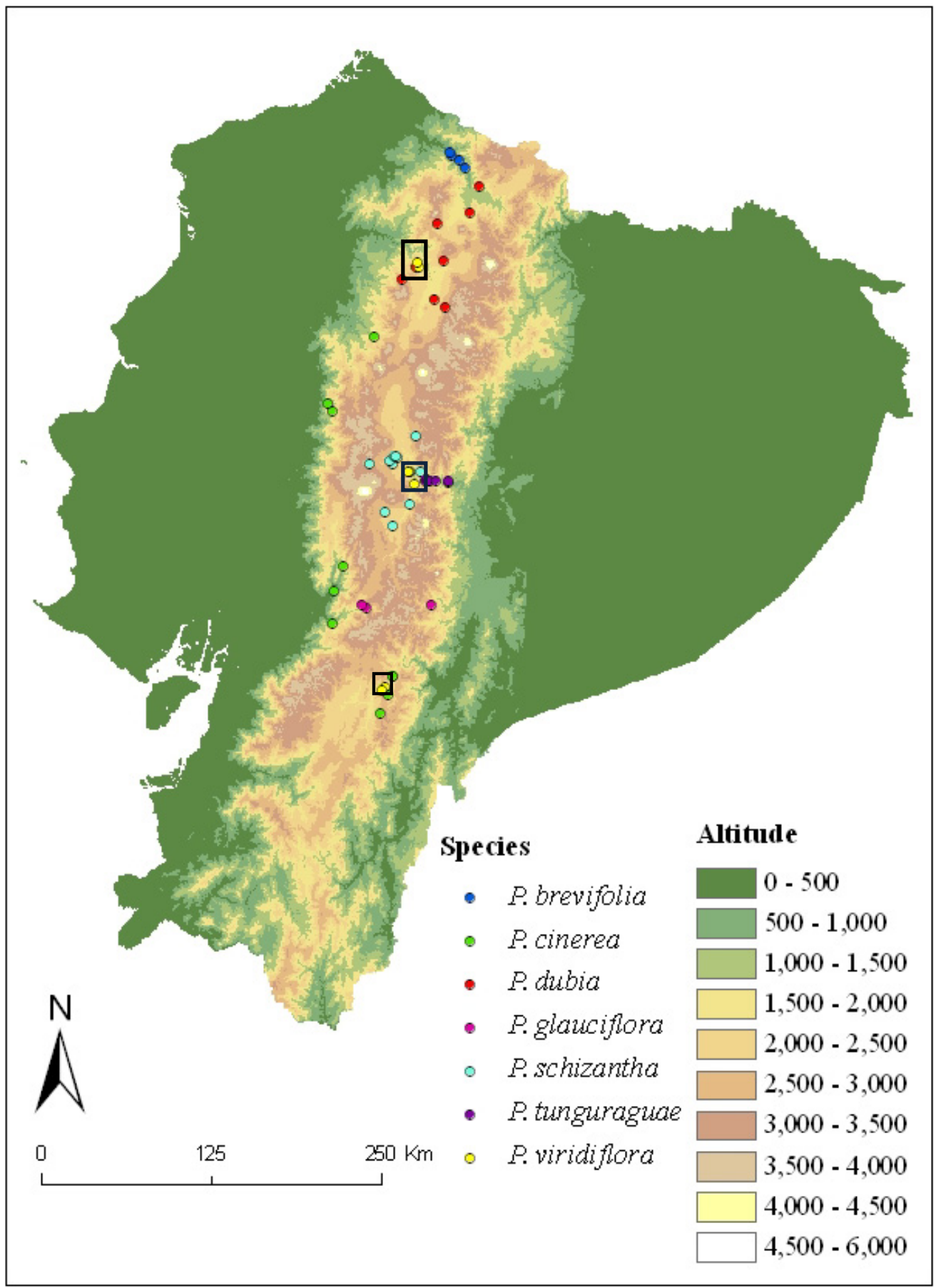

Figure 2. Distribution map of Phaedranassa spp. in Ecuador. Squares are locations with more than one Phaedranassa species 


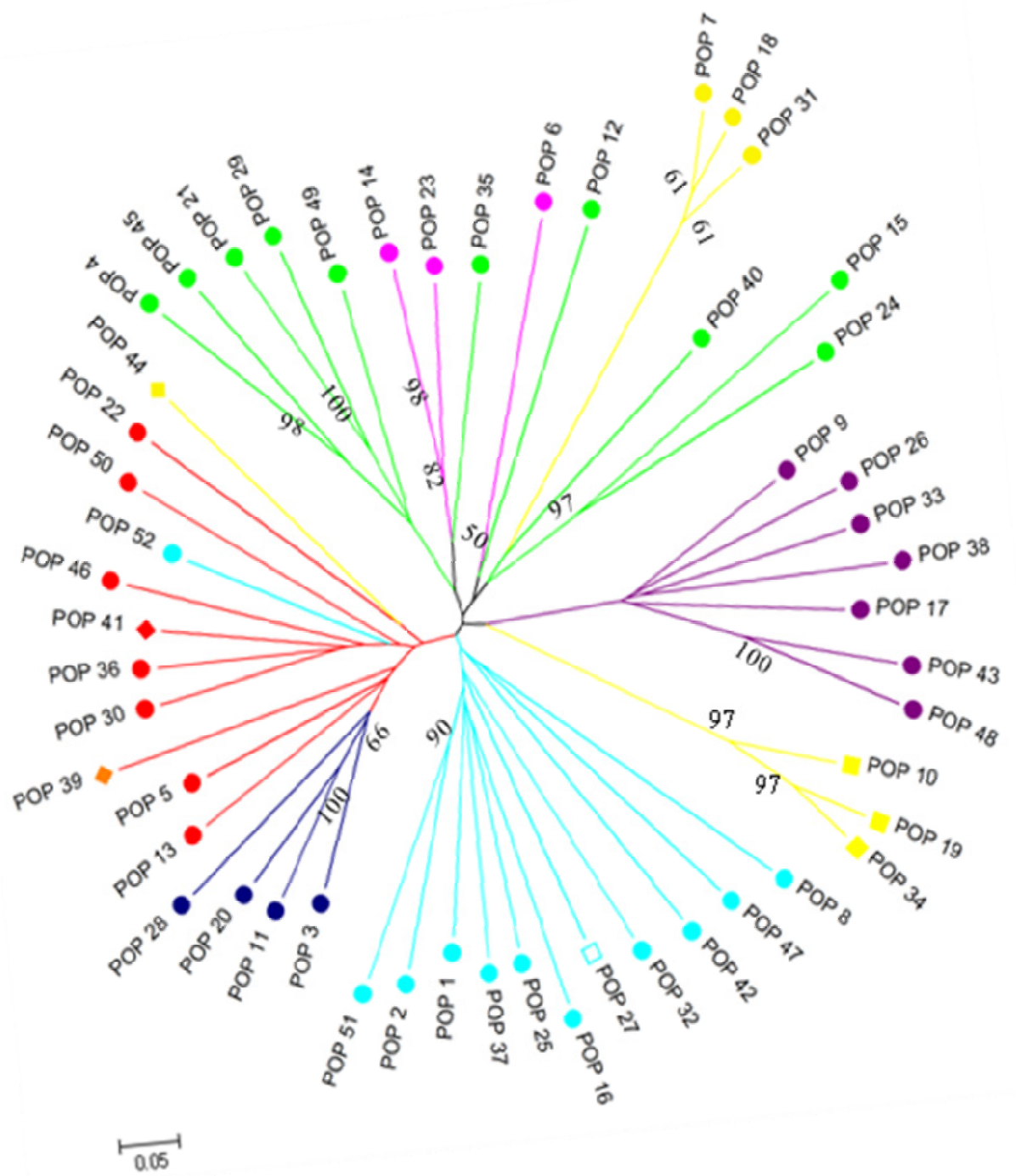
P. brevifolia
P. glauciflora
$>$ P. dubia (Pululahua)
P. cinerea
P. schizantha
P. viridiflora (Pululahua)
P. dubia
P. tunguraguae
P. vidiflora?
P. dubia $\mathrm{x}$ viridiflora?
P. viridiflora

Figure 3. Unrooted neighbor joining tree showing relationship among populations of Phaedranassa spp. in Ecuador. Number in branches are boostrap values $>50 \%$ with 1000 replications 


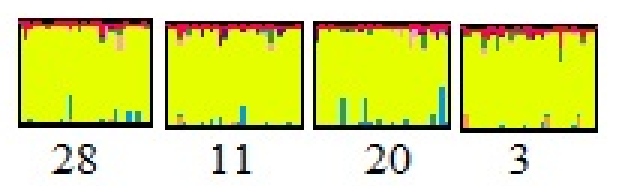

\section{P. brevifolia}
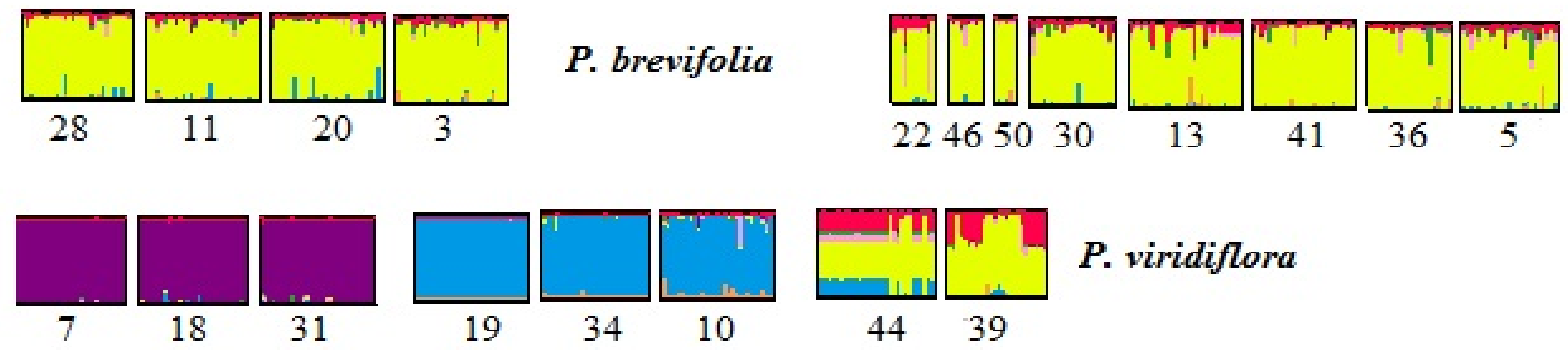

\section{P. viridiflora}
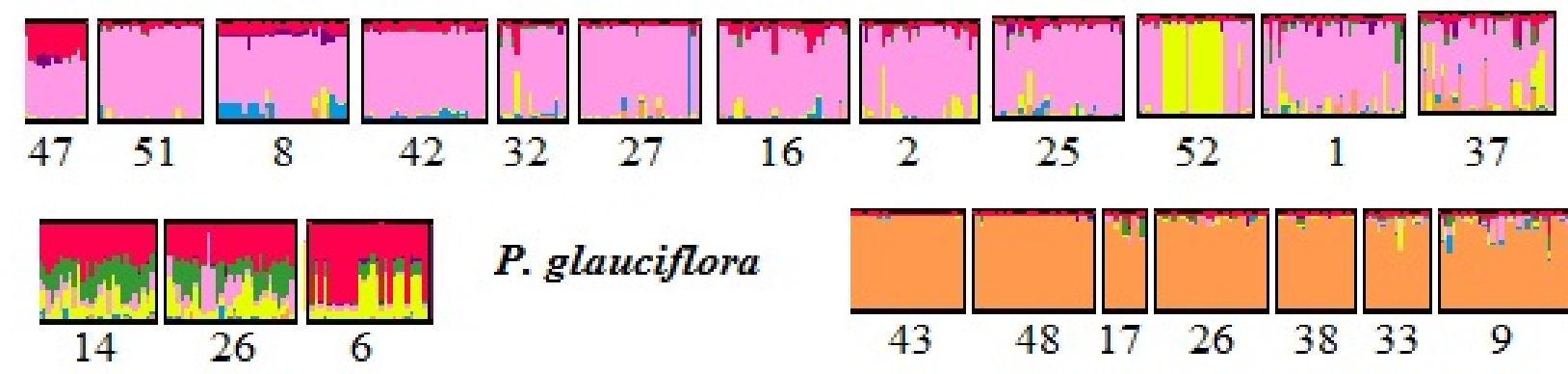

P. schizantha
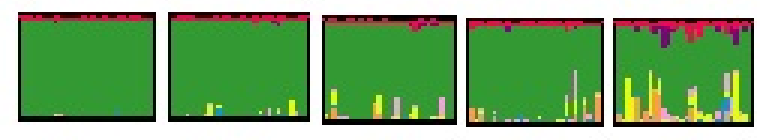

$21 \quad 29$

49
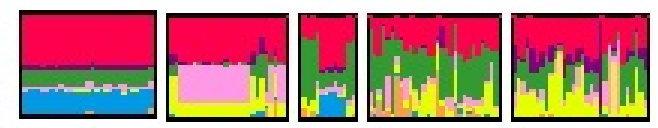

P. cinerea

4

$45 \quad 21$

15

$\begin{array}{llll}12 & 24 & 35 & 40\end{array}$

Figure 4. Plots of the individual assignment of Phaedranassa under the assumption of $k=7$ (number of species). Individuals are represented as a thin vertical line with colors indicating cluster membership. Population ID is listed under the plot 


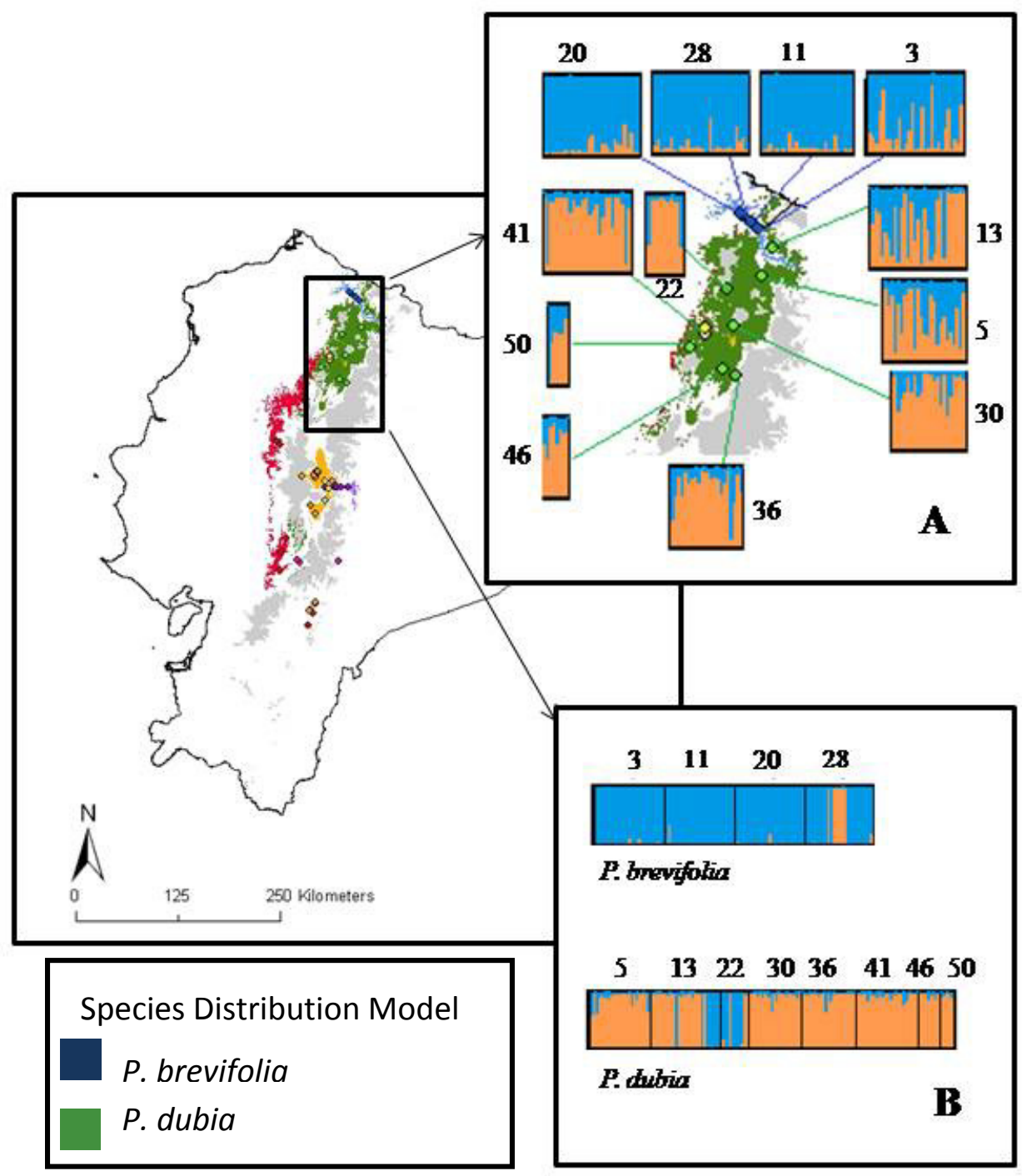

Figure 5. Bayesian individual assignment for Phaedranassa brevifolia and P. dubia. A) Assignment with number of populations $k=2$ with both species analyzed together, B) Assignment for each species separately $(k=2$ each). Area in grey is altitude $>3500 \mathrm{~m}$ 


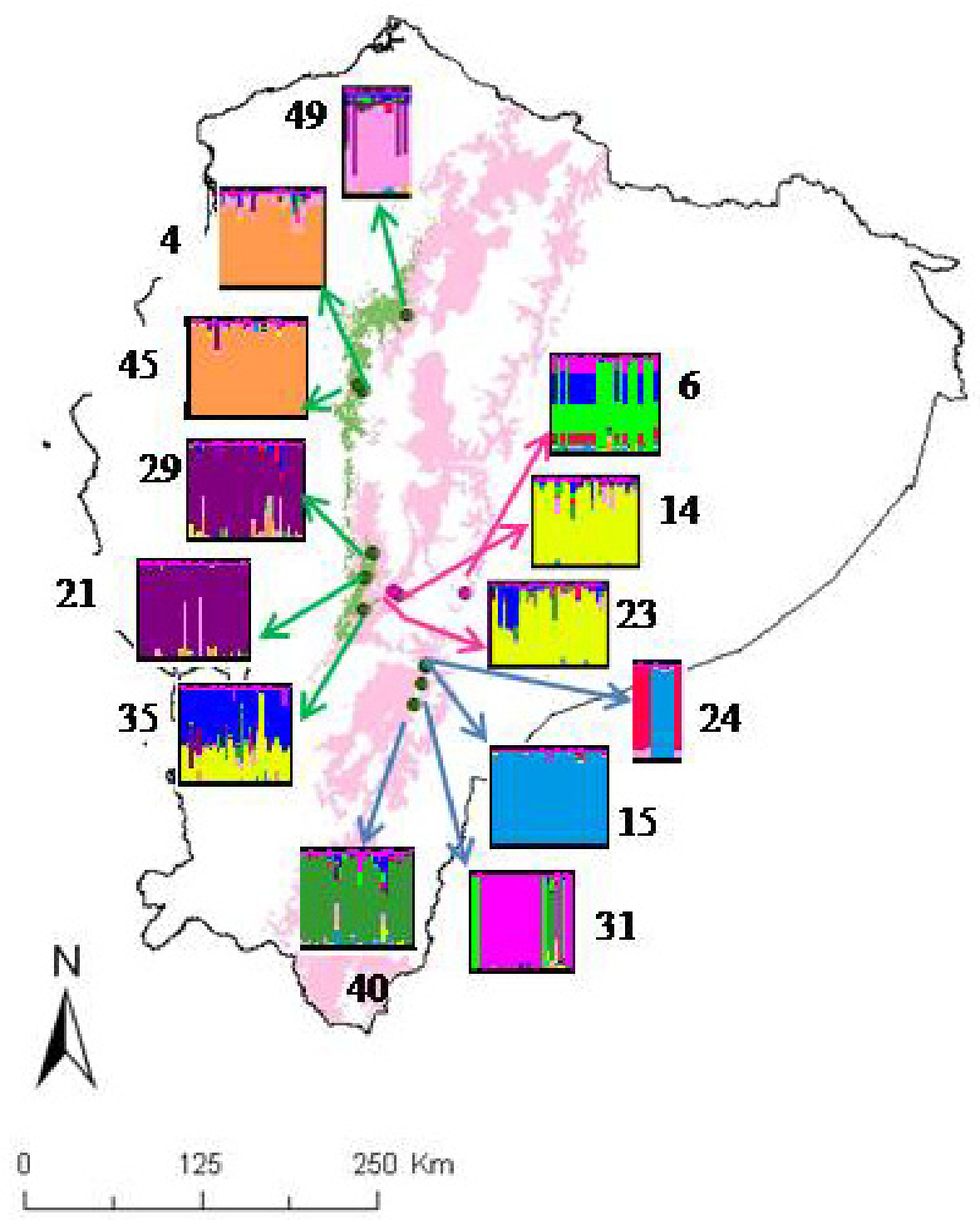

Figure 6. Analysis of population structure of P.glauciflora, and P. cinerea. Plot bar represent the estimated population structure per each one of the species' populations $(k=10)$. Area in pink represent the species distribution model (SDM) for P. glauciflora, in green is SDM for $P$. cinerea. 

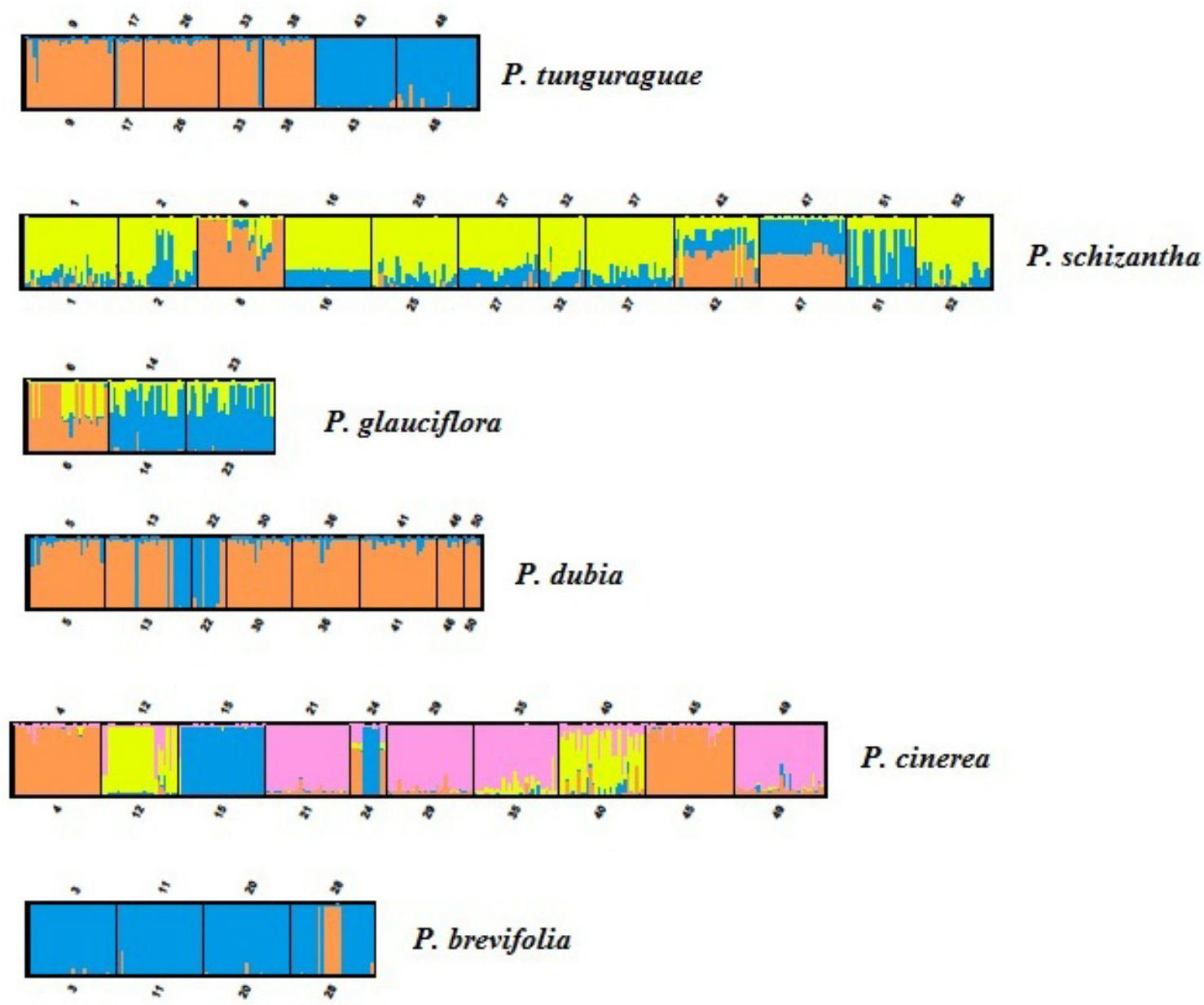

P. brevifolia

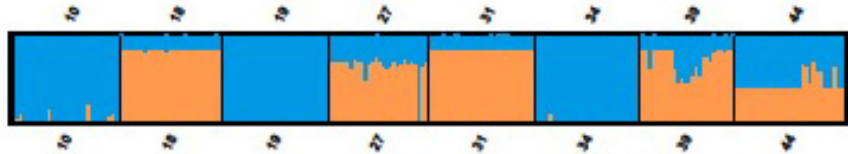

P. viridiflora

Figure 7. Plots of the individual assignment of each species of Phaedranassa analyzed separately. Individuals are represented as a thin vertical line with colors indicating cluster membership 


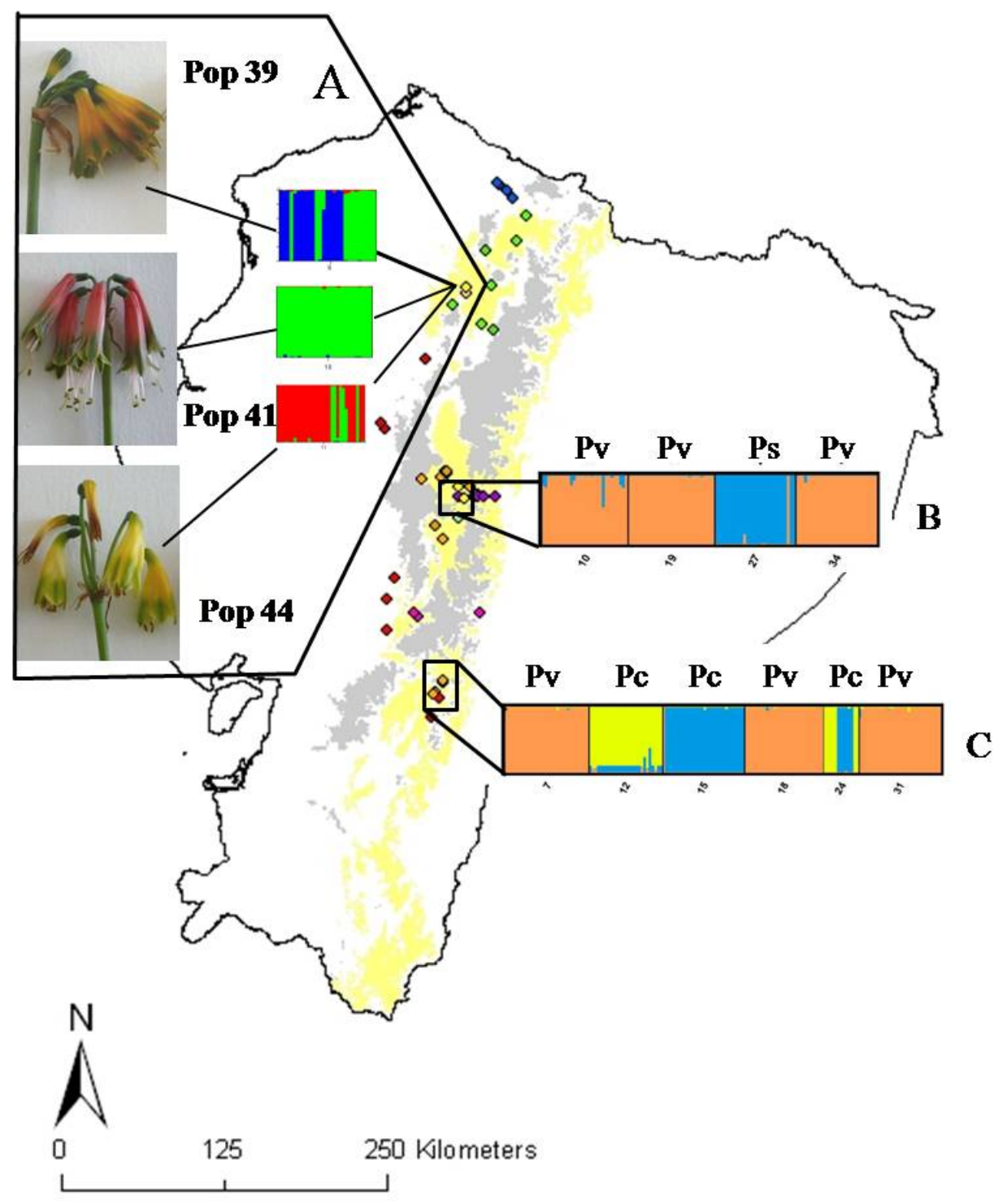

Figure 8. Population genetic structure of P.viridiflora. A) P. viridiflora and P. dubia in Pululahua, B) $P$. viridiflora $(\mathrm{Pv})$ and $P$. schizantha $(\mathrm{Ps}), \mathrm{C}) P$. viridiflora $(\mathrm{Pv})$ and $P$. cinerea $(\mathrm{Pc})$. Plot bar represent the estimated population structure per each of the species' populations. Area in yellow is $P$. viridiflora's distribution model, area in grey is area with altitude $>3500 \mathrm{~m}$ 


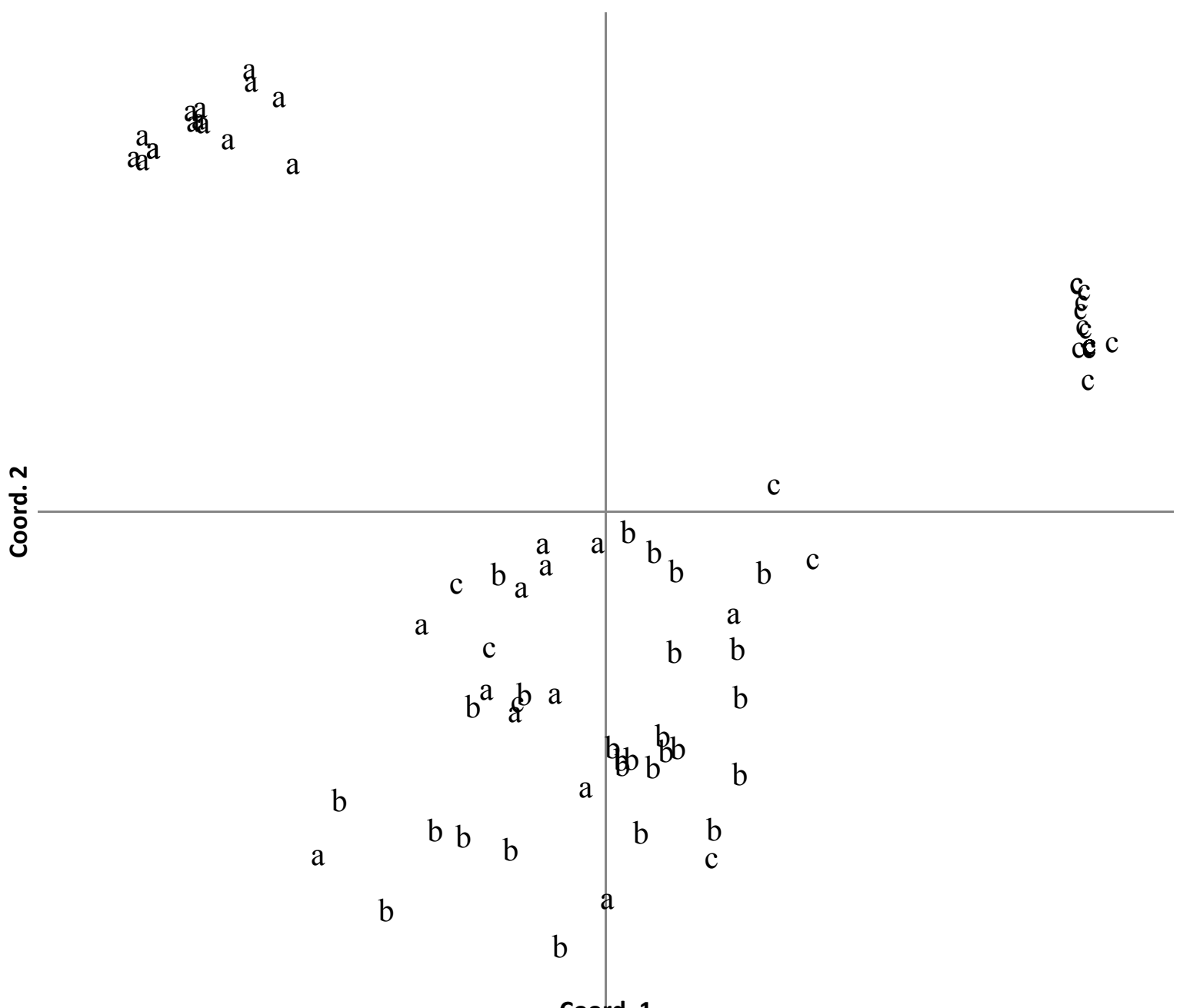

Coord. 1

Figure 9. Principal Coordinates Analysis (PCA) of Phaedranassa individuals in Pululahua crater. The first, second and third axes explained 44, 23 and $10 \%$ respectively, of the total variability. Symbols are: orange flowers (a), red flowers (b) and yellow flowers (c) 
Phaedranassa glauciflora

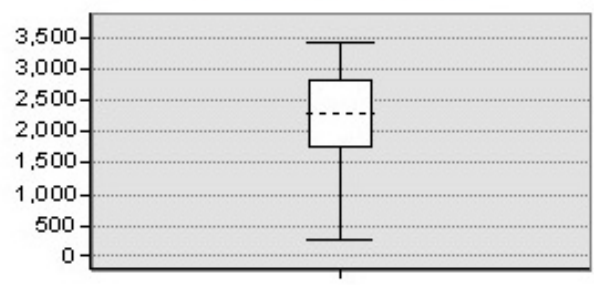

Phaedranassa schizantha

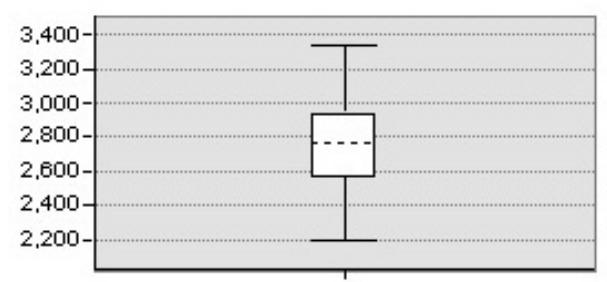

Phaedranassa dubia

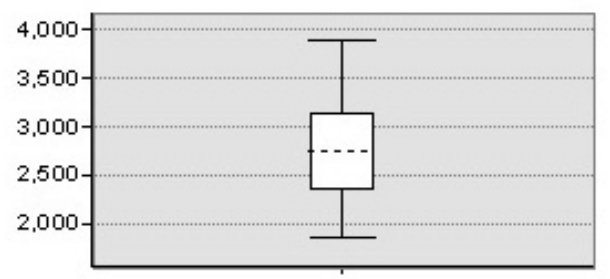

Phaedranassa brevifolia

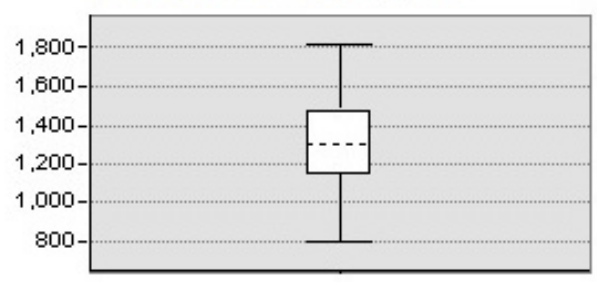

Phaedranassa viridiflora

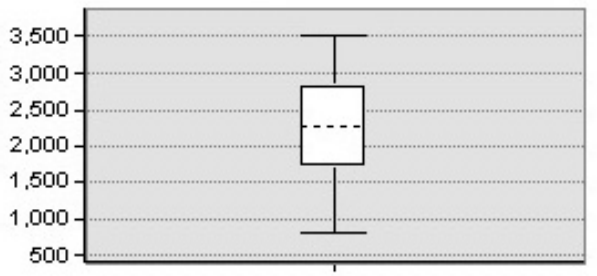

Phaedranassa tunguraguae

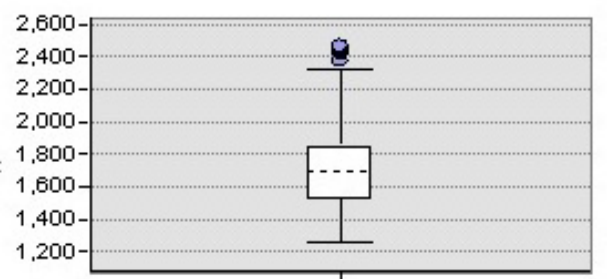

Phaedranassa cinerea

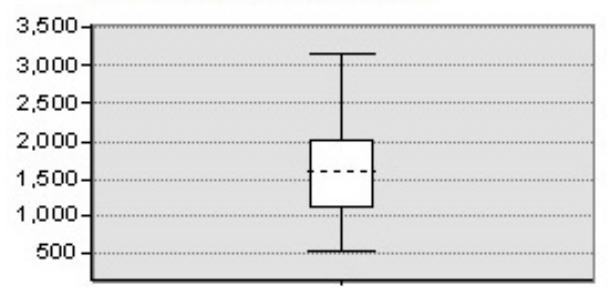

Figure 10. Altitudinal range (m) from the Species Distribution Model of seven

Phaedranassa species in Ecuador 
Table 1. Basic descriptive statistics of the genetic structure of Phaedranassa spp. Population name (Pop ID); Collection ID, (Col ID) on bold are species assignment changed after further study; Sample number (N); Clone individuals (C); Number of alleles (Na); Effective Allele number (Ne), Expected and Observed heterogosity (He, Ho), Fixation index (F), Number of pair of locus with Linkage disequilibrium (LD), Number of Private alleles (PA), Loci with evidence of null alleles (NL)

\begin{tabular}{|c|c|c|c|c|c|c|c|c|c|c|c|c|}
\hline Species & Pop ID & Col ID & $\mathbf{N}$ & $\mathrm{C}$ & $\mathbf{N a}$ & $\mathrm{Ne}$ & Ho & He & $\mathbf{F}$ & LD & $\mathbf{P A}$ & NL \\
\hline P. brevifolia & Pop28 & $4 \mathrm{pb}$ & 29 & 3 & 6.92 & 3.47 & 0.38 & 0.68 & 0.46 & 0 & 1 & 12 \\
\hline P. brevifolia & Pop11 & $2 \mathrm{pb}$ & 30 & 0 & 7.31 & 4.05 & 0.44 & 0.66 & 0.30 & 0 & 2 & 8 \\
\hline P. brevifolia & Pop20 & $3 \mathrm{pb}$ & 30 & 0 & 7.38 & 4.12 & 0.40 & 0.65 & 0.35 & 0 & 2 & 10 \\
\hline P. brevifolia & Pop3 & $1 \mathrm{pb}$ & 30 & 0 & 8.92 & 5.18 & 0.43 & 0.72 & 0.39 & 0 & 3 & 10 \\
\hline Mean & & & 28.75 & 0.75 & 7.63 & 4.21 & 0.41 & 0.68 & 0.37 & $\mathbf{0}$ & 2 & 10 \\
\hline$P$. cinereal & Pop4 & $1 \mathrm{pc}$ & 30 & 0 & 4.77 & 2.21 & 0.31 & 0.48 & 0.33 & 0 & 0 & 7 \\
\hline P. cinereal & Pop45 & $7 \mathrm{pc}$ & 31 & 0 & 6.54 & 2.60 & 0.36 & 0.51 & 0.28 & 0 & 1 & 5 \\
\hline P. cinereal & Pop21 & $3 p c$ & 29 & 0 & 6.38 & 3.11 & 0.40 & 0.58 & 0.30 & 0 & 3 & 7 \\
\hline P. cinereal & Pop29 & $4 p c$ & 30 & 0 & 8.92 & 3.25 & 0.43 & 0.60 & 0.30 & 0 & 8 & 5 \\
\hline P. cinereal & Pop49 & $8 \mathrm{pc}$ & 31 & 0 & 8.23 & 4.22 & 0.35 & 0.70 & 0.48 & 0 & 2 & 10 \\
\hline Mean & & & 28.92 & $\mathbf{0}$ & 6.97 & 3.08 & 0.37 & 0.58 & 0.34 & $\mathbf{0}$ & 2.8 & 6.8 \\
\hline
\end{tabular}


Table 1. Continued

\begin{tabular}{|c|c|c|c|c|c|c|c|c|c|c|c|c|}
\hline Species & Pop ID & Col ID & $\mathbf{N}$ & $\mathrm{C}$ & $\mathbf{N a}$ & $\mathrm{Ne}$ & Ho & $\mathrm{He}$ & $\mathbf{F}$ & LD & PA & NL \\
\hline P. cinerea 2 & Pop15 & $2 \mathrm{ps}$ & 30 & 13 & 4.08 & 2.04 & 0.32 & 0.32 & 0.27 & 0 & 0 & 9 \\
\hline P. cinerea 2 & Pop12 & $2 \mathrm{pc}$ & 27 & 4 & 5.69 & 2.50 & 0.41 & 0.49 & 0.20 & 18 & 1 & 7 \\
\hline P. cinerea 2 & Pop24 & $3 p s$ & 13 & 0 & 3.92 & 3.10 & 0.41 & 0.62 & 0.42 & 0 & 0 & 6 \\
\hline P. cinerea 2 & Pop35 & $5 \mathrm{pc}$ & 29 & 0 & 8.46 & 4.47 & 0.41 & 0.68 & 0.39 & 0 & 2 & 8 \\
\hline P. cinerea 2 & Pop40 & $6 \mathrm{pc}$ & 30 & 0 & 8.62 & 4.82 & 0.42 & 0.73 & 0.41 & 0 & 3 & 10 \\
\hline Mean & & & 24.32 & 3.4 & 6.15 & 3.39 & 0.39 & 0.57 & 0.34 & 2.0 & 1.0 & 8 \\
\hline P. dubia & Pop22 & $3 p d$ & 12 & 0 & 3.54 & 2.43 & 0.63 & 0.52 & -0.09 & 0 & 1 & 2 \\
\hline P. dubia & Pop46 & $7 \mathrm{pd}$ & 9 & 0 & 5.00 & 3.29 & 0.47 & 0.57 & 0.19 & 0 & 1 & 2 \\
\hline P. dubia & Pop50 & $8 \mathrm{pd}$ & 6 & 0 & 4.15 & 3.50 & 0.52 & 0.64 & 0.21 & 0 & 0 & - \\
\hline P. dubia & Pop30 & $4 p d$ & 23 & 1 & 6.85 & 4.07 & 0.41 & 0.63 & 0.31 & 0 & 0 & 9 \\
\hline P. dubia & Pop13 & $2 \mathrm{pd}$ & 30 & 2 & 8.00 & 4.10 & 0.42 & 0.70 & 0.38 & 7 & 4 & 10 \\
\hline P. dubia & Pop41 & $6 \mathrm{pd}$ & 27 & 0 & 8.08 & 4.13 & 0.45 & 0.69 & 0.34 & 0 & 3 & 8 \\
\hline P. dubia & Pop36 & $5 \mathrm{pd}$ & 23 & 1 & 7.85 & 4.22 & 0.49 & 0.69 & 0.29 & 0 & 1 & 10 \\
\hline P. dubia & Pop5 & $1 \mathrm{pd}$ & 26 & 0 & 9.23 & 4.82 & 0.44 & 0.75 & 0.40 & 0 & 2 & 12 \\
\hline Mean & & & 18.45 & 0.5 & 6.59 & 3.82 & 0.48 & 0.65 & 0.25 & 0.9 & 1.5 & 6.6 \\
\hline
\end{tabular}


Table 1. Continued

\begin{tabular}{|c|c|c|c|c|c|c|c|c|c|c|c|c|}
\hline Species & Pop ID & Col ID & $\mathbf{N}$ & $\mathrm{C}$ & $\mathbf{N a}$ & $\mathrm{Ne}$ & Ho & He & $\mathbf{F}$ & LD & $\mathbf{P A}$ & NL \\
\hline P. glauciflora & Pop14 & $2 p g$ & 27 & 0 & 7.69 & 4.05 & 0.42 & 0.69 & 0.37 & 0 & 2 & 9 \\
\hline P. glauciflora & Pop23 & $3 p g$ & 30 & 0 & 8.62 & 4.48 & 0.43 & 0.71 & 0.39 & 0 & 2 & 10 \\
\hline P. glauciflora & Pop6 & $1 \mathrm{pg}$ & 28 & 4 & 4.15 & 2.15 & 0.35 & 0.47 & 0.28 & 27 & 1 & 6 \\
\hline Mean & & & 28.33 & 1.3 & 6.82 & 3.56 & 0.40 & 0.63 & 0.35 & 9 & 1.7 & 8.3 \\
\hline P. schizantha & Pop47 & $7 \mathrm{ps}$ & 30 & 9 & 3.85 & 2.20 & 0.53 & 0.47 & -0.11 & 1 & 1 & 5 \\
\hline P. schizantha & Pop51 & $8 \mathrm{ps}$ & 24 & 0 & 5.92 & 2.82 & 0.38 & 0.59 & 0.31 & 0 & 0 & 7 \\
\hline P. schizantha & Pop8 & $1 \mathrm{psi}$ & 30 & 8 & 5.15 & 2.85 & 0.38 & 0.55 & 0.39 & 39 & 3 & 6 \\
\hline P. schizantha & Pop42 & $6 \mathrm{ps}$ & 29 & 10 & 5.15 & 2.87 & 0.48 & 0.56 & 0.14 & 39 & 2 & 6 \\
\hline P. schizantha & Pop32 & $4 \mathrm{psi}$ & 16 & 2 & 5.38 & 3.31 & 0.50 & 0.65 & 0.22 & 11 & 0 & 4 \\
\hline P. schizantha & Pop27 & $3 p v$ & 28 & 1 & 7.85 & 3.66 & 0.39 & 0.69 & 0.44 & 0 & 2 & 12 \\
\hline P. schizantha & Pop16 & $2 \mathrm{psi}$ & 30 & 0 & 7.85 & 3.77 & 0.43 & 0.65 & 0.37 & 0 & 2 & 8 \\
\hline P. schizantha & Pop2 & $11 \mathrm{ps}$ & 27 & 0 & 8.15 & 4.11 & 0.43 & 0.69 & 0.36 & 0 & 2 & 10 \\
\hline P. schizantha & Pop25 & $3 p s i$ & 30 & 0 & 9.23 & 4.30 & 0.46 & 0.73 & 0.37 & 0 & 4 & 10 \\
\hline P. schizantha & Pop52 & $9 \mathrm{ps}$ & 26 & 4 & 7.62 & 4.37 & 0.44 & 0.69 & 0.31 & 7 & 0 & 9 \\
\hline P. schizantha & Pop1 & $10 \mathrm{ps}$ & 33 & 0 & 9.77 & 5.05 & 0.52 & 0.77 & 0.33 & 0 & 2 & 8 \\
\hline
\end{tabular}


Table 1. Continued

\begin{tabular}{|c|c|c|c|c|c|c|c|c|c|c|c|c|}
\hline Species & Pop ID & Col ID & $\mathbf{N}$ & $\mathbf{C}$ & $\mathbf{N a}$ & $\mathrm{Ne}$ & Ho & He & $\mathbf{F}$ & LD & $\mathbf{P A}$ & NL \\
\hline P. schizantha & Pop37 & $5 p s$ & 31 & 2 & 10.69 & 5.39 & 0.44 & 0.75 & 0.39 & 0 & 4 & 10 \\
\hline Mean & & & 26.32 & 3 & 7.22 & 3.73 & 0.45 & 0.65 & 0.29 & 8.0 & 1.8 & 7.9 \\
\hline P. tunguraguae & Pop43 & $6 \mathrm{pt}$ & 28 & 1 & 5.00 & 2.45 & 0.40 & 0.48 & 0.19 & 0 & 0 & 0 \\
\hline P. tunguraguae & Pop48 & $7 \mathrm{pt}$ & 28 & 3 & 5.15 & 2.95 & 0.37 & 0.50 & 0.34 & 0 & 1 & 0 \\
\hline P. tunguraguae & Pop17 & $2 \mathrm{pt}$ & 10 & 0 & 5.69 & 3.98 & 0.54 & 0.62 & 0.12 & 0 & 0 & 0 \\
\hline P. tunguraguae & Pop26 & $3 p t$ & 26 & 0 & 6.92 & 4.11 & 0.57 & 0.66 & 0.10 & 0 & 1 & 0 \\
\hline P. tunguraguae & Pop38 & $5 \mathrm{pt}$ & 18 & 0 & 6.62 & 4.18 & 0.47 & 0.60 & 0.24 & 0 & 0 & 0 \\
\hline P. tunguraguae & Pop33 & $4 \mathrm{pt}$ & 15 & 0 & 6.77 & 4.67 & 0.51 & 0.68 & 0.21 & 0 & 1 & 0 \\
\hline P. tunguraguae & Pop9 & $1 \mathrm{pt}$ & 31 & 0 & 9.85 & 4.75 & 0.51 & 0.67 & 0.32 & 0 & 1 & 0 \\
\hline Mean & & & 22.28 & 0.5 & 6.57 & 3.87 & 0.48 & 0.60 & 0.22 & $\mathbf{0}$ & 0.57 & $\mathbf{0}$ \\
\hline P. viridifloral & Pop7 & $1 p s$ & 31 & 26 & 1.92 & 1.29 & 0.25 & 0.14 & -0.45 & 0 & 1 & 0 \\
\hline P. viridifloral & Pop18 & $2 p v$ & 29 & 18 & 2.31 & 1.41 & 0.33 & 0.21 & -0.22 & 0 & 0 & 2 \\
\hline P. viridifloral & Pop31 & $4 \mathrm{ps}$ & 30 & 12 & 2.77 & 1.48 & 0.31 & 0.22 & -0.12 & 0 & 0 & 7 \\
\hline Mean & & & 30 & 18.67 & 2.33 & 1.39 & 0.30 & 0.19 & -0.27 & $\mathbf{0}$ & 0.33 & 3 \\
\hline P. viridiflora 2 & Pop19 & $2 p x$ & 30 & 28 & 1.54 & 1.32 & 0.31 & 0.17 & -0.41 & 0 & 0 & 1 \\
\hline
\end{tabular}


Table 1. Continued

\begin{tabular}{|c|c|c|c|c|c|c|c|c|c|c|c|c|}
\hline Species & Pop ID & Col ID & $\mathbf{N}$ & $\mathrm{C}$ & $\mathbf{N a}$ & $\mathrm{Ne}$ & Ho & He & $\mathbf{F}$ & LD & PA & NL \\
\hline P. viridiflora2 & Pop34 & $4 p v$ & 29 & 19 & 2.15 & 1.34 & 0.24 & 0.16 & -0.01 & 0 & 0 & 3 \\
\hline P. viridiflora 2 & Pop10 & $1 p x$ & 30 & 6 & 3.54 & 1.66 & 0.33 & 0.31 & 0.14 & 0 & 0 & 6 \\
\hline Mean & & & 29.67 & 17.67 & 2.41 & 1.44 & 0.29 & 0.21 & -0.09 & $\mathbf{0}$ & $\mathbf{0}$ & 3.3 \\
\hline P. viridiflora3 & Pop44 & $6 \mathrm{pv}$ & 31 & 14 & 4.92 & 2.10 & 0.51 & 0.47 & 0.08 & 22 & 2 & 4 \\
\hline P. viridiflora3 & Pop39 & $5 p v$ & 27 & 2 & 6.85 & 2.90 & 0.20 & 0.59 & 0.66 & 19 & 1 & 12 \\
\hline Mean & & & 29 & 8 & 5.88 & 2.50 & 0.36 & 0.53 & 0.37 & 5.1 & 1.5 & 8 \\
\hline Total Mean & & & 25.01 & & 6.31 & 3.38 & 0.42 & 0.57 & 0.26 & & 1.4 & \\
\hline SE & & & 0.26 & & 0.14 & 0.08 & 0.01 & 0.01 & 0.02 & & & \\
\hline
\end{tabular}


Table 2. Test for recent bottleneck events in seven populations of Phaedranassa spp. on the basis of three tests. In bold are evidence of bottleneck cases
(1)Sign test
(2)Wilcox test
(3)Mode-shift

Species

Pop ID IAM SSM IAM SMM

$\begin{array}{llllll}\text { P. brevifolia } & \text { Pop11 } & 0.32 & 0.11 & 0.23 & 0.86\end{array}$

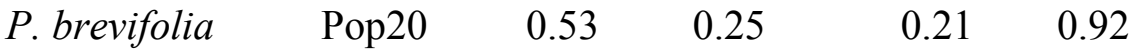

$\begin{array}{llllll}\text { P. brevifolia } & \text { Pop28 } & 0.31 & \mathbf{0 . 0 4} & \mathbf{0 . 0 5} & 0.98\end{array}$

$\begin{array}{llllll}\text { P. brevifolia } & \text { Pop3 } & \mathbf{0 . 0 5} & \mathbf{0 . 0 1} & \mathbf{0 . 0 3} & 0.97\end{array}$

$\begin{array}{llllll}\text { P. cinereal } & \text { Pop21 } & 0.51 & \mathbf{0 . 0 0} & 0.34 & 1.00\end{array}$

$\begin{array}{llllll}\text { P. cinereal } & \text { Pop29 } & \mathbf{0 . 0 1} & \mathbf{0 . 0 0} & 1.00 & 1.00\end{array}$

$\begin{array}{llllll}\text { P. cinereal } & \text { Pop4 } & 0.44 & \mathbf{0 . 0 0} & 0.53 & 1.00\end{array}$

$\begin{array}{llllll}\text { P. cinereal } & \text { Pop45 } & 0.27 & \mathbf{0 . 0 0} & 0.86 & 1.00\end{array}$

$\begin{array}{llllll}\text { P. cinereal } & \text { Pop49 } & 0.44 & \mathbf{0 . 0 4} & 0.08 & 0.99\end{array}$

$\begin{array}{llllll}\text { P. cinerea2 } & \text { Pop12 } & \mathbf{0 . 0 1} & \mathbf{0 . 0 0} & 0.98 & 1.00\end{array}$

$\begin{array}{llllll}\text { P. cinerea2 } & \text { Pop15 } & 0.23 & \mathbf{0 . 0 2} & 0.92 & 1.00\end{array}$

$\begin{array}{llllll}\text { P. cinerea2 } & \text { Pop35 } & 0.33 & \mathbf{0 . 0 4} & 0.39 & 0.98\end{array}$

$\begin{array}{llllll}\text { P. cinerea2 } & \text { Pop40 } & 0.16 & \mathbf{0 . 0 0} & \mathbf{0 . 0 0} & 1.00\end{array}$

$\begin{array}{llllll}\text { P. dubia } & \text { Pop13 } & 0.33 & \mathbf{0 . 0 0} & 0.15 & 0.99\end{array}$

$\begin{array}{llllll}\text { P. dubia } & \text { Pop30 } & 0.28 & 0.12 & 0.07 & 0.92\end{array}$

$\begin{array}{llllll}\text { P. dubia } & \text { Pop36 } & 0.54 & \mathbf{0 . 0 4} & 0.11 & 1.00\end{array}$

$\begin{array}{llllll}\text { P. dubia } & \text { Pop41 } & 0.15 & \mathbf{0 . 0 0} & \mathbf{0 . 0 5} & 1.00\end{array}$

$\begin{array}{llllll}\text { P. dubia } & \text { Pop5 } & 0.23 & \mathbf{0 . 0 0} & 0.19 & 1.00\end{array}$

$\begin{array}{llllll}\text { P. glauciflora } & \text { Pop14 } & 0.56 & \mathbf{0 . 0 1} & 0.12 & 1.00\end{array}$

$\begin{array}{llllll}\text { P. glauciflora } & \text { Pop23 } & 0.35 & \mathbf{0 . 0 0} & 0.11 & 1.00\end{array}$

Table 2 Continued 


\begin{tabular}{llllll}
\hline Species & Pop ID & (1)Sign test & (2)Wilcox test & (3)Mode-shift \\
& & IAM & SSM & IAM & SMM \\
\hline P. schizantha & Pop1 & 0.17 & $\mathbf{0 . 0 1}$ & $\mathbf{0 . 0 2}$ & 1.00 \\
P. schizantha & Pop16 & 0.31 & $\mathbf{0 . 0 0}$ & 0.27 & 1.00 \\
P. schizantha & Pop2 & 0.57 & $\mathbf{0 . 0 0}$ & 0.45 & 1.00 \\
P. schizantha & Pop25 & 0.44 & $\mathbf{0 . 0 0}$ & 0.25 & 1.00 \\
P. schizantha & Pop27 & 0.46 & $\mathbf{0 . 0 1}$ & 0.27 & 1.00 \\
P. schizantha & Pop37 & 0.58 & $\mathbf{0 . 0 1}$ & 0.34 & 1.00 \\
P. schizantha & Pop42 & 0.25 & 0.29 & 0.12 & 0.83 \\
P. schizantha & Pop47 & 0.23 & 0.53 & 0.08 & 0.66 \\
P. schizantha & Pop51 & 0.30 & $\mathbf{0 . 0 0}$ & 0.42 & 1.00 \\
P. schizantha & Pop52 & 0.05 & $\mathbf{0 . 0 4}$ & $\mathbf{0 . 0 0}$ & 0.98 \\
P. schizantha & Pop8 & 0.44 & 0.13 & 0.07 & 0.96 \\
P. tunguraguae & Pop26 & 0.30 & 0.14 & $\mathbf{0 . 0 5}$ & 0.93 \\
P. tunguraguae & Pop43 & 0.53 & $\mathbf{0 . 0 1}$ & 0.35 & 1.00 \\
P. tunguraguae & Pop48 & 0.45 & $\mathbf{0 . 0 4}$ & 0.18 & 0.97 \\
P. tunguraguae & Pop9 & 0.45 & $\mathbf{0 . 0 0}$ & 0.66 & 1.00 \\
P. viridiflora1 & Pop18 & 0.53 & 0.20 & 0.63 & 0.85 \\
P. viridiflora1 & Pop31 & 0.13 & 0.08 & 0.68 & 0.97 \\
P. viridiflora1 & Pop7 & 0.39 & 0.26 & 0.58 & 0.95 \\
P. viridiflora2 & Pop10 & 0.10 & $\mathbf{0 . 0 0}$ & 0.93 & 1.00 \\
P. viridiflora2 & Pop19 & 0.35 & 0.45 & $\mathbf{0 . 0 5}$ & $\mathbf{0 . 0 5}$ \\
P. viridiflora2 & Pop34 & 0.22 & $\mathbf{0 . 0 4}$ & 0.81 & 0.95 \\
P. viridiflora3 & Pop44 & 0.50 & $\mathbf{0 . 0 0}$ & 0.77 & 1.00 \\
P. viridiflora h & Pop39 & 0.26 & $\mathbf{0 . 0 0}$ & 0.88 & 1.00 \\
\hline & & & &
\end{tabular}


Table 3. Analysis of molecular variance (AMOVA) results as average over 13 loci

\begin{tabular}{llll}
\hline Source of variation & Sum of squares & $\begin{array}{l}\text { Variance } \\
\text { components }\end{array}$ & $\begin{array}{l}\text { Percentage } \\
\text { variation }\end{array}$ \\
\hline Among groups & 1479.05 & 0.50 & 9.34 \\
$\begin{array}{l}\text { Among populations } \\
\text { within groups }\end{array}$ & 2753.63 & 1.16 & 21.54 \\
Within populations & 9519.23 & 3.74 & 69.12 \\
\hline Total & 13751.90 & & \\
\hline
\end{tabular}


Table 4. Number of migrants ( $\mathrm{Nm})$ using private alleles method (after size correction)

\begin{tabular}{lll}
\hline Species & $\begin{array}{l}\text { Mean frequency } \\
\text { private alleles }\end{array}$ & $\mathrm{Nm}$ \\
\hline P. brevifolia & 0.03 & 4.19 \\
P. cinerea & 0.03 & 3.2 \\
P. cinerea 1 & 0.04 & 1.93 \\
P. cinerea 2 & 0.04 & 2.74 \\
P. cinerea 2 (no Pop35) & 0.06 & 1.44 \\
P. cinerea (no Pop35) & 0.05 & 1.74 \\
P. dubia & 0.04 & 3.73 \\
P. glauciflora & 0.05 & 1.74 \\
P. schizantha & 0.05 & 1.95 \\
P. tunguraguae & 0.05 & 2.45 \\
P. viridiflora & 0.07 & 0.97 \\
P. cinerea $-P$. & 0.03 & 3.4 \\
glauciflora & & \\
Phaedranassa all & 0.04 & 2.3 \\
& & \\
\hline
\end{tabular}


Table 5. Comparison of the number of collecting sites and the population number $(k)$, inferred genetically by Evanno method (2008). The average pairwise similarity (H') among 20 runs

\begin{tabular}{|c|c|c|c|}
\hline Species & $\begin{array}{l}\text { Collecting } \\
\text { sites }\end{array}$ & $k$ & $\mathrm{H}^{\prime}$ \\
\hline P. brevifolia & 4 & 2 & 0.99 \\
\hline P. cinerea & 10 & 4 & 0.85 \\
\hline P. dubia & 8 & 2 & 0.99 \\
\hline P. glauciflora & 3 & 3 & 0.68 \\
\hline P. schizantha & 12 & 3 & 0.88 \\
\hline P. tunguraguae & 7 & 2 & 0.99 \\
\hline P. viridiflora & 3 & 2 & 0.61 \\
\hline P. cinerea $-P$. glauciflora & 13 & 10 & 0.74 \\
\hline $\begin{array}{l}\text { P. cinerea - P.viridiflora South } \\
\text { (case } 1 \text { ) }\end{array}$ & 6 & 3 & 0.93 \\
\hline $\begin{array}{l}\text { P. schizantha }-P \text {. viridiflora Pelileo } \\
\text { (case } 2 \text { ) }\end{array}$ & 3 & 2 & 0.99 \\
\hline $\begin{array}{l}\text { P. dubia - P. viridiflora Puluhahua } \\
\text { (case } 3 \text { ) }\end{array}$ & 1 & 3 & 0.99 \\
\hline
\end{tabular}


Table 6. Percentages of Species Distribution Model overlap

\begin{tabular}{ll}
\hline Species pair comparison & Kappa \\
\hline P. glauciflora - P. viridiflora & $\mathbf{0 . 6 9 3}$ \\
P. glauciflora - P. schizantha & $\mathbf{0 . 4 5 1}$ \\
P. schizantha - P. viridiflora & $\mathbf{0 . 4 5 1}$ \\
P. dubia - P. viridiflora & $\mathbf{0 . 1 8 8}$ \\
P. dubia - P. glauciflora & $\mathbf{0 . 1 6 5}$ \\
P. dubia - P. schizantha & $\mathbf{0 . 0 9 9}$ \\
P. tunguraguae - P. viridiflora & 0.038 \\
P. glauciflora - P. tunguraguae & 0.032 \\
P. cinerea - P. viridiflora & 0.013 \\
P. brevifolia - P. glauciflora & 0.005 \\
P. brevifolia - P. viridiflora & 0.004 \\
P. cinerea - P. dubia & 0.004 \\
P. brevifolia - P. schizantha & 0.003 \\
P. brevifolia - P. cinerea & 0.002 \\
P. brevifolia - P. tunguraguae & -0.002 \\
P. brevifolia - P. dubia & -0.003 \\
P. schizantha - P. tunguraguae & -0.004 \\
P. cinerea - P. tunguraguae & -0.005 \\
P. dubia - P. tunguraguae & -0.005 \\
P. cinerea - P. schizantha & -0.019 \\
P. cinerea - P. glauciflora & $\mathbf{- 0 . 2 3}$ \\
\hline
\end{tabular}


Table 7. New proposed conservation status of Phaedranassa (Amaryllidaceae) in Ecuador

\begin{tabular}{lll}
\hline Species & IUCN 2010 status & 2011 status proposed \\
\hline$P$. brevifolia & Endangered B1ab(iii); C2a(i) & Endangered B1ab(iii) \\
$P$. cinerea & Vulnerable B1ab(iii) & Endangered B1ab(iii) \\
$P$. glauciflora & Endangered B1ab(iii) & Endangered B1ab(iii) \\
$P$. schizantha & Vulnerable B1ab(iii) & Endangered B1ab(ii,iii) \\
$P$. tunguraguae & Endangered B1ab(iii) & Endangered B1ab(iii) \\
$P$. viridiflora & Endangered B1ab(iii) & Endangered B1ab(iii) \\
\hline
\end{tabular}




\section{REFERENCES}

Amos W (1999) A comparative approach to the study of microsatellite evolution. In: Microsatellites: Evolution and Applications (eds Goldstein DB, Schlötterer C), pp. 66 -79. Oxford University Press, Oxford, UK

Arnold ML, Tang S, Knapp SJ, Martin NH (2010) Asymmetric Introgressive Hybridization Among Louisiana Iris Species. Genes 1:9-22

Baker JG (1877) Phaedranassa viridiflora. The Gardeners' Chronicle \& Agricultural Gazette 8:134

Balloux F, Lugon-Moulin N (2002) The estimation of population differentiation with microsatellite markers. Molecular Ecology 11:155-165

Beaumont MA, Rannala B (2004) The Bayesian revolution in genetics. Nature Reviews Genetics 5:251-261

Beerli P (2008) Migrate version 3.0- a maximum likelihood and Bayesian estimator of gene flow using coalescent. Distributed over the internet at http://ppgen.scs.edu/migrate.html

Bell C, Donoghue M (2005) Phylogeny and biogeography of Valerianaceae (Dipsacales) with special reference to the South American valerians. Organisms Diversity \& Evolution 5:147-159

Bodmer WF, Cavalli-Sforza LL (1968) A migration matrix model for the study of random genetic drift. Genetics 59:565-592

Borchsenius F (1997) Patterns of plant species endemism in Ecuador. Biodiversity and Conservation 6:379-399

Brown WLJ (1957) Centrifugal speciations. The Quaternary Review of Biology 32:247277

Carstens BC, Stevenson AL, Degenhardt JD, Sullivan J (2004) Testing nested phylogenetic and phylogeographic hypothesis in the Plethodon vandykei species group. Systematic Biology 53:781-792

Cavalli-Sforza LL, Edwards AWF (1967) Phylogenetic analysis: models and estimation procedures. American Journal of Human Genetics 19:233-257 
Chambers GK, MacAvoy ES (2000) Microsatellites: consensus and controversy. Comparative Biochemistry and Physiology Part B 126:455-476

Coltorti M, Ollier CD (2000) Geomorphic and tectonic evolution of the Ecuadorian Andes. Geomorphology 32:1-19

Cornuet J, Luikart G (1996) Description and power analysis of two tests for detecting recent populations bottlenecks from allele frequency data. Genetics 144:20012014

Cruzan MB (1998) Genetic markers in plant evolutionary ecology. Ecology 79:400-412

Csencsics D, Brodbeck S, Holderegger R (2010) Cost-effective, species-specific microsatellite development for the endangered Dwarf Bulrush (Typha minma) using next-generation sequencing technology. Journal of Heredity 101:789-793

Earl DA (2011) Structure harvester version 0.6.1. Distributed over the internet at http://taylor0.biology.ucla.edu/structure_harvester

Estoup A, Cornuet J (1999) Microsatellite evolution: inference from population data.in D. B. Goldstein and C. Schlotterer, editors. Microsatellites, evolution and applications. Oxford University Press, Oxford

Evanno G, Regnaut S, Goudet J (2005) Detecting the number of cluster of individuals using the software STRUCTURE: a simulation study. Molecular Ecology $14: 2611-2620$

Excoffier L, Laval G, Schneider S (2005) Arlequin ver. 3.0: An integrated software package for population genetics data analysis. Evolutionary Bioinformatics Online 1:47-50

Fernandez JF, Sork VL (2005) Mating patterns of a subdivided population of the Andean Oak (Quercus humboldtii., Fagaceae). Journal of Heredity 96:635-643

Fisher R (1930) The genetical theory of natural selection. Clarendon, Oxford

Fitzpatrick BM, Fordyce JA, Gavrilets S (2008) What, if anything, is sympatric speciation? Journal of Evolutionary Biology 21:1452-1459

Fjeldsa J, Irestedt M (2009) Diversification of the South American avifauna: patterns and implications. Annals of the Missouri Botanical Garden 96:398-409 
Frankel OH, Brown AHD, Burdon J (1995) The conservation of plant biodiversity. Cambridge University Press, New York

Franklin J (2009) Mapping species distributions: spatial inference and prediction. Cambridge University Press, Cambridge, New York

Gavrilets S (2003) Models of speciation: what have we learned in 40 years? Evolution 57:2197-2215

Gavrilets S, Li H, Vose MD (2000) Patterns of parapatric speciation. Evolution 54:11261134

Hall ML, Mothes PA (2008) Volcanic impediments in the progressive development of pre-columbian civilizations in the ecuadorian Andes. Journal of Volcanology and Geothermal Research 176:344-355

Hanski IA, Gilpin ME (1991) Metapopulation biology: dinamics: brief history and conceptual domain. Biological Journal of Linnean Society 42:3-16

Hardy OJ, Charbonnel N (2003) Microsatellite allele sizes: a simple test to assess their significance on genetic differentiation. Genetics 1482:1467-1482

Hardy OJ, Vekemans X (1999) Isolation by distance in a continuous population : reconciliation between spatial autocorrelation analysis and population genetics models. Heredity 83:145-154

Hardy OJ, Vekemans X (2002) SPAGEDI: a versatile computer program to analyse spatial genetic structure at the individual or population level. Molecular Ecology Notes 2:618-620

Hedrick PW (2000) Genetics of Populations. Jones and Bartlett Publishers, Inc., Sudbury, Mass

Hey J, Machado CA (2003) The study of structured populations - new hope for a difficult and divided science. Nature Reviews Genetetics 4:535-543

Holderegger R, Buehler D, Gugerli F, Manel S (2010) Landscape genetics of plants. Trends in Plant Science 15:675-683

Hudson RR (1990) Gene genealogies and the coalescent process. Pages 1-44 in D. Futuyama and J. Antonovics, editors. Oxford Surveys in Evolutionary Biology. Oxford University Press, Oxford 
Hughes C, Eastwood R (2006) Island radiation on a continental scale: Exceptional rates of plant diversification after uplift of the Andes. Proceedings of the National Academy of Sciences 103:10334-10339

Jakobsson M, Rosenberg NA (2007) CLUMPP: a cluster matching and permutation program for dealing with label switching and multimodality in analysis of population structure. Bioinformatics 23:1801-1806

Jarne P, Lagoda PJL (1996) Microsatellites, from molecules to populations and back. Tree 11:424-429

Jørgensen PM, Ulloa-Ulloa C, Madsen JE, Valencia R (1995) A floristic analysis of the high andes of Ecuador. The New York Botanical Garden, New York

Kay KM, Reeves P, Olmstead RG, Schemske DW (2005) Rapid speciation and the evolution of hummingbird pollination in neotropical Costus subgenus Costus (Costaceae): evidence from NRDNA ITS and ETS sequemces. American Journal of Botany 92:1899-1910

Kimura M, Crow JF (1964) The number of alleles that can be maintained in a finite population. Genetics 49:725-738

Kimura M, Ohta T (1978) Stepwise mutation model and distribution of allelic frequencies in a finite population. Proceedings of the National Academy of Sciences 75:2868-2872

Kingman JFC (1982) The coalescent. Stochastic Processes and their Applications 13:235248

Kumar S, Tamura K, Nei M (2004) MEGA3: Integrated software for Molecular Evolutionary Genetics Analysis and sequence alignment. Briefings in Bioinformatics 5:150-163

Kumar SA, Skjaeveland A, Orr RJ, Enger P, Ruden T, Mevik BH, Burki F, Botnen A, Shalchian-Tabrizi K (2009) AIR: batch-oriented web program package for construction of supermatrices ready for phylogenomic analyses. BMC Bioinformatics 10:357

Lai Y, Shinde D, Arnheim N, Sun F (2003) The mutation process of microsatellites during the polymerase chain reaction. Journal of Computational Biology 10:143155 
Langella O (1999) Populations 1.2.28. Distributed over the internet at http://www.pge.cnrs-gif.fr/bioinfo/populations/index.php

Li Y-C, Korol AB, Fahima T, Beiles A, Nevo E (2002) Microsatellite: genomic distribution, putative functions and mutational mechanisms: a review. Molecular Ecology 11:2453-2465

Livingstone DI, Freeman B, Tondo CL, Cariaga KA, Oleas NH, Meerow AW, Schnell RJ, Kuhn DN (2009) Improvement of High-throughput Genotype Analysis After Implementation of a Dual-curve Sybr Green I-based Quantification and Normalization Procedure. HortScience 44:1228-1232

Losos JB, Glor RE (2003) Phylogenetic comparative methods and the geography of speciation. Trends in Ecology and Evolution 18:220-227

Luikart G, Allendorf FW, Cornuet J, Sherwin WB (1998) Distortion of Allele Frequency Distributions Provides a Test for Recent Population Bottlenecks. Journal of Heredity 89:238-247

Luteyn JL (2002) Diversity, Adaptation, and Endemism in Neotropical Ericaceae: Biogeographical Patterns in the Vaccinieae. The Botanical Review 68:55-87

Manel S, Schwartz MK, Luikart G, Taberlet P (2003) Landscape genetics: combining landscape ecology and population genetics. Trends in Ecology and Evolution 18:189-197

Matolweni LO, Balkwill, K, McLellan T (2000) Genetic diversity and gene flow in the morphologically variable, rare endemics Begonia dregei and Begonia homonyma (Begoniaceae). American Journal of Botany 87:431-439

Mayr E (1963) Animal species and evolution Belknap Press, Cambridge, MA

Meerow AW (1990) Amaryllidaceae.in G. Harling and L. Andersson, editors. Flora of Ecuador, Vol. 41. University of Gotenborg; Riksmuseum, Pontificia Universidad Católica del Ecuador, Goteborg, Stockholm, Quito

Meerow AW, Guy CL, Li Q (2000) Phylogeny of the American Amaryllidaceae based on nrDNA ITS sequences. Systematic Botany 25:708-726

Millar MA, Byrne M, Coates DJ (2010) The maintenance of disparate levels of clonality, genetic diversity and genetic differentiation in disjunct subspecies of the rare Banksia ionthocarpa. Molecular Ecology 19:4217-4227 
Mittermeier RA, Myers N, Mittermeier CG (1999) Hotspots Earth's biologically richest and most endangered terrestrial ecoregions. CEMEX, Conservation International, New York

Mock KE, Latch EK, Rhodes OE (2004) Assessing losses of genetic diversity due to translocation: long-term case histories in Merriam's turkey (Meleagris gallopavo merriami). Conservation Genetics 5:631-645

Myers N, Mittermeier RA, Mittermeier CG, Fonseca GAB, Kent J (2000) Biodiversity hotspots for conservation priorities. Nature 403:853-859

Nakazato T, Housworth EA (2011) Spatial genetics of wild tomato species reveals roles of the Andean geography on demographic history. American Journal of Botany 98:88-98

Nosil P (2008) Speciation with gene flow could be common. Molecular Ecology $17: 2103-2106$

Oleas N (2000) Amaryllidaceae. Pages 66-67 in R. Valencia, Pitman, N., Leon, S., Jorgensen, P., editor. Libro Rojo de las Plantas Endémicas del Ecuador 2000. Herbario QCA, Pontificia Universidad Católica del Ecuador, Quito

Oleas N, Meerow AW, Francisco-Ortega J (2009) Eight microsatellite loci in Phaedranassa schizantha Baker (Amaryllidaceae) and cross-amplification in other Phaedranassa species. Conservation Genetics 10:1887-1889

Oleas NH, Meerow AW, Francisco-Ortega J (2005) Isolation and characterization of eight microsatellite loci from Phaedranassa tunguraguae (Amaryllidaceae). Molecular Ecology Notes 5:791-793

Peakall R, Smouse PE (2006) GENALEX 6: genetic analysis in Excel. Population genetic software for teaching and research. Molecular Ecology Notes 6:288-295

Pennington RT, Lavin M, Sarkinen T, Lewis GP, Klitgaard BB, Hughes CE (2010) Contrasting plant diversification histories within the Andean biodiversity hotspot. Proceedings of National Academy of Sciences 107:13783-13787.

Piry S, Luikart G, Cornuet JM (1998) Bottleneck: A Computer Program for Detecting Recent Reductions in the Effective Population Size Using Allele Frequency Data. Journal of Heredity 90:502-503 
Pitman NCA, Jørgensen PM (2002) Estimating the Size of the World's Threatened Flora. Science 298:989

Pritchard JK, Stephens M, Donnelly P (2000) Inference of Population Structure Using Multilocus Genotype Data. Genetics 155:945-959

Ravenna PF (1984) New species in Phaedranassa and Eucrosia (Amaryllidaceae). Phytologia 56:196-198

Raymond M, Rousset F (1995) GENEPOP (version 1.2): population genetics software for exact test and ecumenicism. Journal of Heredity 83:248-249

Rice WR (1989) Analyzing Tables of Statitical Test. Evolution 43:223-225

Richardson JE, Pennington RT, Pennington TD, Hollingsworth PM (2001) Rapid Diversification of a Species-Rich Genus of Neotropical Rain Forest Trees. Science 293:2242-2245

Rieseberg LH, Willis JH (2007) Plant Speciation. Science 317:910-914

Rosenberg NA (2004) DISTRUCT: a program for the graphical display of population structure. Molecular Ecology Notes 4:137-138

Rossetto M, McLauchlan A, Harris FCL, Henry RJ, Baverstock PR, Lee LS, Maguire TL, Edwards KJ (1999) Abundance and polymorphism of microsatellite markers in the tea tree (Mellaleuca alternifolia, Myrtaceae). Theoretical and Applied Genetics 98:1091-1098

Rousset F (2008) Genepop'007: a complete reimplementation of the Genepop software for Windows and Linux. Molecular Ecology Resources 8:103-106

Ruiz MC, Lees JM, Johnson JB (2006) Source constraints of Tungurahua volcano explosion events. Bulletin of Volcanology 68:480-490

Rull V (2008) Speciation timing and neotropical biodiversity: the Tertiary-Quaternary debate in the light of molecular phylogenetic evidence. Molecular Ecology $17: 2722-2729$

Sauer W (1957) EL mapa geologico del Ecuador. Editorial Universitaria, Quito.

Schlotterer C (2004) The evolution of molecular markers - just a matter of fashion? Nature Reviews Genetics 5:63-69 
Schulte K, Silvestro D, Kiehlmann E, Vesely S, Novoa P, Zizka G (2010) Detection of recent hybridization between sympatric Chilean Puya species (Bromeliaceae) using AFLP markers and reconstruction of complex relationships. Molecular Phylogenetics and Evolution 57:1105-1119

Selkoe KA, Toonen RJ (2006) Microsatellites for ecologists: a practical guide to using and evaluating microsatellite markers. Ecology Letters 9:615-629

Soltis PS, Soltis DE (2009) The role of hybridization in plant speciation. Annual Review of Plant Biology 60:561-588

Squirrell J, Hollingsworth PM, Woodhead M, Russell J, Lowe AJ, Gibby M, Powell W (2003) How much effort is required to isolate nuclear microsatellites from plants? Molecular Ecology 12:1339-1348

Stoeckel S, Grange J, Fernandez-Manjarres JF, Bilger I, Frascaria-Lacoste N, Mariette S (2006) Heterozygote excess in a self-incompatible partially clonal forest tree species - Prunus avium L. Molecular Ecology 15:2109-2118

Storfer A, Murphy MA, Spear SF, Holderegger R, Waits LP (2010) Landscape genetics: where are we now? Molecular Ecology 19:3496-3514

Struwe L, Haag S, Heiberg E, Grant JR (2009) Andean speciation and vicariance in neotropical Macrocarpaea (Gentianaceae-Helieae). Annals of the Missouri Botanical Garden 96:450-469

Susol E, Eyre S, John S (2000) Hight-Thorughput genotyping of microsatellite markers.in A. Hajeer, J. Worthington, and S. John, editors. SNP and Microsatellites Genotyping: Markers for genetic analysis. A Biotechniques Books Publication. Eaton Publishing, Natick, MA

Symonds VV, Lloyd AM (2003) An analysis of microsatellite loci in Arabidopsis thaliana: Mutational Dynamics and Application. Genetics 165:1475-1488

Takesaki N, Nei M (1996) Genetic distances and reconstruction of phylogenetic trees from microsatellite DNA. Genetics 144:389-399

Tomimatsu H, Ohara M (2003) Genetic diversity and local population structure of fragmented populations of Trillium camschatcense (Trilliaceae). Biological Conservation 109:249-258 
Trenel P, Hansen MM, Normand S, Borchsenius F (2008) Landscape genetics, historical isolation and cross-Andean gene flow in the wax palm, Ceroxylon echinulatum (Arecaceae). Molecular Ecology 17:3528-3540

Valencia R, Cerón C, Palacios W, Sierra R (1999) Las formaciones Naturales de la Sierra del Ecuador. Propuesta Preliminar de un Sistema de Clasificación de Vegetación para el Ecuador Continental. Proyecto INEFAN/GEF-BIRF y EcoCiencia, Quito

Valencia R, Pitman N, Leon-Yanez S, Jorgensen PM (2000) Libro rojo de las plantas endemicas del Ecuador. Pontificia Universidad Catolica del Ecuador, Quito

van Droogenbroeck, B, Kyndt T, Romeijn-Peeters E, van Thuyne W, Goetghebeur P, Romero-Motochi JP, Gheysen G (2006) Evidence of natural hybridization and introgression between Vasconcellea species (Caricaceae) from Southern Ecuador revealed by chloroplast, mitochondrial and nuclear DNA markers. Annals of Botany 97:793-805

Van Geert A, Van Rossum F, Triest L (2008) Genetic diversity in adult and seedling populations of Primula vulgaris in a fragmented agricultural landscape. Conservation Genetics 9:845-853

Van Oosterhout C, Hutchinson WF, Wills DPM, Shipley P (2004) Micro-checker: software for identifying and correcting genotyping errors in microsatellite data. Molecular Ecology Notes 4:535-538

von Hagen KB, Kadereit JW (2003) The diversification of Halenia (Gentianaceae): ecological opportunity versus key innovation. Evolution 57:2507-2518

Wang IJ (2010) Recognizing the temporal distinctions between landscape genetics and phylogeography. Molecular Ecology 19:2605-2608

Weber JL, Wong C (1993) Mutation of human short tandem repeats. Human Molecular Genetics 2:1123-1128

Wright S (1931) Evolution in mendelian populations. Genetics 16:97-159

Wright S (1940) Breeding structure of populations in relation to speciation. American Naturalist 74:232-248

Wright S (1943) Isolation by distance. Genetics 28:114-138 
Young KR, Ulloa-Ulloa C, Luteyn JL, Knapp S (2002) Plant Evolution and Endemism in Andean South America: An Introduction. The Botanical Review 68:4-21

Zane L, Bargelloni L, and Patarnello T (2002) Strategies for microsatellite isolation: a review. Molecular Ecology 11:1-16 


\section{CHAPTER V.}

\section{CONCLUSIONS AND FUTURE RESEARCH DIRECTIONS}

In this research, I developed eight newly designed microsatellite primers for $P$. schizantha. These primers and the results of cross-amplification with other Phaedranassa species are presented in Chapter II in this dissertation. Because of their high level of polymorphism and the amplification success with all other Phaedranassa species in Ecuador, these loci were used for the investigation of genetic variation of the genus (Chapter IV).

Another difficulty in working with tropical plants is the general deficiency of species records. Before this study, three of the seven Phaedranassa species were known by less than two populations each. The use of Species Distribution Models (SDMs), as addressed in Chapter III, is a valuable tool to identify areas where the species can potentially be found. Using the models designed as part of this research, I was able to find six new populations. However, as documented in Chapter III, species records used for SDMs require exhaustive prior verification in order to avoid misinterpretations caused by errors in the data. I choose to exemplify this problem by developing SDMs with three different dataset sources: (1) species records from databases available online only, (2) species records which taxonomy was verified and (3) species records confirmed at the field. My study showed that considerable differences were found between models obtained from different data sources.

Finally, genetic diversity is not randomly distributed across the landscape. The complexity of the demography with real species is not fully explained by simple models of speciation. Furthermore speciation processes in a genus do not necessarily follow the 
same path for all the species. My study provides empirical evidence of spatial divergence of Phaedranassa species in Ecuador, a pattern that is evident in the majority of the species in the genus. The mechanism of speciation in Phaedranassa resembles a parapatric speciation model. My data suggests that the speciation process is occurring at the periphery of the species distributions, probably by migration and colonization along the Andes topography. At the same time, I provided the first natural hybridization support in the genus, between $P$. viridiflora and P. dubia in Pululahua crater. Moreover, two putative sympatric speciation cases were also described in this research.

Molecular studies of adult individuals in long-lived perennial plants such as Phaedranassa might still show an historical condition in which the genetic erosion as a result of habitat fragmentation is less severe (Tomimatsu and Ohara 2003, Van Geert et al. 2008). Further studies should included analysis of seedlings which will be affected by present processes (Van Geert et al. 2008). Also, the findings of this research need to be corroborated with other molecular markers, in order to overcome the violation of assumptions in the models analyzed (i.e., Non Hardy-Weinberg equilibrium, Linkage disequilibrium, non-random reproduction, selfing and null alleles).

The results of this study need to be taken as a first step towards understanding the genetic structure of Phaedranassa species. Pursuing these kinds of studies on non-model species in the tropics is challenging. Even for species with a relatively recent taxonomic review, species identification is not always clear-cut. In the process of this investigation I change the species names of seven out of the 52 populations collected (13\%), using molecular data and additional field work. My results point out the need for a taxonomic review of the genus, especially for $P$. cinerea and $P$. glauciflora and $P$. viridiflora. For 
this, additional collections are needed, especially for the southern taxa, because the species delimitations in this group require a taxonomic revision. New occurrence records can then be incorporated in the SDM for a better model of species range. 


\section{REFERENCES}

Tomimatsu H, Ohara M (2003) Genetic diversity and local population structure of fragmented populations of Trillium camschatcense (Trilliaceae). Biological Conservation 109:249-258

Van Geert A, Van Rossum F, Triest L (2008) Genetic diversity in adult and seedling populations of Primula vulgaris in a fragmented agricultural landscape. Conservation Genetics 9:845-853 
VITA

NORA HELENA OLEAS GALLO

1995-2000 B.Sc. Biology

Pontificia Universidad Católica del Ecuador

Quito, Ecuador

2002-2004 Fulbright Grantee

2002-2004 M.S. Biology

Florida International University

Miami, Florida

2005 Specialty Graduate Course in Botany

Organization for Tropical Studies

San Jose, Costa Rica

2005 Best Master student presentation.

Seventh Annual Biology Research Symposium.

Fairchild Tropical Botanical Garden

2005 Judith Evans Parker Travel Grant.

2006 Third prize. Biology and Earth Science. GSA-FIU Scholarly Forum

2007 Delzie Demaree Travel Award, Botanical Institute of Texas

2009 Dissertation Evidence Acquisition Fellowship, FIU

South Florida Chapter of the Explorers Club Grant

PUBLICATIONS AND PRESENTATIONS

Oleas, N, Meerow, A, Francisco-Ortega, J 2005. Isolation and characterization of eight microsatellite loci from Phaedranassa tunguraguae (Amaryllidaceae). Molecular Ecology Notes 5: 791-793.

Oleas, N, Meerow, A, Francisco-Ortega, J, Kuhn, D 2005. Genetic structure of Phaedranassa tunguraguae Ravenna (Amaryllidaceae), an endangered species of Ecuador. Botany 2005, Austin, Texas. 
Oleas, N 2006. Population genetic structure and migration pattern of Phaedranassa tunguraguae Ravenna (Amaryllidaceae), an endangered species of Ecuador. 2006 Scholarly Forum, Graduate Student Association, Florida International University, Miami.

Oleas, N, Meerow, A, Francisco-Ortega, J 2009. Eight microsatellite loci in Phaedranassa schizantha Baker (Amaryllidaceae) and cross-amplification in other Phaedranassa species. Conservation Genetics (10):1887-1889.

Meerow AW, Noblick, L, Borrone, JW, Couvreur, TLP, Mauro-Herrera, M, Hahn WJ, Kuhn, DN, Nakamura, K, Oleas, NH, Schnell, RJ 2009. Phylogenetic Analysis of Seven WRKY Genes across the Palm Subtribe Attaleinae (Arecaceae) Identifies Syagrus as Sister Group of the Coconut. PLoS ONE 4(10): e7353.doi:10.1371/journal.pone.0007353.

Livingstone, D, Freeman, B, Tondo, CL, Cariaga, KA, Oleas, NH, Meerow, AW, Schnell, R, Kuhn DN 2009. Improvement of High-throughput Genotype Analysis After Implementation of a Dual-curve Sybr Green I-based Quantification and Normalization Procedure. HortScience 44(5):1-5.

Oleas, N, Meerow, AW, Francisco-Ortega, J 2009. Managements units of the endangered Phaedranassa tunguraguae Ravenna (Amaryllidaceae) based on microsatellite variation between and within populations. Eleventh Annual Biology Research Symposium, Biscayne Bay Campus, Florida International University, Miami.

Oleas, N., Meerow, A. W., Francisco-Ortega, J 2010. Niche-modeling speed bumps: the Phaedranassa case. 2010 Biology Research Symposium, Biscayne Bay Campus, Florida International University, Miami.

Oleas, N, Meerow AW, Francisco-Ortega, J 2010. Use of molecular markers for species conservation, the Phaedranassa spp case. X Congreso Latinoamericano de Botánica, October 4-10, La Serena, Chile.

Oleas, N, et al. 2010. Molecular phylogenies of endangered plant species in Latin America: Unique patterns and conservation priorities. X Congreso Latinoamericano de Botánica, October 4-10, La Serena, Chile.

Oleas, N, Meerow AW, Francisco-Ortega, J 2011. Population genetics in a geographic context, the Phaedranassa (Amaryllidaceae) case study. Botany 2011, July 9-13. St Louis, MO. 